Aus der Abteilung Neurologie

(Prof. Dr. med. M. Bähr)

Im Zentrum Neurologische Medizin

der Medizinischen Fakultät der Universität Göttingen

\title{
Zur Funktion des zellulären Prion-Proteins: \\ Eine Verhaltensstudie
}

\section{INAUGURAL-DISSERTATION}

zur Erlangung des Doktorgrades

der Medizinischen Fakultät der

Georg-August-Universität zu Göttingen

vorgelegt von

Catharina Greis

aus

Hann. Münden

Göttingen, 2012 
Dekan: Prof. Dr. med. M. P. Schön

I. Berichterstatterin: Prof. Dr. med. I. Zerr

II. Berichterstatter/in: Prof. Dr. rer. nat. A. Fischer

III. Berichterstatter/in: Prof. Dr. med., Dr. rer. nat. T. Crozier

Tag der mündlichen Prüfung: 21.11.2012 


\section{Inhaltsverzeichnis}

1 Einleitung ............................................................................................................................... 1

1.1 Transmissible spongiforme Enzephalopathien (TSEs) ........................................1

1.1.1 Historie der transmissiblen spongiformen Enzephalopathien ............................ 1

1.1.2 Verschiedene Formen der transmissiblen spongiformen Enzephalopathien..1

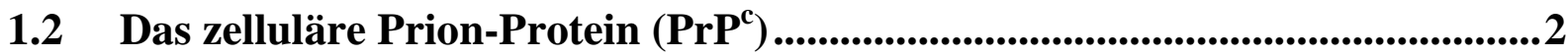

1.2.1 Entdeckung des Prion-Proteins .....................................................................................2

1.2.2 Die Prion-Hypothese.........................................................................................................

1.2.3 Struktur des zellulären Prion-Proteins.....................................................................5

1.2.4 Vorkommen des zellulären Prion-Proteins im Zentralen Nervensystem.........6

1.3 Herstellung von „Knockout-Mäusen“.........................................................................7

1.3.1 Prion-Protein-Knockout-Mäuse .................................................................................9

1.4 Physiologische Funktion des zellulären Prion-Proteins......................................10

1.5 Zielsetzung der Arbeit...........................................................................................................14

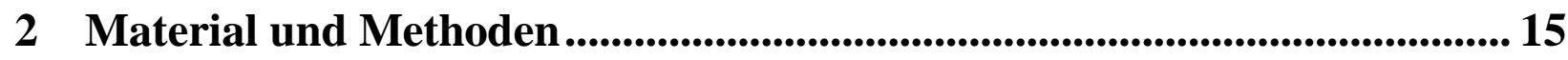

2.1 Material ..............................................................................................................................15

2.1.1 Geräte................................................................................................................ 15

2.1.2 Verbrauchs- und spezielles Material ................................................................... 15

2.1.3 Chemikalien und Reagenzien ............................................................................... 15

2.1.4 Lösungen und Puffer .............................................................................................. 16

2.1.5 Antikörper .................................................................................................................... 17

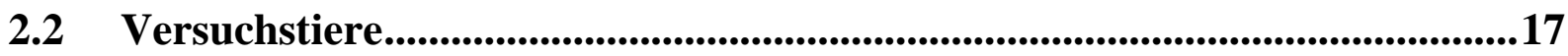

2.3 Haltung der Tiere ............................................................................................................17

2.4 Methoden ................................................................................................................................18

2.4.1 Perfusion ............................................................................................................................ 18

2.4.2 Herstellung von Proteinextrakten aus Hirngewebe............................................. 18

2.4.3 Vermessung von Proteinen .................................................................................... 19

2.4.4 SDS-Polyacrylamidgelelektrophorese (SDS-PAGE) .......................................... 19

2.4.5 Elektrochemischer Proteintransfer auf eine PVDF-Membran (Western

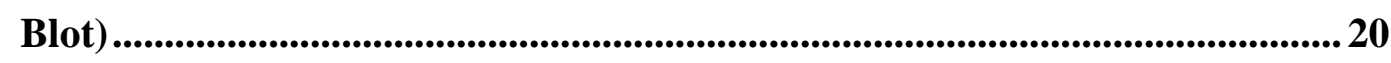

2.4.6 Immunologische Detektion von Proteinen auf der PVDF-Membran ............. 20 


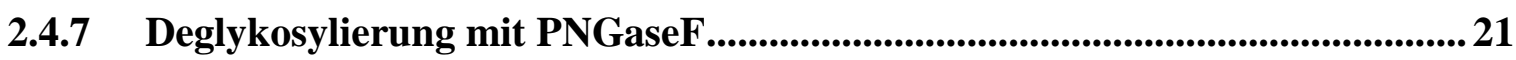

2.4.8 Membranen-Stripping........................................................................... 21

2.5 Verhaltenstests .........................................................................................................22

2.5.1 Elevated Plus Maze (EPM) ............................................................................................... 22

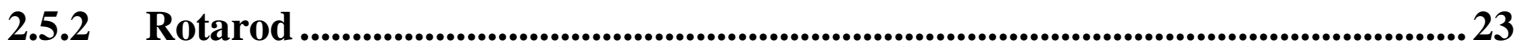

2.5.3 Furchtkonditionierung ..............................................................................24

2.5.4 Kontextabhängige Furchtkonditionierung........................................................ 25

2.5.5 Tonabhängige Furchtkonditionierung............................................................26

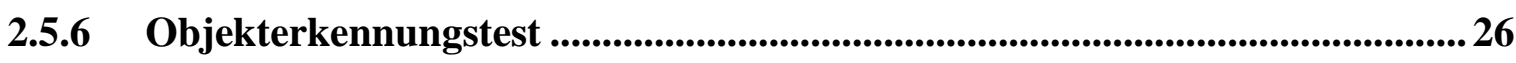

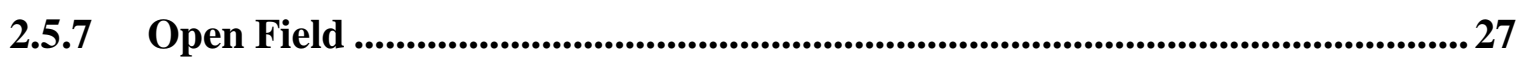

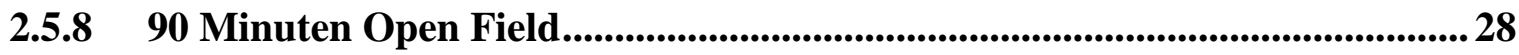

2.5.9 Morris Water Maze ............................................................................................ 28

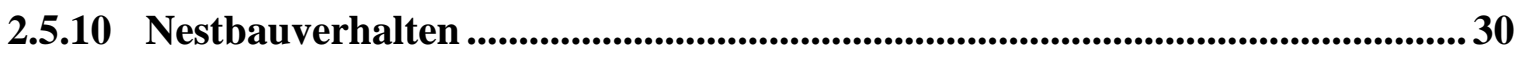

2.6 Statistische Analyse ........................................................................................31

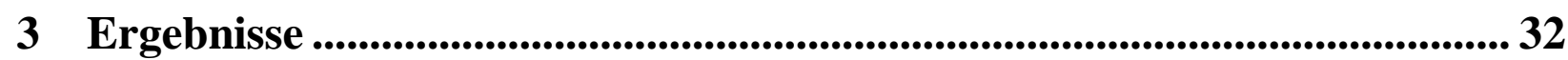

3.1 Phänotyp......................................................................................................................................32

3.2 Darstellung von verschiedenen $\operatorname{PrP}^{\mathrm{c}}$-Isoformen in den Gehirnen von WTMäusen.....................................................................................................33

3.3 Verändertes Nestbauverhalten bei Prnp ${ }^{0 / 0}$-Mäusen...........................................35

3.4 Abnahme des Angstverhaltens und erhöhte Latenzzeit bei Prnp ${ }^{0 / 0}$-Mäusen im fünf Minuten Open-Field-Test ..................................................................36

3.5 Abnahme des Aktivitäts- und Erkundungsverhaltens bei drei Mo-nate alten Prnp $^{0 / 0}$-Mäusen im 90 Minuten Open-Field-Test ................................................40

3.6 Zunahme der Aufenthaltsdauer in den offenen Armen des Eleva-ted Plus Maze bei Prnp ${ }^{0 / 0}$-Mäusen .......................................................................................42 42

3.7 Geringeres Erstarrungsverhalten bei Prnp ${ }^{0 / 0}$-Mäusen im Furchtkonditionierungstest .............................................................................................46

3.7.1 Kontextabhängige Furchtkonditionierung................................................................ 47

3.7.2 Tonabhängige Furchtkonditionierung.......................................................... 48

3.8 Kein Unterschied der motorischen Fähigkeiten zwischen Prnp ${ }^{\text {0/0 }}$-Mäusen und Wildtyp-Mäusen..................................................................................................49

3.9 Abnahme der kognitiven Funktionen bei Prnp ${ }^{0 / 0}$-Mäusen..............................50 
3.10 Kein Unterschied im räumlichen Lernen zwischen Prnp ${ }^{0 / 0}$-Mäu-sen und Wildtyp-Mäusen im Morris Water Maze ..................................................................52

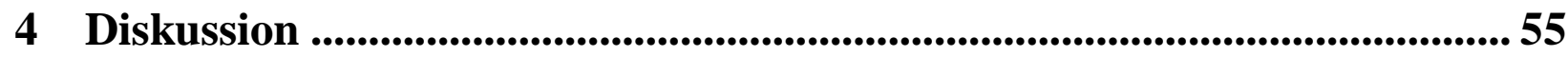

4.1 Veränderungen im nativen Nestbauverhalten bei Prnp ${ }^{0 / 0}$-Mäusen...............55

4.2 Einfluss des $\operatorname{PrP}^{\mathrm{c}}$ auf das Erkundungs- und Bewegungsverhalten.................56

4.3 Einfluss des $\operatorname{PrP}^{\mathrm{c}}$ auf das Angstverhalten ...............................................................58

4.4 Involvierung von $\operatorname{PrP}^{\mathrm{c}}$ in kognitive Lernprozesse ............................................60

4.5 Keine motorischen Defizite bei Prnp ${ }^{0 / 0}$-Mäusen.................................................64

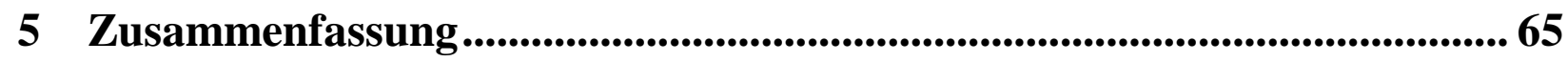

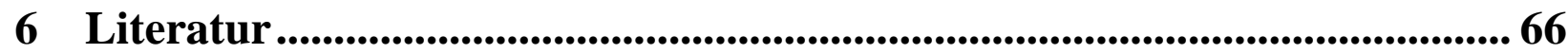




\section{Abbildungsverzeichnis}

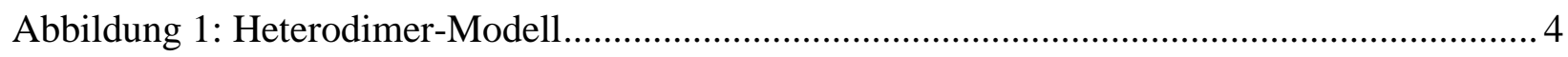

Abbildung 2: Struktur des humanen Prion-Proteins (Becker 2005, S.4) ..................................... 6

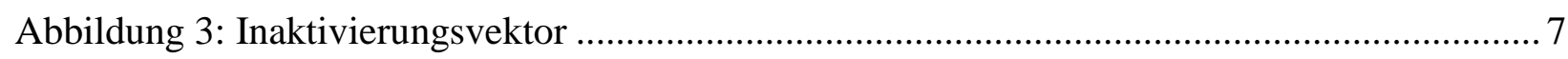

Abbildung 4: Herstellung von Knockout-Mäusen (Braun und Willnow 1996, S. 1766)............... 8

Abbildung 5: Chimäre mit ihren Nachkommen ....................................................................... 9

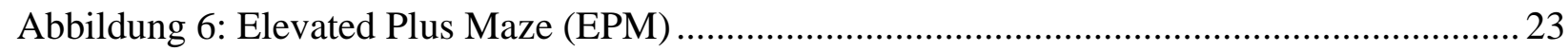

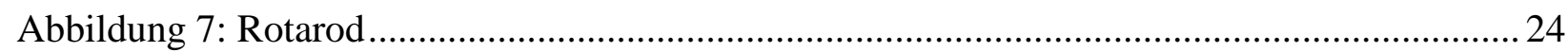

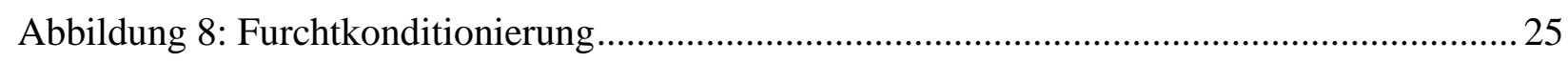

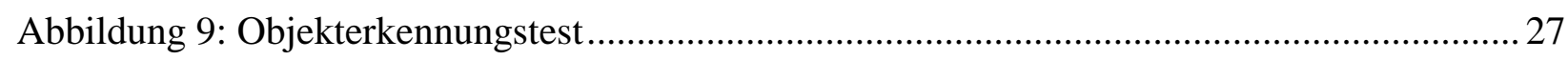

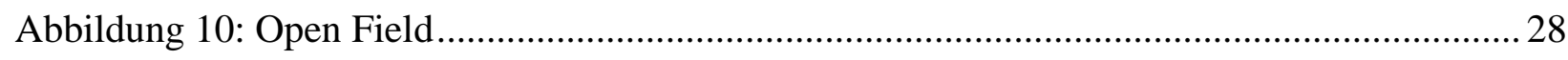

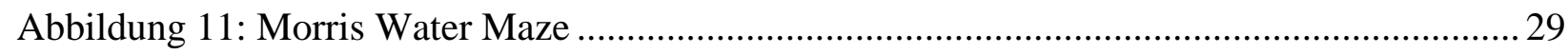

Abbildung 12: Fünf-Punkte-Skala des Nestbauverhaltens (Deacon 2006, S. 1119) ................... 30

Abbildung 13: Vergleich des Körpergewichts der Prnp ${ }^{0 / 0}$-Mäuse und der WT-Mäuse................. 32

Abbildung 14: Vergleich von Prnp ${ }^{0 / 0}$-Maus und Wildtyp-Maus (WT) im Alter von drei und 20

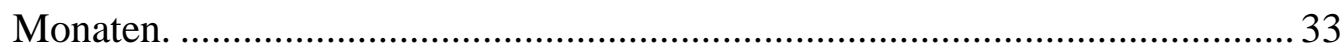

Abbildung 15: Fehlende Expression von $\operatorname{PrP}^{\mathrm{c}}$ bei den $\operatorname{Prnp}^{0 / 0}$-Mäusen....................................... 34

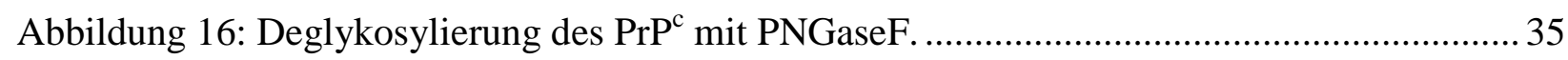

Abbildung 17: Nestbauverhalten von WT- und Prnp ${ }^{0 / 0}$-Mäusen. ................................................ 36

Abbildung 18: Anzahl der Linienüberschreitungen im Open-Field-Test. ................................. 37

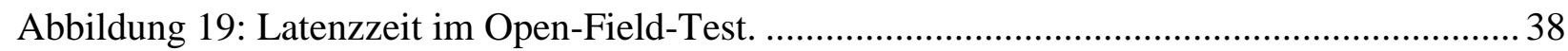

Abbildung 20: Aufenthalt im Zentrum im Open-Field-Test..................................................... 39

Abbildung 21: Aufenthalt in der Peripherie im Open-Field-Test. .............................................. 39

Abbildung 22: Zurückgelegter Weg im Open-Field-Test. ..................................................... 40

Abbildung 23: Anzahl der Linienüberschreitungen im 90 Minuten Open-Field-Test................. 41

Abbildung 24: Aufenthalt im Zentrum (A) und in der Peripherie (B) im 90 Minuten Open-Field-

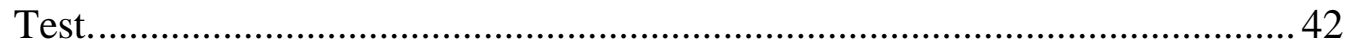

Abbildung 25: Aufenthalt auf den geschlossenen Armen des EPM. ........................................ 43

Abbildung 26: Aufenthalt auf den offenen Armen (A) und im Zentrum (B) des EPM.............. 44

Abbildung 27: Anzahl der Eintritte in die geschlossenen Arme (A), in die offenen Arme (B) und

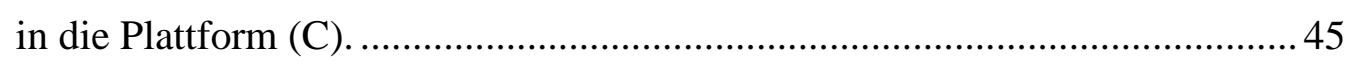

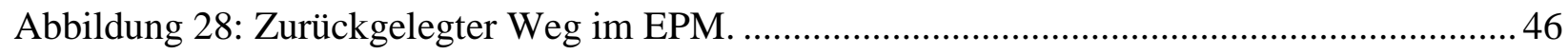

Abbildung 29: Mittlere Geschwindigkeit der Tiere während der Schockphase und während des schockfreien Intervalls. 47 
Abbildung 30: Freezingverhalten der Prnp ${ }^{0 / 0}$-Mäuse und der WT-Mäuse in der

kontextabhängigen Furchtkonditionierung. 48

Abbildung 31: Erstarrungsverhalten der Prnp ${ }^{0 / 0}$-Mäuse und der WT-Mäuse in der tonabhängigen

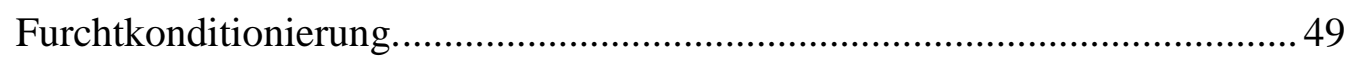

Abbildung 32: Analyse der motorischen Fähigkeiten von Prnp ${ }^{0 / 0}$-Mäusen und WT-Mäusen im

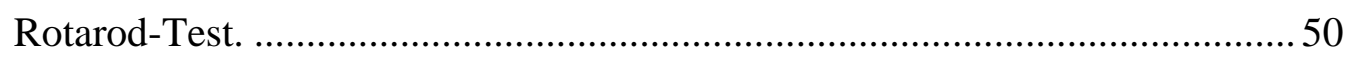

Abbildung 33: Verhalten der Prnp ${ }^{0 / 0}$-Mäuse und der WT-Mäuse im Objekterkennungstest. ....... 52

Abbildung 34: Lernkurve der Prnp ${ }^{0 / 0}$ - und WT-Mäuse im Morris-Water-Maze-Test................... 53

Abbildung 35: Verhalten der Prnp ${ }^{0 / 0}$ - und der WT-Mäuse im Morris Water Maze. ..................... 54 


\section{Tabellenverzeichnis}

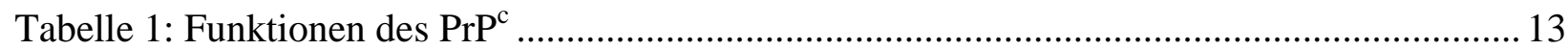

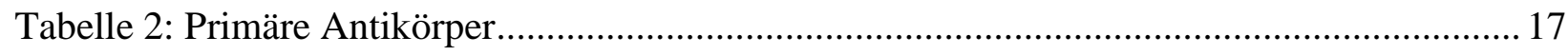

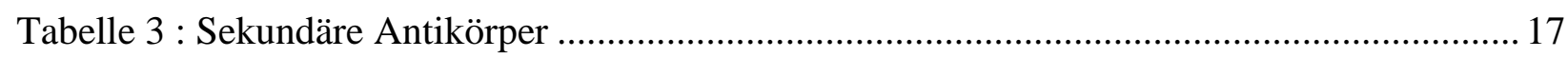

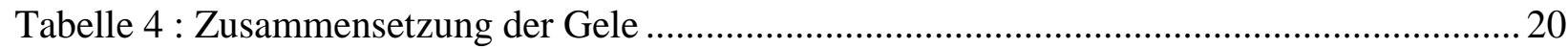




\section{Abkürzungsverzeichnis}

\section{Abkürzung \\ Bedeutung}

\section{A}

$\mathrm{A} \beta$

APP

APS

Asp

BSA

BSE

C

c-

${ }^{\circ} \mathrm{C}$

CB

CJK

C-Terminus

$\mathrm{dH}_{2} \mathrm{O}$

Dpl

ECL

EDTA

ELISA

EPM

ER

g

(x) $\mathrm{g}$

GABA

GPI

GSS

$\mathrm{h}$

$\mathrm{H}$

$\mathrm{H}_{2} \mathrm{O}$

HRP

HSV

$\operatorname{IgG}$

\section{Ampere}

Amyloid $\beta$

Amyloid-Vorläufer-Protein (engl.: Amyloid precursor protein)

Ammoniumpersulfat

Asparagin

Rinderserumalbumin (engl.: bovine serum albumine)

Bovine spongiforme Enzephalopathien

Cortex

zenti $\left(1 \times 10^{-2}\right)$

Grad Celsius

Cerebellum

Creutzfeldt-Jakob-Krankheit

carboxyterminales Ende von Proteinen

destilliertes Wasser

Protein Doppel

engl.: enhanced chemiluminescence

Ethylendiamintetraessigsäure

engl.: enzyme-linked immunosorbent assay

Elevated Plus Maze (deutsch: Erhöhtes Plus-Labyrinth)

Endoplasmatisches Retikulum

Gramm

Vielfaches der Erdbeschleunigung $\left(\mathrm{g}=9,80665 \mathrm{~m} / \mathrm{s}^{2}\right)$

$\gamma$-Aminobuttersäure

Glycosylphosphatidylinositol

Gerstmann-Sträussler-Scheinker-Krankheit

Stunde

Hippocampus

Wasser

Meerrettich-Peroxidase (engl.: horseradish peroxidase)

Herpes-simplex-Virus

Immunglobulin $\mathrm{G}$ 
Liter

M

$\operatorname{molar}(=\mathrm{mol} / \mathrm{l})$

$\mathrm{m}$

Meter

m-

milli $\left(1 \times 10^{-3}\right)$

$\min$

Minute

$\mu-$

mikro $\left(1 \times 10^{-6}\right)$

NO-Synthase

Stickstoffmonoxid-Synthase

OB

Bulbus olfactorius

PAGE

Polyacrylamid-Gelelektrophorese

PBS

phosphatgepufferte Kochsalzlösung

(engl.: phosphate buffered saline)

PFA

$\mathrm{pH}$

Paraformaldehyd

PNS

negativer dekadischer Logarithmus der Protonenkonzentration

Peripheres Nervensystem

Prion

PRNP

engl.: proteinaceous infectious particle

Prnp

Prion-Protein-Gen (Mensch)

$\operatorname{Prnp}^{0 / 0}$-Maus

Prion-Protein-Gen (Maus)

PrP

$\operatorname{PrP}^{\mathrm{c}}$

Prion-Protein-Knockout-Maus

$\operatorname{PrP}^{\mathrm{Sc}}$

Prion-Protein

PVDF

zelluläres Prion-Protein (engl.: c-cellular)

Pathogenes Prion-Protein (engl.: Sc-Scrapie)

Polyvinylidendifluorid

$\mathrm{s}$

Sekunde

SDS

Natriumdodecylsulfat (engl.: sodium dodecylsulfate)

SEM

Standardabweichung (engl.: standard error of the mean)

STI1

Stress-induzierbares Protein 1

TEMED

Tetramethylethylendiamin

Tris

Tris-hydroxymethyl-aminomethan

TSE

Transmissible spongiforme Enzephalopathie

Tween

Polyoxyethylensorbitanmonolaurat

Upm

Umdrehungen pro Minute

V

Volt

WT

Wildtyp

ZNS

Zentrales Nervensystem 


\section{Einleitung}

\subsection{Transmissible spongiforme Enzephalopathien (TSEs)}

\subsubsection{Historie der transmissiblen spongiformen Enzephalopathien}

Historisch wurden die transmissiblen spongiformen Enzephalopathien, auch PrionenErkrankungen genannt, erstmals im Jahre 1732 in Großbritannien beschrieben (Mc Gowan 1922). Als erstes wurde die Traberkrankheit Scrapie entdeckt, die bei Schafen und Ziegen auftritt. Später beschrieben Creutzfeldt und Jakob in den Jahren 1920 und 1921 unabhängig voneinander die ersten humanen spongiformen Enzephalopathien (Creutzfeldt 1920, Jakob 1921). Die Symptome wurden einer Krankheit zugeordnet, die damals als „Spastische Pseudosklerose“ bezeichnet wurde und später nach ihren Erstbeschreibern Creutzfeldt-Jakob-Krankheit (CJK) genannt wurde. In den darauf folgenden Jahren berichteten Gajdusek und Zigas über Kuru, eine infektiöse Erkrankung, die epidemieartig auf Papua-Neuguinea auftrat und durch rituellen Kannibalismus verursacht wurde (Gajdusek und Zigas 1957). Kurz darauf wurde man auf die Gemeinsamkeiten beider Erkrankungen aufmerksam und ging von einem gemeinsamen Krankheitserreger aus, der bis zu diesem Zeitpunkt jedoch noch unbekannt war.

\subsubsection{Verschiedene Formen der transmissiblen spongiformen Enzephalopathien}

Prionen-Erkrankungen gehören zu den transmissiblen spongiformen Enzephalopathien, die sowohl beim Tier als auch beim Menschen vorkommen. Es handelt sich hierbei um eine Gruppe neurodegenerativer Erkrankungen, die sporadisch, genetisch oder iatrogen verursacht werden können und in der Regel innerhalb weniger Monate zum Tode führen. Die Creutzfeldt-Jakob-Erkrankung (CJK) stellt die wichtigste Prionen-Erkrankung beim Menschen dar. Bisher wurden vier Formen der CJK beschrieben: die Sporadische Creutzfeldt-Jakob-Krankheit (sCJK), die Familiäre Creutzfeldt-Jakob-Krankheit (fCJK), die Iatrogene Creutzfeldt-Jakob-Krankheit (iCJK) und die Neue Variante der Creutzfeldt-Jakob-Krankheit (nvCJK).

Von den genannten Formen der CJK ist die sporadische Form mit 85\% die bekannteste und häufigste humane Prionen-Erkrankung. Ihre genaue Ursache ist bisher unbekannt. Alle genannten Prionen-Erkrankungen zeichnen sich durch eine lange Inkubationszeit aus und stellen eine Gruppe schnell progredienter Erkrankungen dar. Unterschiede zeigen sich bei den verschiedenen humanen Prionen-Erkrankungen in den betroffenen Ge- 
hirnregionen, dem Erkrankungsalter sowie dem Krankheitsverlauf. Zu den Symptomen der TSEs gehören motorische Störungen wie Myoklonien und Ataxie, Störungen der Wahrnehmung (Halluzinationen) und der Vigilanz, visuelle Störungen und Veränderungen der Persönlichkeit, Depression sowie vegetative Störungen und Gedächtnisstörungen bis hin zur Demenz. Des Weiteren können im Krankheitsverlauf sowohl pyramidale als auch extrapyramidale Störungen wie pathologische Reflexe, Spastik, Tremor und Rigor auftreten. Im terminalen Krankheitsstadium entwickeln die Patienten häufig einen akinetischen Mutismus (Belay 1999, Aguzzi et al. 2008). Histopathologisch weisen die TSEs einige Gemeinsamkeiten auf. So zeigen die Gehirne der betroffenen Individuen neben dem Fehlen einer Entzündungsreaktion eine schwammartige (spongiöse) Auflockerung des Neuropils, einen massiven Verlust von Nervenzellen, Vakuolisierung, Hypertrophie der Astro- und Mikroglia sowie Ablagerungen von Plaques (Belay 1999).

\subsection{Das zelluläre Prion-Protein $\left(\operatorname{PrP}^{c}\right)$}

Auslöser für die bisher genannten Erkrankungen sind Prionen ( $\mathrm{PrP}$ von proteinaceous infectious particle), bei denen es sich um aggregiertes Prion-Protein handelt, ohne dass bisher der Nachweis von Nukleinsäuren gelang. Das zelluläre Prion-Protein $\left(\operatorname{PrP}^{c}\right)$ ist ein Glycosylphosphatidylinositol (GPI)-verankertes Membranprotein, dessen abnormale, Proteinase-resistente Isoform durch Fehlfaltung akkumuliert und die Erkrankung auslöst. Das PrP-Gen ist evolutionär unter den Säugetieren hoch konserviert, wobei die Homologie der Aminosäuren unter den Säugetieren $85 \%$ bis $97 \%$ beträgt (Gabriel et al. 1992). Das $\operatorname{PrP}^{c}$ wird in mehreren Geweben unterschiedlich stark exprimiert (Toni et al. 2006). Die Umwandlung von $\operatorname{PrP}^{\mathrm{c}}$ in die pathogene Form erzeugt konformationelle Änderungen, die eine entscheidende Rolle in der Entstehung der TSEs spielen.

\subsubsection{Entdeckung des Prion-Proteins}

Nachdem zwischen Kuru, CJK und Scrapie viele neuropathologische Ähnlichkeiten entdeckt wurden, folgte die Suche nach dem Auslöser dieser Erkrankungen. Zu der Natur des Krankheitserregers der TSEs wurden in der Vergangenheit viele unterschiedliche Hypothesen aufgestellt. Im Jahre 1954 wurde von Sigurdsson der Begriff ,slow virus infections“ geprägt, während er in Island an der Scrapie-Erkrankung von Schafen forschte (Sigurdsson 1954). Diese Bezeichnung beschrieb Infektionen, die eine auffallend lange Inkubationszeit aufwiesen. In den darauf folgenden Jahren konnten jedoch keine krankheitsauslösenden Viren isoliert werden. Einige Jahre später wurde beobach- 
tet, dass der Erreger eine außergewöhnlich hohe Resistenz gegenüber UV- und ionisierender Strahlung, hohen Temperaturen und Chemikalien aufweist, die Viren und weitere Krankheitserreger unschädlich machen. Daher stellte Alper im Jahre 1967 die Hypothese auf, dass sich der Erreger ohne das Vorhandensein von Nukleinsäuren vermehren kann und postulierte damit eine neuartige Erregerform als Auslöser der Erkrankungen (Alper et al. 1967, Pattison und Jones 1967). Prusiner behauptete 1982, dass der Erreger lediglich aus Proteinen bestehe, da Prozeduren, die Proteine zerstören, die Infektiosität aufhoben (Prusiner et al. 1981, Prusiner 1982). Aus dieser Entdeckung heraus wurde der Begriff Prion geprägt, um das infektiöse Agens von herkömmlichen Krankheitserregern wie Bakterien und Viren zu unterscheiden.

Es gelang mit Hilfe einer DNA-Sonde, das kodierende Gen für das Prion-Protein zu identifizieren, das als PRNP bezeichnet wurde und sowohl in gesunden als auch in infizierten Hamstern in gleicher Weise exprimiert wird (Oesch et al. 1985). Dieses Gen kodiert sowohl für $\operatorname{PrP}^{\mathrm{c}}$ als auch für die pathogene Form, die als $\mathrm{PrP}^{\mathrm{Sc}}$ (Prion-Protein Scrapie-Isoform) bezeichnet wird. Als Protease-resistenter Bestandteil von $\operatorname{PrP}^{\mathrm{Sc}}$ wurde ein Glykoprotein mit einem Molekulargewicht von 27 bis $30 \mathrm{kDa}$ identifiziert, das $\operatorname{PrP}^{\mathrm{res}}$ oder $\operatorname{PrP}^{27-30}$ genannt wird. Es zeigte sich, dass $\operatorname{PrP}^{\mathrm{Sc}}$ die gleiche Primärstruktur aufweist wie $\operatorname{PrP}^{c}$, und dass der offene Leserahmen in nur einem Exon liegt. Das für das murine PrP kodierende Gen besteht aus drei Exons und ist auf Chromosom 2 lokalisiert. Der gesamte proteinkodierende Teil des Gens (Open Reading Frame, ORF) ist in Exon 3 enthalten. Somit kann die Entstehung von $\operatorname{PrP}^{\mathrm{c}}$ und $\mathrm{PrP}^{\mathrm{Sc}}$ durch Splicing der mRNA ausgeschlossen werden. Diese Erkenntnis führte in der Literatur zu verschiedenen Hypothesen, die die Entstehung von $\mathrm{PrP}^{\mathrm{Sc}}$ erklären sollten.

\subsubsection{Die Prion-Hypothese}

Prusiner stellte 1982 die ,protein-only“-Hypothese auf, die besagt, dass die pathogene Form des Prion-Proteins, das $\mathrm{PrP}^{\mathrm{Sc}}$, für die Prionen-Erkrankungen verantwortlich ist und somit ein Protein die Erkrankungen auslöst (Prusiner 1982). Bei dieser Hypothese wird angenommen, dass das natürlich vorhandene $\operatorname{PrP}^{\mathrm{c}}$ durch Infektion mit dem abnormalen $\mathrm{PrP}^{\mathrm{Sc}}$ in die pathogene Form umgewandelt wird und somit zur Erkrankung führt. Weitere Untersuchungen an Prnp-Knockout-Mäusen $\left(\operatorname{Prnp}^{0 / 0}\right)$, welche das $\operatorname{PrP}^{\mathrm{c}}$ nicht exprimieren, unterstützten diese Hypothese. Diese Mäuse können nicht mit $\operatorname{PrP}^{\mathrm{Sc}}$ infiziert werden. Dies ändert sich jedoch, sobald die Expression von $\operatorname{PrP}^{c}$ in diesen Mäusen wieder hergestellt wird (Büeler et al. 1994). Diese Untersuchungen zeigten, dass das 
Vorhandensein des zellulären Prion-Proteins für die Entstehung von PrionenErkrankungen notwendig ist, und dass dem Entstehungsmechanismus der TSEs die Umwandlung des $\mathrm{PrP}^{\mathrm{c}}$ in die pathogene Isoform $\mathrm{PrP}^{\mathrm{Sc}}$ zugrunde liegt. Für den Replikationsmechanismus des $\mathrm{PrP}^{\mathrm{Sc}}$ wird das Heterodimer-Modell diskutiert:

Das Heterodimer-Modell nach Prusiner beruht auf der Annahme, dass eine autokatalytische Konversion vorliegt, bei der $\operatorname{PrP}^{\mathrm{c}}$ und $\operatorname{PrP}^{\mathrm{Sc}}$ ein Heterodimer bilden, wobei $\operatorname{PrP}^{\mathrm{c}}$ durch den Einfluss von $\mathrm{PrP}^{\mathrm{Sc}}$ in die pathologische Form umgefaltet wird (Prusiner 1994).

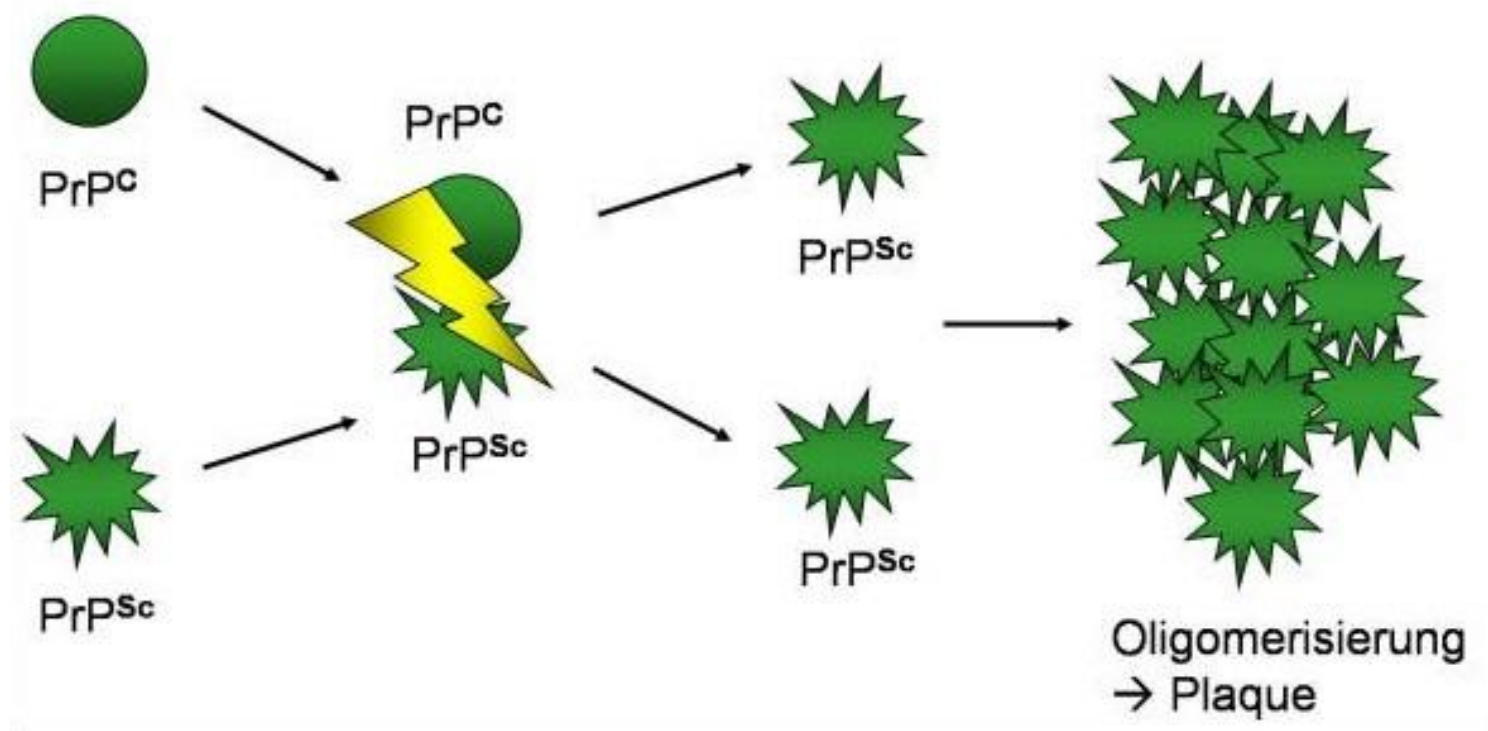

Abbildung 1: Heterodimer-Modell

Schematische Darstellung des Heterodimer-Modells. Durch den Kontakt des $\operatorname{PrP}^{\mathrm{c}}$ mit dem $\operatorname{Pr} \mathrm{P}^{\mathrm{Sc}}$ kommt es zu einer Konversion des $\operatorname{PrP}^{\mathrm{c}}$ in die pathologische Form. Es kommt zur Oligomerisierung der $\mathrm{PrP}^{\mathrm{Sc}}$-Moleküle und damit zu einer Plaquebildung (Becker 2005, S.6). 


\subsubsection{Struktur des zellulären Prion-Proteins}

Das $\operatorname{PrP}^{\mathrm{c}}$ ist ein evolutionär hoch konserviertes Glykoprotein, dessen primäres Translationsprodukt im Menschen aus 253 Aminosäuren besteht. $\operatorname{PrP}^{\mathrm{c}}$ wird im rauen Endoplasmatischen Retikulum (ER) synthetisiert. In den darauf folgenden Schritten wird im ER und im Golgiapparat das N-terminale Signalpeptid von 22 Aminosäuren abgespalten und der C-terminale Rest von 231 Aminosäuren durch den Glykosylphosphatidylinositol-Anker (GPI-Anker) ersetzt. Anschließend wird $\operatorname{PrP}^{\mathrm{c}}$ an die Zelloberfläche transportiert und mit dem GPI-Anker an der äußeren Zellmembran fixiert. Mit Hilfe von Nuklearmagnetresonanzmessungen gelang es, die Struktur verschiedener rekombinanter PrP-Formen zu bestimmen. Hierbei wurden globale Strukturähnlichkeiten festgestellt:

Das Prion-Protein besitzt eine gut strukturierte C-terminale Domäne und eine flexible, unstrukturierte N-terminale Domäne. Als sekundäre Strukturelemente weist der Cterminale Bereich drei $\alpha$-Helices und zwei antiparallele $\beta$-Faltblattstrukturen auf (Riek et al. 1997, Zahn et al. 2000). Die Helix-1-Domäne wird durch die Bereiche der beiden kleinen antiparallelen Faltblätter eingeschlossen, woran sich die Helices 2 und 3 anschließen, die durch eine stabilisierende Disulfidbrücke miteinander verbunden sind. Die N-terminale Region enthält ein Segment aus fünf Oktarepeat-Regionen (Riek et al. 1997). Dieser Bereich gilt als Hauptreaktionsdomäne, der u.a. für den Import in das ER benötigt wird und bevorzugt an Kupferionen bindet. Den Übergang von der unstrukturierten N-terminalen Domäne zur strukturierten C-terminalen Domäne bilden 20 hydrophobe Aminosäuren, die auch als „Hydrophobe Domäne“ bezeichnet werden (Yost et al. 1990). $\operatorname{PrP}^{\mathrm{c}}$ kann als di-, mono- oder unglykosylierte Isoform vorliegen. $\operatorname{PrP}^{\mathrm{c}}$ kann an den Aminosäuren Asparagin-181 und Asparagin-197 glykosyliert werden (Haraguchi et al. 1989), wobei an diese Stellen jeweils bis zu 50 verschiedene Oligosaccharide binden können (Rudd et al. 1999). 


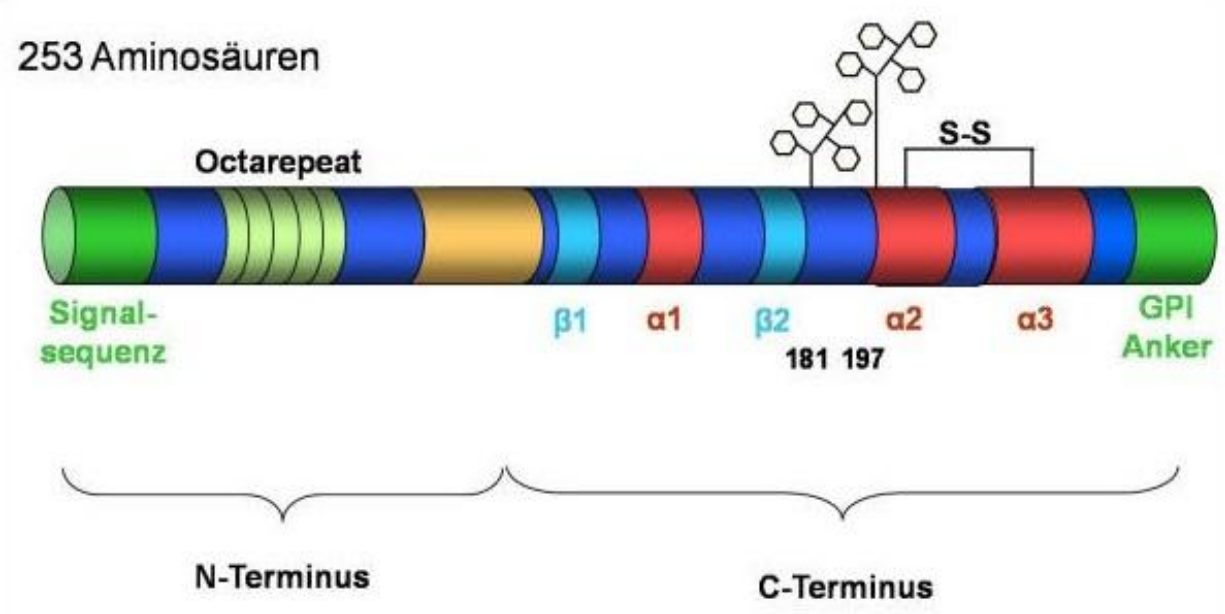

Abbildung 2: Struktur des humanen Prion-Proteins (Becker 2005, S.4)

\subsubsection{Vorkommen des zellulären Prion-Proteins im Zentralen Nervensystem}

$\operatorname{PrP}^{\mathrm{c}}$ wird in verschiedenen Geweben sowie in einem hohen Maß im Zentralen Nervensystem (ZNS) exprimiert. Hauptproduzenten im ZNS sind Neurone (Kretzschmar et al. 1986), wogegen $\operatorname{PrP}^{\mathrm{c}}$ auch in Astrozyten, Oligodendrozyten (Moser et al. 1995) und in Mikroglia (Brown DR et al. 1998) exprimiert wird. Die Proteinmenge variiert in den verschiedenen Hirnregionen, den verschiedenen Zelltypen und Neuronen (Linden et al. 2008). Immunhistochemische Untersuchungen an Gehirnen von Hamstern haben gezeigt, dass $\operatorname{PrP}^{\mathrm{c}}$ in hoher Konzentration in der CA1-Region des Hippocampus anzutreffen ist. Darüber hinaus weisen die Neurone des Cortex, des Thalamus, des Cerebellums und der Medulla oblongata einen hohen Gehalt an PrP-mRNA auf (Makrinou et al. 2002). Auch außerhalb des ZNS wird $\operatorname{PrP}^{c}$ in verschiedenen Zellen des Immunsystems, im Knochenmark, im Blut und in den Geweben einer Reihe anderer Organe wie Niere, Skelettmuskulatur und Herz exprimiert (Aguzzi et al. 2008, Linden et al. 2008).

An Gehirnschnitten von Hamstern wurde nachgewiesen, dass das $\operatorname{PrP}^{\mathrm{c}}$ in erster Linie im Neuropil von Neuronen, also im Gewebe der Dendritenbäume, Axonterminalen und Synapsen zu finden ist (Taraboulos et al. 1992). Weitere Untersuchungen ergaben, dass im ZNS eine Diskrepanz zwischen den Konzentrationen von $\operatorname{PrP}^{\mathrm{c}}$ und der PrP-mRNA besteht. Es zeigte sich, dass $\operatorname{PrP}^{\mathrm{c}}$-negative dopaminerge Neurone der Substantia nigra und des Bulbus olfactorius einen hohen Gehalt an PrP-mRNA haben. Der Grund für diese Diskrepanz zwischen mRNA und Proteingehalt ist nicht bekannt (Ford et al. 
2002). Während der Embryogenese wird das Prion-Protein sowohl im ZNS als auch im Peripheren Nervensystem (PNS) exprimiert (Büeler et al. 1992). Neuere Untersuchungen weisen auf eine $\mathrm{PrP}^{\mathrm{c}}$-Lokalisation im Gewebe des olfaktorischen Systems hin (Le Pichon and Firestein 2008).

\subsection{Herstellung von „Knockout-Mäusen“}

Knockout-Mäuse sind Mäuse, bei denen durch genetische Manipulation ein oder mehrere Gene inaktiviert werden, wodurch das entsprechende Protein nicht mehr exprimiert wird. Die Generierung von Knockout-Mäusen stellte einen großen Fortschritt in der Medizin dar, da Krankheiten, biologische Mechanismen und Funktionen verschiedener Gene und Proteine besser untersucht und verstanden werden können.

Ausgangspunkt für die Geninaktivierung ist die Herstellung eines Inaktivierungsvektors (Braun und Willnow 1996). Der Vektor enthält längere Bereiche von DNA, die zu dem Zielgen homolog sind und später die homologe Rekombination ermöglichen. Dazwischen befindet sich fremde DNA, die das Zielgen verändert und eine Positiv-NegativSelektion zulässt. Hierbei handelt es sich gewöhnlich um eine Resistenz gegenüber dem Antibiotikum Neomycin. Der Vektor enthält außerhalb des homologen Bereiches noch ein zweites Selektionsgen, mit dem getestet wird, ob der Einbau an der richtigen Stelle im Maus-Genom erfolgt ist. Hierzu dient das Gen für die Thymidinkinase (HSV-tk) des Herpes-simplex-Virus (HSV). Durch Einsatz von Gancyclovir im Medium sterben die Zellen, die die Thymidinkinase exprimieren.

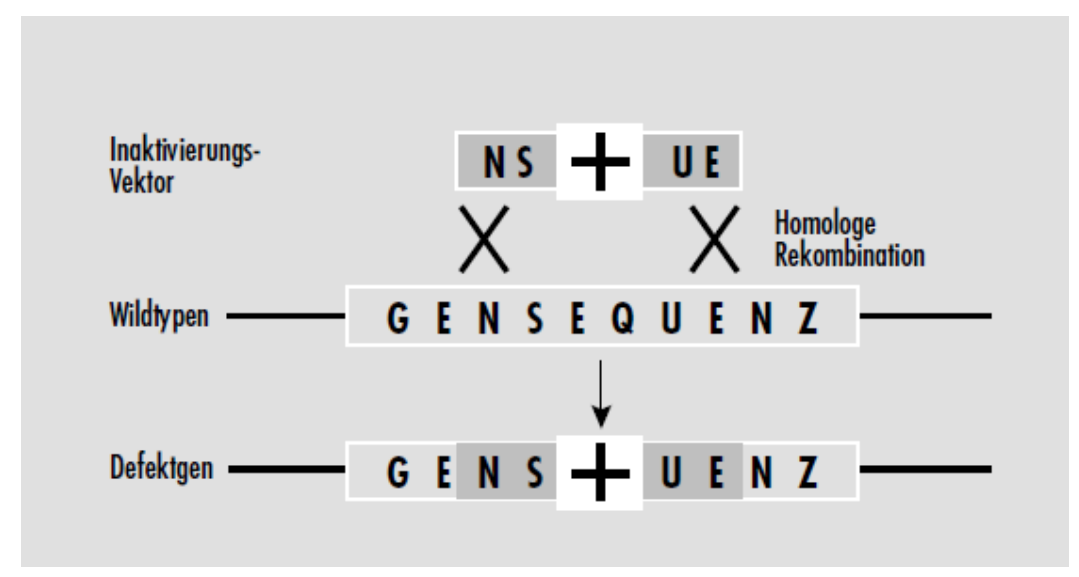

\section{Abbildung 3: Inaktivierungsvektor}

Herstellung eines Inaktivierungsvektors mittels homologer Rekombination. Der Geninaktivierungsvektor setzt sich zusammen aus dem selektierbaren Gen, welches von zwei benachbarten Bereichen des Wildtyp-Gens eingerahmt wird (Braun und Willnow 1996, S. 1766). 
Der oben beschriebene Inaktivierungsvektor wird in isolierte pluripotente embryonale Stammzellen aus Mausembryonen eingebracht (Transfektion). Durch Rekombination homologer Gensequenzen erfolgt die Integration der Vektor-Genfragmente und der dazwischenliegenden Selektionsgene in das Zielgen. Durch Antibiotikaselektion werden die Zellen angereichert, die den Vektor und damit die Neomycin-Resistenz aufgenommen haben. Nachdem diese Zellklone isoliert und vermehrt wurden, werden die so veränderten embryonalen Stammzellen in Blastozysten injiziert und bilden dort ein Mosaik mit den anderen Zellen der inneren Zellmasse. Nachdem die Blastozysten einer weiblichen Maus implantiert wurden, entwickeln sich die Embryonen zu Mosaik-Mäusen, auch Chimären genannt. Diese Chimären sind eine Mischung von Zellen der Blastozyste und der genetisch veränderten embryonalen Stammzelle.

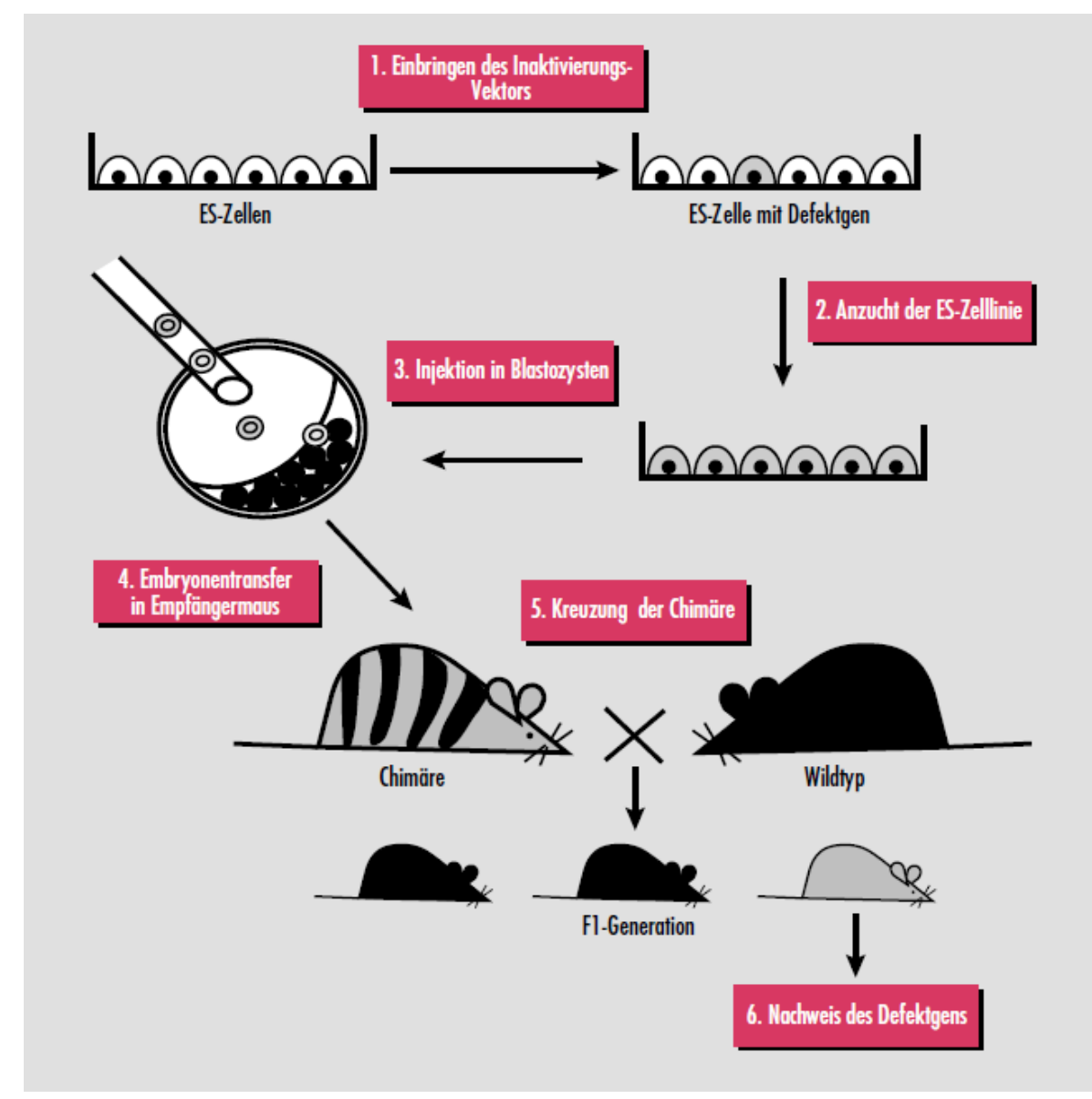

Abbildung 4: Herstellung von Knockout-Mäusen (Braun und Willnow 1996, S. 1766).

Die Fellfärbung zeigt den Anteil dieser beiden Zelltypen an der Chimäre. Die Blastozysten stammen aus einem Mausstamm mit schwarzem Fell (C57BL/6J), während die embryonalen Stammzellen aus Mäusen mit brauner Fellfarbe (Agouti-Maus) gewonnen werden. Chimären haben aus diesem Grund ein braun-schwarz geflecktes Fell. Die 
Chimären werden wieder mit Wildtyp-Mäusen (C57BL/6J) gekreuzt, um Tiere mit ausschließlich heterozygotem Gendefekt zu erhalten. Tiere, die das genetisch veränderte Erbgut tragen, weisen die braune (Agouti-)Fellfarbe auf. Durch weitere Kreuzung der heterozygoten Tiere erhält man homozygote Knockout-Mäuse (Braun und Willnow 1996).

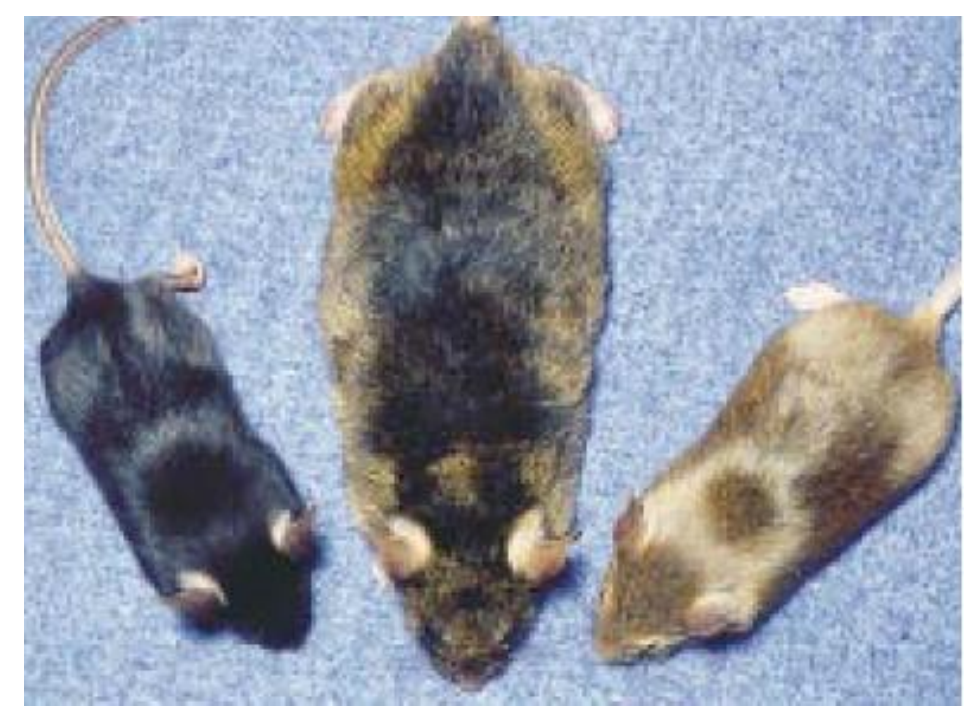

Abbildung 5: Chimäre mit ihren Nachkommen

Chimäre mit gemischter Fellfarbe (Mitte) und Nachkommen mit schwarzer und Agouti-Fellfarbe (Braun und Willnow 1996, S. 1766).

\subsubsection{Prion-Protein-Knockout-Mäuse}

Die erste Prion-Protein-Knockout-Maus wurde 1992 von Büeler beschrieben und eröffnete neue und wichtige Möglichkeiten zur Erforschung des Prion-Proteins (Büeler et al. 1992). Bei diesen Mäusen handelte es sich um eine Kreuzung von Mäusen der Stämme C57BL/6J x 129/Sv(ev). Das Vektor-Genfragment ersetzt hier durch homologe Rekombination den Bereich zwischen Codon 4-187 auf dem offenen Leserahmen. Diese PrionProtein-Knockout-Mäuse werden auch als Prnp $^{0 / 0}$ - oder Zürich-I-Mäuse (ZrchI) bezeichnet (Büeler et al. 1992). Eine weitere Linie von Knockout-Mäusen wurde durch Unterbrechung des offenen Leserahmens an Codon 93 und homologer Rekombination hergestellt. Diese Mäuse sind bekannt als Npu-Mäuse oder Prnp ${ }^{-/-E d i n b u r g h-M a ̈ u s e ~}$ (Edbg) (Manson et al. 1994). Beide genannten Mauslinien zeigten zum Zeitpunkt ihrer Entwicklung keine Auffälligkeiten in Bezug auf Verhalten und Entwicklung. Bei den sogenannten Nagasaki-Mäusen (Ngsk) wurde neben einer normalen Entwicklung im fortgeschrittenen Alter eine Ataxie und eine Degeneration der Purkinje-Zellschicht beobachtet. Bei dieser Mauslinie sind neben dem offenen Leserahmen des Prnp-Gens zu- 
sätzlich Bereiche durch einen Vektor mit Neomycinresistenzgen ersetzt worden (Sakaguchi et al. 1996). Dieselben Beobachtungen wurden bei den Rcm0-Mäusen gemacht. Diese Mauslinie weist die gleiche Prnp-Deletion, aber ein anderes Resistenzgen als die Nagasaki-Mäuse auf. Bei dem Resistenzgen handelt es sich um das Hypoxanthin-Phosphoribosyl-Transferase-Gen (Moore et al. 1999). Die als Zürich II (ZrchII) bezeichneten Mäuse weisen eine ähnliche Entwicklung auf. Bei ihnen bestehen zusätzlich zu dem offenen Leserahmen noch weitere Deletionen (Rossi et al. 2001).

Hinsichtlich der Entwicklung und des Verhaltens wiesen die ersten Prion-ProteinKnockout-Mäuse (Zrch I und Edbg) keine Unterschiede im Phänotyp im Vergleich zu den Wildtyp-Mäusen auf (Büeler et al. 1992, Manson et al. 1994). Später konnte jedoch gezeigt werden, dass diese Mäuse elektrophysiologische Veränderungen sowie Störungen im Schlaf-Wach-Rhythmus hatten (Tobler et al. 1996, Tobler et al. 1997) und Ataxien entwickelten (Roesler et al. 1999). Weiterhin wurde vermutet, dass das $\operatorname{PrP}^{\mathrm{c}}$ eine bedeutende Funktion im Angst- und Stressverhalten (Nico et al. 2005, Lobão-Soares et al. 2008), im Lernverhalten und in der Gedächtniskonsolidierung (Nishida et al. 1997) sowie im olfaktorischen System hat (Le Pichon et al. 2009).

\subsection{Physiologische Funktion des zellulären Prion-Proteins}

Obwohl in den vergangenen Jahren einige Untersuchungen an den Prion-ProteinKnockout-Mäusen durchgeführt wurden, ist die Funktion des $\operatorname{PrP}^{\mathrm{c}}$ bis heute noch nicht vollständig geklärt.

Einige Studien ergaben, dass $\operatorname{PrP}^{\mathrm{c}}$ mit verschiedenen Proteinen interagiert, wozu auch Laminin gehört. Die Interaktion mit Laminin könnte eine essentielle Rolle bei der Gedächtniskonsolidierung spielen und möglicherweise durch die beiden Proteinkinasen PKA und ERK1/2 vermittelt werden (Coitinho et al. 2006). Der genaue Mechanismus dieser Interaktion ist noch unbekannt. Es besteht aber Grund zu der Annahme, dass durch Laminin das Wachstum von Neuriten stimuliert wird (Graner et al. 2000).

Außerdem scheint $\operatorname{PrP}^{c}$ eine wichtige Rolle in der Kupferhomöostase zu spielen. Es konnte nachgewiesen werden, dass die Oktarepeatregion in der N-terminalen Domäne des Proteins Kupferionen binden kann (Brown DR et al. 1997a). Die Kupferbindung an $\operatorname{PrP}^{c}$ hat eine Konformationsänderung in der Oktarepeatregion zur Folge (Qin et al. 2000). Die physiologische Funktion dieser Konformationsänderung ist noch ungeklärt. Es wird jedoch vermutet, dass die Kupferbindung die Endozytose von $\operatorname{PrP}^{\mathrm{c}}$ stimuliert 
und $\mathrm{PrP}^{\mathrm{c}}$ somit als Transporter für Kupfer dient (Pauly und Harris 1998). Einen direkten Beweis für diese Transportfunktion des $\mathrm{PrP}^{\mathrm{c}}$ gibt es allerdings noch nicht. Andere Autoren gehen davon aus, dass die Kupferbindung und die daraus folgende Endozytose von $\operatorname{PrP}^{\mathfrak{c}}$ ein Signal für die antioxidative Schutzfunktion des $\operatorname{PrP}^{\mathfrak{c}}$ ist (Vassallo und Herms 2003).

Die Lokalisation des $\operatorname{PrP}^{c}$ in den Synapsen und dessen Interaktion mit der Tyrosinkinase fyn lässt vermuten, dass $\operatorname{PrP}^{c}$ an der Signaltransduktion in Synapsen beteiligt ist (Mouillet-Richard et al. 2000) und somit eine essentielle Rolle für die normale Funktion der Synapsen spielt. In einigen Studien wurde dem $\operatorname{PrP}^{c}$ eine neuroprotektive Funktion zugesprochen, da es mit dem Stress-induzierbaren Protein 1 (STI1) interagiert und somit vor Anisomycin-induzierter Apoptose schützt (Chiarini et al. 2002). Da $\operatorname{PrP}^{\mathrm{c}}$ und STI1 eine besonders hohe Expression im Hippocampus aufweisen, wird angenommen, dass diese Interaktion vor allem in Neuronen des Hippocampus Neurogenese induziert und eine neuroprotektive Funktion einnimmt (Lopes et al. 2005).

Neben dieser Neuroprotektion konnte gezeigt werden, dass $\operatorname{PrP}^{c}$ auch eine neuroprotektive Funktion nach ischämisch bedingten Hirninfarkten hat. Eine Studie belegte, dass $\operatorname{Prnp}^{0 / 0}$-Mäuse nach einem ischämischen Insult deutlich größere Infarktareale mit Hirnödem aufwiesen als die Wildtyp-Mäuse und die $\operatorname{PrP}^{\mathrm{c}}$ überexprimierenden Mäuse. Das Infarktgebiet war ungefähr 200\% größer als das der Wildtyp-Mäuse und erstreckte sich über Cortex und Striatum, während sich das Areal bei den Wildtypen auf das Striatum beschränkte (Spudich et al. 2005). PrP ${ }^{c}$ überexprimierende Mäuse zeigen zudem eine verminderte postischämische Erk1/2 Phosphorylierung, eine Signalkaskade, die neuronale Schäden nach ischämischem Insult triggert (Weise et al. 2006, Weise et al. 2008). Auch die N-terminale Oktarepeatregion des $\operatorname{PrP}^{\mathrm{c}}$ zusammen mit den Phosphatidylinositol-3-Kinase $(\mathrm{PI} 3 \mathrm{~K}) /$ Akt-Signalkaskaden scheinen eine bedeutende neuroprotektive Funktion einzunehmen. Es wurde gezeigt, dass Mäuse, denen die Oktarepeatregion fehlt (C4/- Mäuse), nach einem ischämischen Insult ein dreifach größeres Infarktareal aufweisen als die Wildtyp-Mäuse. Dieses Infarktareal der C4/- Mäuse war vergleichbar mit dem der Prnp $^{0 / 0}$-Mäuse (Mitteregger et al. 2007).

Weitere Studien nehmen einen Zusammenhang zwischen dem $\operatorname{PrP}^{\mathrm{c}}$ und der AlzheimerErkrankung an. Einige zeigten, dass $\operatorname{PrP}^{\mathrm{c}}$ die $\beta$-Sekretase-Aktivität inhibiert, wodurch die Spaltung des Amyloid-Vorläufer-Proteins (Amyloid precursor protein, APP) in Amyloid $\beta(\mathrm{A} \beta)$ vermindert wird. Im Zusammenhang mit dieser inhibitorischen Funkti- 
on des $\operatorname{PrP}^{\mathrm{c}}$ auf die $\beta$-Sekretase-Aktivität wurden im Vergleich zu den Wildtyp-Mäusen in den Gehirnen von Prion-Protein-Knockout-Mäusen signifikant höhere Konzentrationen von $A \beta_{1-40}$ und $A \beta_{1-42}$ gefunden (Parkin et al. 2007).

Die Lokalisation des $\operatorname{PrP}^{c}$ in peripheren Organsystemen lässt vermuten, dass $\operatorname{PrP}^{c}$ auch außerhalb des ZNS eine Rolle spielt, z.B. im Immunsystem und bei Entzündungsreaktionen. So zeigten Prion-Protein-Knockout-Mäuse eine geringere immunologische Antwort auf eine künstlich induzierte Entzündungsreaktion als Wildtyp-Mäuse (De Almeida et al. 2005). Die PrP $^{c}$-Konzentration im Plasma, sowie in entzündetem und ischämischem Gewebe nimmt bei Patienten nach einem ischämischen Ereignis zu und scheint somit einen Einfluss auf hypoxische Zellschäden zu nehmen (Mitsios et al. 2007).

\begin{tabular}{|c|c|c|}
\hline Funktion & $\begin{array}{l}\text { Auswirkung und Mecha- } \\
\text { nismus }\end{array}$ & Literatur \\
\hline $\begin{array}{l}\text { Beeinflussung der Ge- } \\
\text { dächtniskonsolidierung }\end{array}$ & $\begin{array}{l}\text { Interaktion mit Laminin, } \\
\text { Stimulation } \\
\text { Neuritenwachstums und } \\
\text { der Zellproliferation }\end{array}$ & $\begin{array}{l}\text { Coitinho et al. } 2006 \\
\text { Graner et al. } 2000\end{array}$ \\
\hline $\begin{array}{l}\text { Beeinflussung der Ausbil- } \\
\text { dung des Langzeitgedächt- } \\
\text { nisses }\end{array}$ & $\begin{array}{l}\text { Herabgesetzte Langzeitpo- } \\
\text { tenzierung im Hippocam- } \\
\text { pus bei Prnp }{ }^{0 / 0} \text {-Mäusen }\end{array}$ & Coitinho et al. 2007 \\
\hline $\begin{array}{l}\text { Antioxidative Schutzfunk- } \\
\text { tion }\end{array}$ & $\begin{array}{l}\text { Interaktion mit Kupfer, } \\
\text { fragliche } \\
\text { Superoxiddismutase- } \\
\text { Aktivität }\end{array}$ & $\begin{array}{l}\text { Vassallo und Herms } 2003 \\
\text { Brown DR et al. } 1999 \\
\text { Brown DR et al. } 1997 \mathrm{~b} \\
\text { Sakudo et al. } 2003\end{array}$ \\
\hline $\begin{array}{l}\text { Beteiligung an der } \\
\text { Signaltransduktion in Sy- } \\
\text { napsen }\end{array}$ & $\begin{array}{l}\text { Interaktion mit der } \\
\text { Tyrosinkinase fyn }\end{array}$ & $\begin{array}{l}\text { Mouillet-Richard et al. } \\
2000\end{array}$ \\
\hline $\begin{array}{l}\text { Neuroprotektive Funktion } \\
\text { Antiapoptotische Funktion }\end{array}$ & $\begin{array}{l}\text { Interaktion mit dem STI1 } \\
\text { Anti-Bax-Funktion } \\
\text { (proapoptotisches Protein } \\
\text { der Bcl-2 Familie) }\end{array}$ & Westergard et al. 2007 \\
\hline
\end{tabular}




\begin{tabular}{|c|c|c|}
\hline $\begin{array}{l}\text { Einfluss auf den Schlaf- } \\
\text { Wach-Rhythmus }\end{array}$ & $\begin{array}{l}\text { Prnp }{ }^{0 / 0} \text {-Mäuse zeigten ei- } \\
\text { nen veränderten Schlaf- } \\
\text { Wach-Rhythmus }\end{array}$ & $\begin{array}{l}\text { Tobler et al. } 1996 \\
\text { Tobler et al. } 1997\end{array}$ \\
\hline $\begin{array}{l}\text { Einfluss auf die Immun- } \\
\text { antwort }\end{array}$ & $\begin{array}{l}\text { Mechanismus weitgehend } \\
\text { unbekannt }\end{array}$ & De Almeida et al. 2005 \\
\hline $\begin{array}{l}\text { Einfluss auf depressive } \\
\text { Verhaltensweisen }\end{array}$ & $\begin{array}{l}\text { Prnp }{ }^{0 / 0} \text {-Mäuse zeigten im } \\
\text { Vergleich zu Wildtyp- } \\
\text { Mäusen deutlich depressi- } \\
\text { ve Verhaltensweisen }\end{array}$ & Gadotti et al. 2011 \\
\hline $\begin{array}{l}\text { Einfluss auf das olfaktori- } \\
\text { sche System }\end{array}$ & $\begin{array}{l}\operatorname{PrP}^{\mathrm{c}} \text { scheint einen wichti- } \\
\text { gen Einfluss auf die nor- } \\
\text { male Prozessierung senso- } \\
\text { rischer Informationen des } \\
\text { olfaktorischen Systems zu } \\
\text { haben }\end{array}$ & Le Pichon et al. 2009 \\
\hline
\end{tabular}

Tabelle 1: Funktionen des $\operatorname{PrP}^{\mathrm{c}}$ 


\subsection{Zielsetzung der Arbeit}

Obwohl das Prnp-Gen bereits im Jahre 1986 identifiziert wurde und seit 1992 Studien an Prion-Protein-Knockout-Mäusen möglich sind, ist die Rolle des $\operatorname{PrP}^{\mathrm{c}}$ bis heute noch nicht eindeutig geklärt. Nach wie vor werden verschiedene und teils widersprüchliche Funktionen des $\operatorname{PrP}^{\mathrm{c}}$ diskutiert, die Anlass zu weiteren Untersuchungen geben. Besonders im Bezug auf den Einfluss des $\operatorname{PrP}^{\mathrm{c}}$ auf das Verhalten gehen die Meinungen teils noch deutlich auseinander. Während die ersten Prnp ${ }^{0 / 0}$-Mäuse keine Veränderung in ihrer Entwicklung und in der Verhaltensphysiologie aufwiesen, zeigten spätere Untersuchungen einen Zusammenhang zwischen $\operatorname{PrP}^{\mathrm{c}}$ und veränderten Verhaltensweisen bei Prnp $^{0 / 0}$-Mäusen. Hierzu gehörten Veränderungen im Schlaf-Wach-Rhythmus (Tobler et al. 1996, Tobler et al. 1997), im Angstverhalten (Nico et al. 2005, Lobão-Soares et al. 2008), sowie in der Gedächtniskonsolidierung (Nishida et al. 1997, Coitinho et al. 2007).

Ziel der vorliegenden Arbeit war es, die Funktion des $\operatorname{PrP}^{\mathrm{c}}$ in der Verhaltensphysiologie anhand von transgenen Prnp ${ }^{0 / 0}$-Mäusen und Wildtyp-Mäusen zu untersuchen. Zur Analyse der Tiere wurden verschiedene etablierte Verhaltenstests ausgewählt. Untersucht wurden die kognitiven Leistungen der Tiere, das Angstverhalten, die motorischen Fähigkeiten, das Erkundungs- und Vermeidungsverhalten sowie erstmalig das Nestbauverhalten als angeborene Verhaltensweise. Hierfür wurden der Open-Field-Test, der Objekterkennungstest, der Morris-Water-Maze-Test, die Furchtkonditionierung, das Elevated Plus Maze, der Rotarod-Test sowie ein Test über das Nestbauverhalten eingesetzt.

Ein weiterer Schwerpunkt dieser Arbeit war die Untersuchung möglicher Auswirkungen des Prion-Proteins auf das Verhalten während des natürlichen Alterungsprozesses der Tiere. Hierfür wurden Prnp ${ }^{0 / 0}$-Mäuse und Wildtypen des gleichen Zuchtstammes in drei unterschiedlichen Altersgruppen unter standardisierten Bedingungen untersucht und miteinander verglichen. Die drei Altersklassen umfassten Tiere im Alter von drei, neun und 20 Monaten. 


\section{Material und Methoden}

\subsection{Material}

\subsubsection{Geräte}

\section{Geräte}

Kühlschrank $\left(4^{\circ} \mathrm{C}\right)$

Laborschüttler

Laborwaage TE1502S

Magnetrührer MR 3000

$\mathrm{pH}-$ Meter

Photometer Ultrospec 2100 pro

Pipettierhilfe, elektrisch

Thermomixer comfort

Tiefkühlschrank $\left(-80^{\circ} \mathrm{C}\right)$

Trans Blot SD Semi-Dry Transfer Cell

Vortexer

Zentrifuge $5810 \mathrm{R}$

\section{Hersteller}

Liebherr

Heidolph (Schwabach, D)

Sartorius (Göttingen, D)

Heidolph (Schwabach, D)

Mettler Toledo (Gießen, D)

Amersham (Freiburg, D)

Eppendorf (Hamburg, D)

Eppendorf (Hamburg, D)

Sanyo (München, D)

BioRad (München, D)

Scientific Industries (New York, USA)

Eppendorf (Hamburg, D)

\subsubsection{Verbrauchs- und spezielles Material}

Amersham Hyperfilm ECL

Eppendorf-Cups

Falkon-Röhrchen

Knopfsonde

Petrischale

Pipetten

Spritzen

Pinzetten

Scheren

Skalpell
Amersham (Freiburg, D)

Eppendorf (Hamburg, D)

Sarstedt (Newton, USA)

Rettberg (Göttingen, D)

Falcon (Heidelberg, D)

Eppendorf (Hamburg, D)

Braun (Melsungen, D)

Rettberg (Göttingen, D)

Rettberg (Göttingen, D)

Rettberg (Göttingen, D)

\subsubsection{Chemikalien und Reagenzien}

Acrylamid/Bisacrylamidlösung

APS
Roth (Karlsruhe, D)

BioRad (München,D) 
Aqua Dest

BSA

EDTA

Glycin

Magermilchpulver

Methanol

Natriumchlorid

PBS

Probenpuffer

Proteinstandard

SDS

TEMED

Tris/HCl

Triton X-100

Tween

Western Blot Stripping Buffer
Ampuwa (Bad Homburg, D)

Sigma-Aldrich (München, D)

Fluka (Neu-Ulm, D)

Roth (Karlsruhe, D)

Roth (Karlsruhe, D)

Geyer (Renningen, D)

Roth (Karlsruhe, D)

Biochrom (Berlin, D)

Roth (Karlsruhe, D)

BioRad (München, D)

BioRad (München, D)

Roth (Karlsruhe, D)

Roth (Karlsruhe, D)

Fluka (Neu-Ulm, D)

BioRad (München, D)

Thermo Scientific (Rockford, USA)

\subsubsection{Lösungen und Puffer}

Blockierlösung für den Western Blot: 5\% Magermilchpulver; 0,2\% Tween-20 in PBS

Entwicklungslösung 1: $250 \mathrm{mM}$ Luminol; $90 \mathrm{mM}$ p-Coumarsäure; 1,5 M Tris/HCl pH 8,$5 ; \mathrm{H}_{2} \mathrm{O}$

Entwicklungslösung 2: $30 \%$ ige $\mathrm{H}_{2} \mathrm{O}_{2} ; 1,5 \mathrm{M}$ Tris/ $\mathrm{HCl} \mathrm{pH} 8,5 ; \mathrm{H}_{2} \mathrm{O}$

Entwicklungslösung 1 und 2 werden kurz vor Gebrauch im Verhältnis 1:1 gemischt

Extraktionspuffer: 50 mM Tris $\mathrm{HCl}(\mathrm{pH}$ 7,5); $150 \mathrm{mM} \mathrm{NaCl} ; 2$ mM EDTA; $1 \%$ Triton X-100; vor Gebrauch wurden zu 10 ml des Extraktionspuffers 1/2 Tablette Protease Inhibitor Cocktail, sowie 1 Tablette Phosphatase Inhibitor Cocktail zugesetzt

Laufpuffer für die Gelelektrophorese: 144 g Glycin; 30 g Tris; 10 g SDS ad $1000 \mathrm{ml}$ Okano: 3 mM Tris pH 8; 2 mM NaCl; 0,05\% Triton X 100; 0,1 mM EDTA; 0,002\% SDS; $0,1 \%$ BSA

Transferpuffer für den Western Blot: 48 mM Tris Base; 39 mM Glycin; 1 mM SDS; $20 \%$ Methanol

Waschlösung (T- PBS): 9,55 g PBS ad $11 \mathrm{H}_{2} \mathrm{O} ; 10 \mathrm{ml} 10 \%$ Tween 


\subsubsection{Antikörper}

Tabelle 2: Primäre Antikörper

\begin{tabular}{lll}
\hline Antikörper & Verdünnung & Hersteller \\
\hline SAF32 & $1: 400$ & Spi-Bio, Massy, Frankreich \\
$17 B 4$ & $1: 100$ & Carsten Korth-Lab, Düsseldorf, \\
& & Deutschland \\
Anti-ß-Actin-Antikörper & $1: 20000$ & Abcam, Cambridge, UK
\end{tabular}

Tabelle 3 : Sekundäre Antikörper

\begin{tabular}{lll}
\hline Antikörper & Verdünnung & Hersteller \\
\hline Anti-Maus-IgG & $1: 10000$ & Jackson ImmunoResearch, Suffolk, UK \\
Anti-Rabbit-IgG & $1: 10000$ & Jackson ImmunoResearch, Suffolk, UK \\
Anti-Goat-IgG HRP & $1: 5000$ & Santa Cruz Biotechnology, Santa Cruz, \\
& & USA
\end{tabular}

\subsection{Versuchstiere}

Die Verhaltenstests wurden an männlichen Prnp ${ }^{0 / 0}$-Mäusen, sowie an männlichen Wildtyp-Mäusen durchgeführt. Die Prnp ${ }^{0 / 0}$-Mäuse waren Nachkommen der Zürich-IMauslinie (Büeler et al. 1992), wobei die Tiere ausschließlich homozygot für die entsprechende Gendeletion waren. Die Wildtyp-Mäuse dienten als Kontrollgruppe. Bei diesen handelte es sich um eine Kreuzung der $F_{1}$-Nachkommen von gepaarten Mäusen der Stämme C57BL/6J x 129/Sv(ev). Die Tiere stammten aus der Tierzucht der Universitätsmedizin Göttingen und wurden uns im Zuge einer Zusammenarbeit mit Herrn Dr. Walter Schultz-Schäffer zur Verfügung gestellt. Getestet wurden Tiere aus drei unterschiedlichen Altersgruppen. Zu Beginn der Experimente lag deren durchschnittliches Alter bei drei, neun und 20 Monaten. Die Tests erstreckten sich über einen Zeitraum von etwa vier Wochen. Für die einzelnen Verhaltenstests wurde eine Mindestanzahl von 12 Tieren pro Testgruppe festgelegt.

\subsection{Haltung der Tiere}

Nach Lieferung wurden die Tiere einzeln in Makrolonkäfige $(32 \mathrm{~cm}$ x $15 \mathrm{~cm}$ x $17 \mathrm{~cm}$, Länge x Höhe x Breite) gesetzt sowie unter standardisierten Bedingungen mit Zugang zu Futterpellets und Trinkwasser ad libitum gehalten. Ein Käfigwechsel mit frischem 
Streu, frischem Wasser und frischer Nahrung erfolgte wöchentlich. Die Käfige waren in ventilierten Kontainern (Scantainer) bei konstanter Temperatur $\left(21-22^{\circ} \mathrm{C}\right)$ und Luftfeuchtigkeit $(60 \pm 5 \%)$ untergebracht. Die Scantainer verfügten über einen gefilterten Zulufteinlass sowie über einen Abluftauslass, der direkt an den Abluftschacht gekoppelt war. Sie befanden sich in einem lichtgeschützten Raum, in dem ein künstlicher TagNacht-Rhythmus (12/12 h) aufrecht erhalten wurde, wobei der Tag jeweils um 8.00 Uhr begann. Die Verhaltenstests wurden stets während des Tagzyklus durchgeführt. Die Versuchsräume befanden sich im Tierstall des European-Neuroscience-Instituts in Göttingen und waren vom Haltungsraum der Tiere separiert. Auch die Dekapitierung und darauf folgende Gewebeentnahme fanden in getrennten Räumen statt, um Stressreaktionen der anderen Versuchstiere zu vermeiden.

\subsection{Methoden}

\subsubsection{Perfusion}

Für die Perfusion wurden die Mäuse intraperitoneal mit 0,5 $\mathrm{ml}$ Avertin narkotisiert, wobei darauf zu achten war, dass der Kreislauf der Tiere stabil blieb. Nach Öffnung des Brustkorbes erfolgte bei den Tieren die Freilegung des Herzens. Um das Blut auszuspülen, wurde das rechte Atrium mit einem kleinen Schnitt eröffnet, während über ein Infusionssystem 0,1 M PBS in den linken Ventrikel infundiert wurde. Anschließend wurde die Maus mit einer Schere dekapitiert. Dann erfolgte die vorsichtige Freilegung des Gehirns. Nach Entnahme wurden die Gehirne in der Medianlinie geteilt und die Gehirnregionen Cortex, Hippocampus, Cerebellum und Bulbus olfactorius präpariert. Anschließend wurden die separierten Gehirnteile in Stickstoff schock- und bei $-80^{\circ} \mathrm{C}$ tiefgefroren.

\subsubsection{Herstellung von Proteinextrakten aus Hirngewebe}

Zur weiteren biochemischen Analyse wurden aus den separierten Hirnarealen Hippocampus, Cortex, Cerebellum und Bulbus olfactorius Hirnhomogenate hergestellt. Dazu wurden die jeweiligen Hirnregionen auf Eis mit einer Rasierklinge zu feinen Gewebestücken zerkleinert und in die jeweilige Menge Extraktionspuffer überführt (Hippocampus: $200 \mu$ l, Cortex: $800 \mu$ l, Cerebellum: $800 \mu$ l, Bulbus olfactorius: $100 \mu 1)$. Die Gewebesuspensionen wurden sonifiziert, für 15 Minuten bei $4^{\circ} \mathrm{C}$ im Rotator inkubiert und anschließend für zehn Minuten zentrifugiert $\left(4^{\circ} \mathrm{C} ; 13000\right.$ x g), um die Proteine im 
Überstand anzureichern. Die Überstände wurden in neue Eppendorf-Cups gefüllt, die Pellets dagegen wurden verworfen.

\subsubsection{Vermessung von Proteinen}

Die Bestimmung der Proteinkonzentration erfolgte mit Hilfe des Protein-Tests der Firma BioRad, der auf der Proteinnachweis-Methode von Bradford basiert. Als Vergleichsstandard diente eine Verdünnungsreihe mit BSA. $20 \mu$ l einer 1:30 verdünnten Proteinprobe wurden mit $980 \mu$ l Bradfordreagenz vermischt und für zehn Minuten bei Raumtemperatur inkubiert. Als Leerwert diente eine Küvette mit $20 \mu$ l bidestilliertem Wasser und $980 \mu 1$ Bradfordreagenz. Die Absorption der Proben wurde bei $595 \mathrm{~nm}$ gegen den Leerwert gemessen. Die Referenzwerte der Standardreihe dienten zur Berechnung der Proteinkonzentrationen der Proben.

\subsubsection{SDS-Polyacrylamidgelelektrophorese (SDS-PAGE)}

Mit Hilfe der SDS-Polyacrylamidgelelektrophorese können Proteine ihrer Größe nach aufgetrennt werden. Jedes Protein durchläuft das Gel mit einer bestimmten Geschwindigkeit in Abhängikeit von seiner Größe und Ladung. Das den Gelen zugesetzte SDS bindet an die Proteine und denaturiert sie. Die sich bildenden Komplexe erhalten durch

die Sulfatgruppen eine gleichmäßig verteilte negative Ladung, so dass die Laufgeschwindigkeit der Proteine im Gel ausschließlich von ihrer relativen Molekülmasse und nicht von ihrer Ladung abhängt.

Zur Auftrennung der Proteine wurden 12\%ige oder 15\%ige Trenngele in eine GelApparatur gegossen, mit Wasser überschichtet und für eine Stunde bei Raumtemperatur auspolymerisiert. Im Anschluss daran wurde das Wasser abgenommen und das Sammelgel in die Apparatur gegossen, das für 30 Minuten auspolymerisierte. Um die Proben später auftragen zu können, wurde in das noch flüssige Sammelgel ein Gel-Kamm luftblasenfrei eingesetzt, der nach Fertigstellung des Gels wieder entfernt wurde. Die Gelkammern wurden zusammengesetzt und mit Laufpuffer aufgefüllt. Nachdem zu den Proteinlösungen jeweils 10 $\mu$ l Probenpuffer Roti® Load hinzugefügt wurden, wurden diese fünf Minuten bei $95^{\circ} \mathrm{C}$ erhitzt und anschließend fünf Sekunden zentrifugiert. Die Proben und ein Molekulargewichtsstandard wurden in die vorgeformten Taschen aufgetragen. Die Gelelektrophorese wurde für zwei Stunden bei 100-120 V durchgeführt. 


\begin{tabular}{|l|l|l|l|}
\cline { 2 - 4 } \multicolumn{1}{c|}{} & 2 Sammelgele & 2 Trenngele 12\% & $\begin{array}{l}\text { 4 Trenngele } \\
15 \%\end{array}$ \\
\hline $\mathrm{dH}_{2} \mathrm{O}$ & $2,6 \mathrm{ml}$ & $6,8 \mathrm{ml}$ & $11,6 \mathrm{ml}$ \\
$40 \%$ Acryl- & $0,84 \mathrm{ml}$ & $4,4 \mathrm{ml}$ & $15 \mathrm{ml}$ \\
amid/Bisacrylamidlösung (37,5:1) & & & \\
Tris/SDS-Puffer & $1,05 \mathrm{ml}$ & $3,7 \mathrm{ml}$ & $9 \mathrm{ml}$ \\
Tris/SDS-Puffer pH-Wert & 6,8 & 8,8 & 8,8 \\
APS 10\% & $45 \mu \mathrm{l}$ & $150 \mu \mathrm{l}$ & $180 \mu \mathrm{l}$ \\
TEMED & $5 \mu \mathrm{l}$ & $6 \mu \mathrm{l}$ & $30 \mu \mathrm{l}$ \\
\hline
\end{tabular}

Tabelle 4 : Zusammensetzung der Gele

\subsubsection{Elektrochemischer Proteintransfer auf eine PVDF-Membran (Western Blot)}

Um die elektrophoretisch aufgetrennten Proteine mittels Antikörpern detektieren zu können, mussten diese zuerst vom Gel auf eine Membran übertragen und fixiert werden. Dazu dienten eine Semi-Dry-Blotkammer und eine Polyvinylidendifluorid (PVDF)Membran, die auf die Größe des Gels zugeschnitten werden musste. Das Gel wurde zwischen den Glasplatten der Elektrophoreseapparatur herausgenommen, und das Sammelgel wurde abgetrennt. Damit die PVDF-Membran benetzt werden konnte, wurde sie für zwei Minuten in Methanol inkubiert und anschließend in Wasser und Transferpuffer überführt. Zusätzlich wurden zwei Filterpapiere in Transferpuffer eingelegt. Der Blot erfolgte für 60 Minuten bei einer konstanten Spannung von 12 V bei Raumtemperatur.

\subsubsection{Immunologische Detektion von Proteinen auf der PVDF-Membran}

Nachdem die Proteine auf der Membran fixiert waren, konnten sie mit spezifischen Antikörpern detektiert werden. Die freien Proteinbindungsstellen der Membran wurden durch Inkubation für 60 Minuten bei Raumtemperatur in Blockierlösung abgesättigt. Die Membran wurde über Nacht bei $4^{\circ} \mathrm{C}$ mit dem jeweiligen monoklonalen primären Antikörper in geeigneter Verdünnung in der Blockierlösung inkubiert. Zur Entfernung überschüssiger oder unspezifisch gebundener Antikörper wurde die Membran für 15 Minuten in der Blockierlösung sowie 2 x 10 Minuten in T-PBS gewaschen und für 60 Minuten bei Raumtemperatur mit einem Peroxidase-gekoppelten sekundären Antikörper inkubiert (Anti-Maus-IgG Verdünnung 1:8000 in Blockierlösung). Nach weiteren Waschschritten (1 x 15 min Blockierlösung, 1 x 10 min T-PBS, 1 x 5 min Okano, 3 x 5 min T-PBS) wurde die Membran für eine Minute in die Entwicklungslösung über- 
führt. Die Detektion der mit Antikörper gekoppelten Proteine erfolgte mit Hilfe des ECL-Systems (enhanced chemiluminescence). Die Chemilumineszenzsignale wurden durch Auflegen eines Röntgenfilms (Hyperfilm ECL, Amersham) mit variierenden Expositionszeiten detektiert.

\subsubsection{Deglykosylierung mit PNGaseF}

Um das PrP-Signal im Western Blot zu verifizieren, wurde eine Deglykosylierung des Prion-Proteins mit PNGaseF durchgeführt. Die PNGaseF spaltet die Glykosylketten, die durch N-Glykosylierung der Asparagine an den Positionen 181 und 197 gebunden sind, ab, so dass sich das Molekulargewicht des vormaligen Bandentripletts auf die Höhe der unglykosylierten Form verschiebt. Hierfür wurden $30 \mu 1$ Hirnhomogenat des Cortex mit $10 \mu 15$ x Reaktionspuffer und 2,5 $\mu$ l Denaturierungslösung versetzt und bei $95^{\circ} \mathrm{C}$ für fünf Minuten erhitzt. Der Suspension wurden im Anschluss $2 \mu 110$ x G7-Puffer, $2 \mu 1$ $10 \% \mathrm{NP} 40, \mathrm{H}_{2} \mathrm{O}$ und 2,5 $\mu \mathrm{l}$ PNGaseF zugesetzt. Nach einer Inkubationszeit von drei Stunden bei $37^{\circ} \mathrm{C}$ wurde die Probe kurz anzentrifugiert und im Western Blot untersucht.

\subsubsection{Membranen-Stripping}

Bereits im Western Blot verwendete Membranen können mit „Stripping“-Puffer behandelt und die Proteine im Anschluss mit einem weiteren Antikörper detektiert werden. Der „Stripping“-Puffer dient dazu, die zuvor eingesetzten Antikörper wieder von der Membran zu waschen.

Dazu wurden die Membranen nach der ECL-Entwicklung für zehn Minuten in T-PBS gewaschen und 15 Minuten in „Stripping“-Puffer (Restore ${ }^{\mathrm{TM}}$ Plus Western Blot Stripping Buffer, Thermo Scientific, Rockford USA) inkubiert. Danach wurde die Membran erneut zehn Minuten in T-PBS gewaschen und eine Stunde in Blockierlösung geschüttelt, um freie Bindungsstellen abzusättigen. Der immunchemische Nachweis der Proteine erfolgte dann nach der unter 2.4.6 beschriebenen Vorgehensweise. 


\subsection{Verhaltenstests}

Zur Charakterisierung der $\operatorname{PrP}^{\mathrm{c}}$-Knockout-Mäuse gegenüber Wildtyp-Mäusen kamen verschiedene etablierte Verhaltenstests zur Anwendung. Die durchgeführten Tests sollten helfen, den potentiellen Einfluss des $\operatorname{PrP}^{\mathrm{c}}$ auf das Verhalten zu ermitteln. Die folgenden Tests wurden ausnahmslos in den Versuchsräumen des European-NeuroscienceInstitute (ENI) Göttingen durchgeführt. Die entsprechenden Geräte wurden von der Firma TSE-System erworben.

\subsubsection{Elevated Plus Maze (EPM)}

Der Elevated-Plus-Maze-Test ist ein häufig eingesetzter Test, um generelle Angst bei Nagetieren zu messen. Die Messung des Angstverhaltens ergibt sich aus der natürlichen Aversion der Mäuse gegenüber ungeschützten, offenen, erhöhten Flächen, die in Konflikt steht mit ihrer Neugierde, unbekannte Areale zu erkunden. Der Versuchsaufbau bestand aus einem erhöhten, plusförmigen Gestell, das mittels eines Ständers in einer Höhe von $60 \mathrm{~cm}$ über dem Boden angebracht war, und auf dem sich die Mäuse frei bewegen konnten. Die vier Arme des EPM verfügten jeweils über die gleiche Länge und Breite $(60 \mathrm{~cm}$ x $10 \mathrm{~cm})$ und waren im Zentrum des Kreuzes über eine Plattform $(10 \mathrm{~cm}$ x $10 \mathrm{~cm}$ ) miteinander verbunden. Zwei sich gegenüber liegende Arme waren seitlich und am Ende mit undurchsichtigen, weißen Wänden (Höhe $15 \mathrm{~cm}$ ) eingefasst und stellten die ,geschlossenen Arme“ des EPM dar. Die beiden anderen sich gegenüber liegenden Arme waren an den Seiten und am Ende offen und ragten frei in den Raum hinein (,offene Arme“).

Zu Beginn jedes Versuches wurde das Versuchstier in das Zentrum des EPM mit Ausblick auf einen offenen und einen geschlossenen Arm gesetzt. Jedes Tier hatte fünf Minuten Zeit, die offenen und geschlossenen Teile des Labyrinthes zu erkunden. Die Aktivität der Tiere wurde durch eine an einen Computer angeschlossene Kamera beobachtet, die den Weg, den die Tiere zurücklegten, aufzeichnete. Dabei reflektiert die Zeit, in der sich die Tiere in den offenen bzw. geschlossenen Armen aufhalten, die generelle Angst. Als zusätzliche Parameter des Angstverhaltens wurden die Anzahl der Eintritte in die offenen und geschlossenen Arme sowie die Anzahl der Eintritte in das Zentrum ausgewertet. Der zurückgelegte Weg der Tiere im EPM gibt Aufschluss über deren Aktivität in der Testapparatur. 


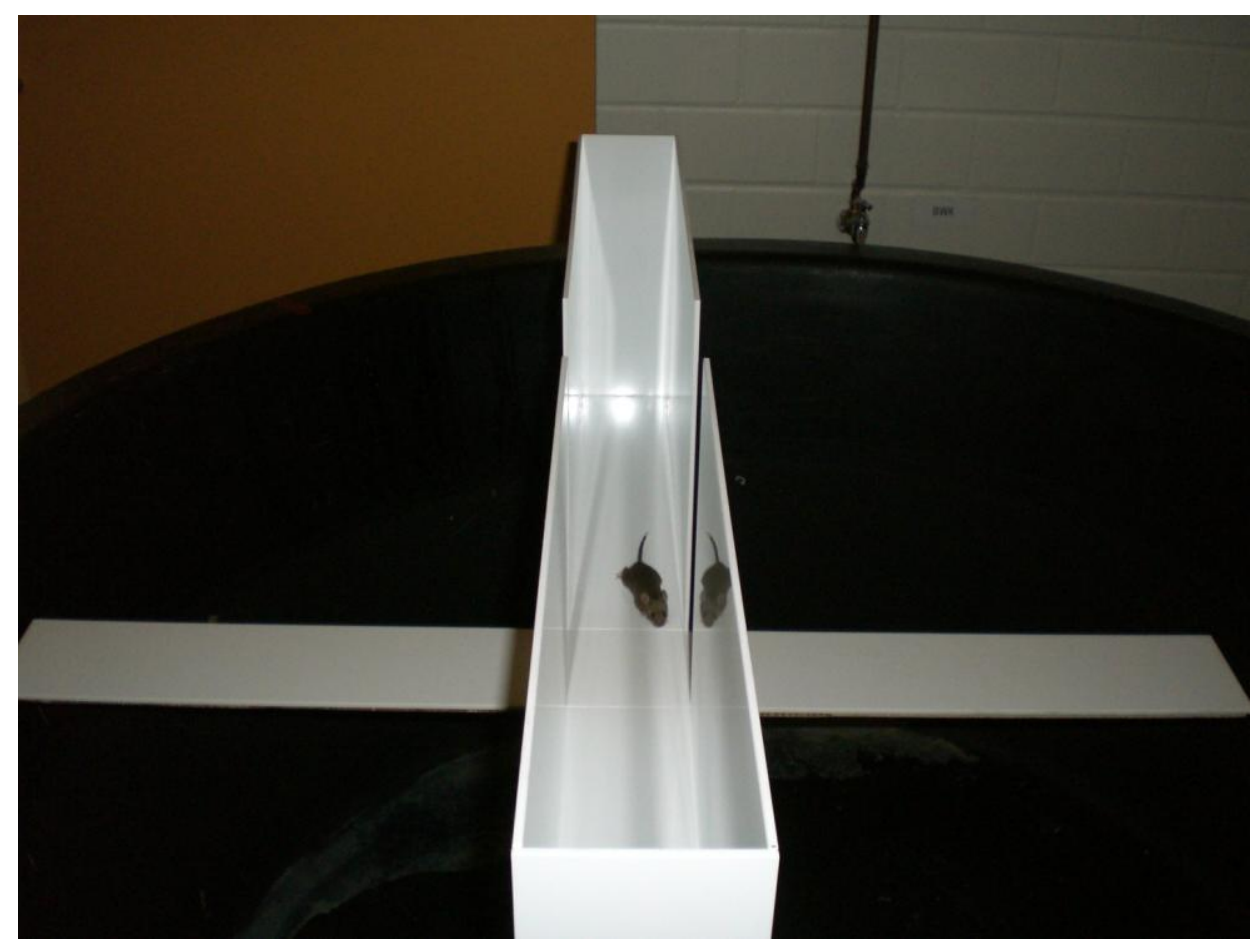

Abbildung 6: Elevated Plus Maze (EPM)

\subsubsection{Rotarod}

Dieser Test dient dazu, die motorischen Funktionen und die Ausdauer von Nagetieren zu messen. Der Versuchsaufbau bestand aus einem erhöhten, rotierenden Balken, der durch seitliche Trennwände in fünf Einzelkabinen aufgeteilt war. Die Rotationsgeschwindigkeit des Balkens konnte über ein Computersystem gesteuert und variiert werden. Um das Balancieren auf dem rotierenden Balken zu erlernen, wurden die Tiere an drei aufeinander folgenden Tagen zweimal täglich bei einer Rotationsgeschwindigkeit von 10 Upm trainiert. Für den Versuch wurden die Tiere für mehr als 180 Sekunden auf den rotierenden Balken gesetzt. Um nicht herunterzufallen, mussten sich die Tiere entgegen dessen Drehrichtung bewegen, was sie in der Trainingsphase erlernt hatten. Als Rotationsgeschwindigkeit wurde für unsere Versuchstiere ein Bereich von 5 bis $40 \mathrm{Upm}$ gewählt. Dies bedeutet, dass sich der Balken mit $5 \mathrm{Upm}$ zu drehen begann und nach 180 Sekunden eine Geschwindigkeit von 40 Upm erreichte. Danach rotierte der Balken weitere 60 Sekunden mit 40 Upm. Fiel eine Maus herunter, wurde dies von dem Computersystem registriert und die Zeit gestoppt. Mäuse, die sich in einem Durchgang mehr als 180 Sekunden auf dem rotierenden Balken hielten, ohne herunterzufallen, wurden wieder heruntergesetzt und mit der Maximalzeit von 180 Sekunden bewertet. Als Maß für 
die motorische Funktion diente dabei die Zeit, die sich die Maus auf dem rotierenden Balken halten konnte.

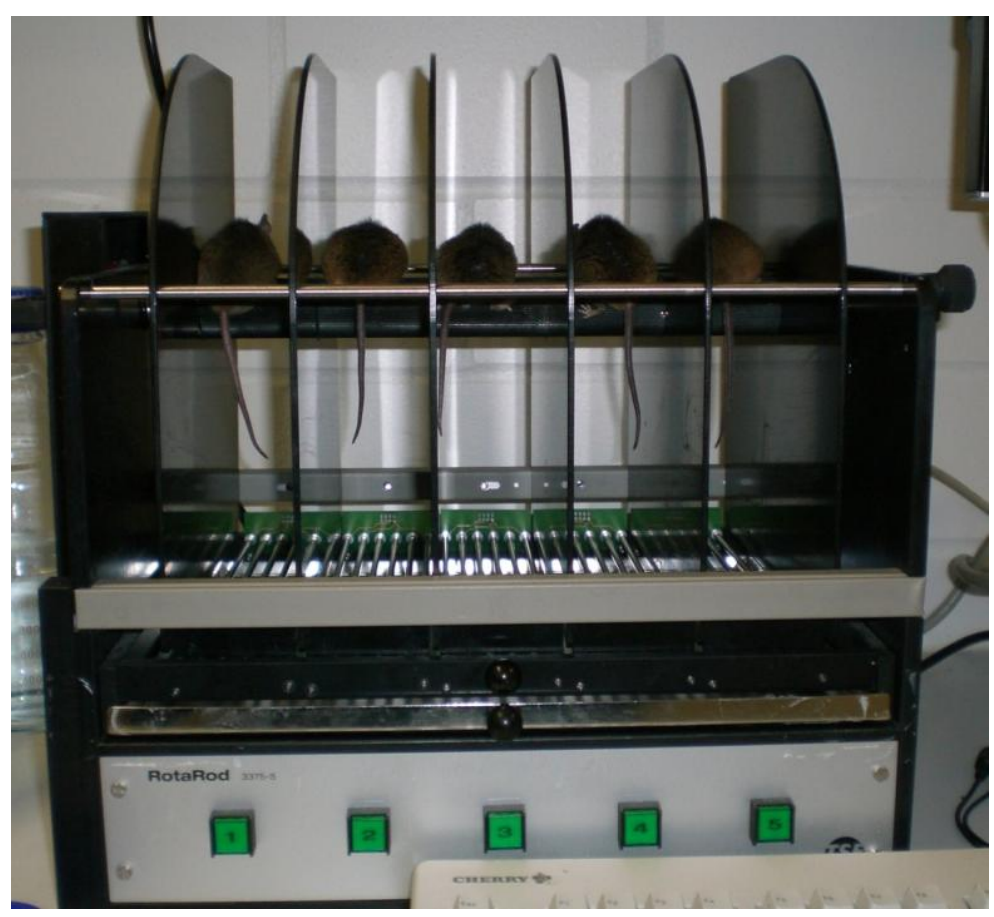

Abbildung 7: Rotarod

\subsubsection{Furchtkonditionierung}

Die Furchtkonditionierung ist ein etablierter Test, um assoziatives Lernen und Gedächtniskonsolidierung bei Nagetieren zu untersuchen.

Der Versuchsaufbau bestand aus einer Plexiglaskammer $(35 \mathrm{~cm}$ x $20 \mathrm{~cm}$ x $20 \mathrm{~cm}$, Länge x Höhe x Breite) mit einem Boden aus Stahlgitter. Über das Bodengitter konnte den Versuchstieren ein elektrischer Strom definierter Stärke $(0,7 \mathrm{~mA}$ Wechselstrom) und Dauer (2 s) verabreicht werden. Die Plexiglaskammer war in ein verschließbares Holzgehäuse eingebaut, an dessen Front ein Beobachtungsfenster angebracht war. In dem Gehäuse befanden sich zusätzlich eine Lampe (12 V) sowie ein Lautsprecher, der ein konstantes Hintergrundrauschen abgab. Die beschriebenen Versuchsbedingungen wurden mit Hilfe eines Computers und einer Kontrolleinheit bestimmt. Die Versuchsapparatur wurde nach jeder Maus mit 70\% Ethanol ausgewischt, um den Geruch der vorherigen Mäuse zu neutralisieren. 


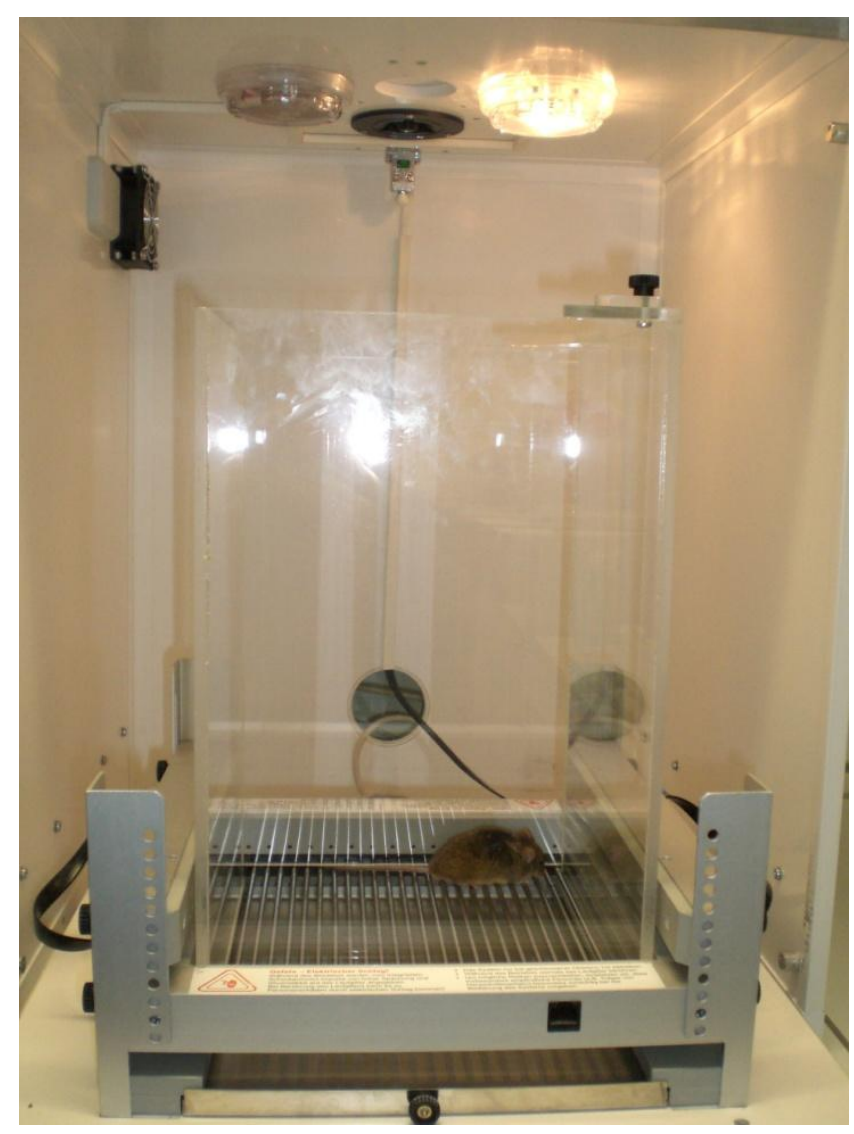

Abbildung 8: Furchtkonditionierung

\subsubsection{Kontextabhängige Furchtkonditionierung}

Bei der kontextabhängigen Furchtkonditionierung wurde das Versuchstier in eine neue Umgebung, die Versuchsbox (Kontext), gesetzt, die das Tier frei erkunden konnte. Nach 180 Sekunden erhielt das Tier über zwei Sekunden einen leichten, aber unangenehmen Stromstoß über das in der Box befindliche Bodengitter. Für den Gedächtnistest wurde die Maus 24 Stunden später wieder für 180 Sekunden in die Versuchsbox gesetzt, ohne dass dabei erneut ein Stromstoß erfolgte. Als Maß für die konditionierte Furcht diente eine Verhaltensweise, die als Erstarren („Freezing“) bezeichnet wird. Erstarren ist definiert als das Fehlen jeglicher Bewegung der Tiere außer Atmung und Herzschlag. Das Erstarren ist ein natürliches, angeborenes Verhalten bei Nagetieren, die Furcht haben. Die Furcht ist in diesem Fall die konditionierte Reaktion und kann daher als Maß für assoziatives Lernen und Gedächtniskonsolidierung verwendet werden. Dokumentiert wurde das Erstarren alle zehn Sekunden über eine Gesamtdauer von 180 Sekunden und als Prozentwert angegeben. 


\subsubsection{Tonabhängige Furchtkonditionierung}

Bei dieser Art der Furchtkonditionierung wurden die Tiere ebenfalls für 180 Sekunden in die Versuchsbox gesetzt. Anschließend wurden sie für 30 Sekunden einem Ton ausgesetzt, auf den für zwei Sekunden ein elektrischer Schock (0,7 mA, Wechselstrom) über das Bodengitter folgte. Zur Analyse des tonabhängigen, assoziativen Lernens wurden die Tiere 24 Stunden später in eine neue Versuchsbox aus Plexiglas $(35 \mathrm{~cm}$ x $20 \mathrm{~cm}$ x $20 \mathrm{~cm}$, Länge x Höhe x Breite) gesetzt, die sich von der vorigen durch das Fehlen des Bodengitters (stattdessen grauer PVC-Boden) und einer weniger hellen Lichtintensität unterschied. Außerdem wurde die Versuchsbox bei diesem Versuch nicht mit $70 \%$ Ethanol, sondern mit 1\% Essigsäure gereinigt. Bei der Durchführung des Versuches wurde den Tieren der bereits bekannte Ton aus der Trainingsbox über eine Dauer von 180 Sekunden verabreicht und das Erstarren wie bereits beschrieben gemessen.

\subsubsection{Objekterkennungstest}

Ein weiterer gängiger Test, der die Gedächtnisleistung von Nagetieren misst, ist der Objekterkennungtest. Dieser basiert auf dem natürlichen, angeborenen Verhalten von Nagetieren, einem neuen, unbekannten Objekt mehr Aufmerksamkeit zu schenken als einem bereits bekannten. Dies setzt voraus, dass die Tiere ein zuvor präsentiertes Objekt wiedererkennen.

Zur Durchführung des Experimentes wurden die Tiere an zwei aufeinander folgenden Tagen jeweils fünf Minuten an die neue Umgebung, das Open Field, gewöhnt. Das Open Field ist eine freie, nach oben offene und seitlich durch Plexiglaswände eingefasste Fläche $(80 \mathrm{~cm}$ x $80 \mathrm{~cm})$, auf der sich die Tiere frei bewegen konnten. Über ein computergesteuertes Videosystem, das über dem Open Field angebracht war, wurde der Weg der Mäuse aufgezeichnet. Nach 24 Stunden wurden die Tiere erneut für fünf Minuten in die Versuchsapparatur gesetzt, in der zusätzlich zwei gleiche Objekte (weiße Plastikboxen) angebracht waren, die die Mäuse erkunden sollten. Nach weiteren 24 Stunden wurden den Tieren wieder fünf Minuten die zwei gleichen Objekte präsentiert. Danach wurden sie für fünf Minuten zurück in ihren Käfig gesetzt. Anschließend wurde ihnen für weitere fünf Minuten eines der beiden bereits bekannten Objekte sowie ein neues, unbekanntes (grau-weißer Stein) präsentiert. Per Computer wurden die Zeit der jeweiligen Objekterkundungen und die Anzahl der Objektbesuche aufgezeichnet. 


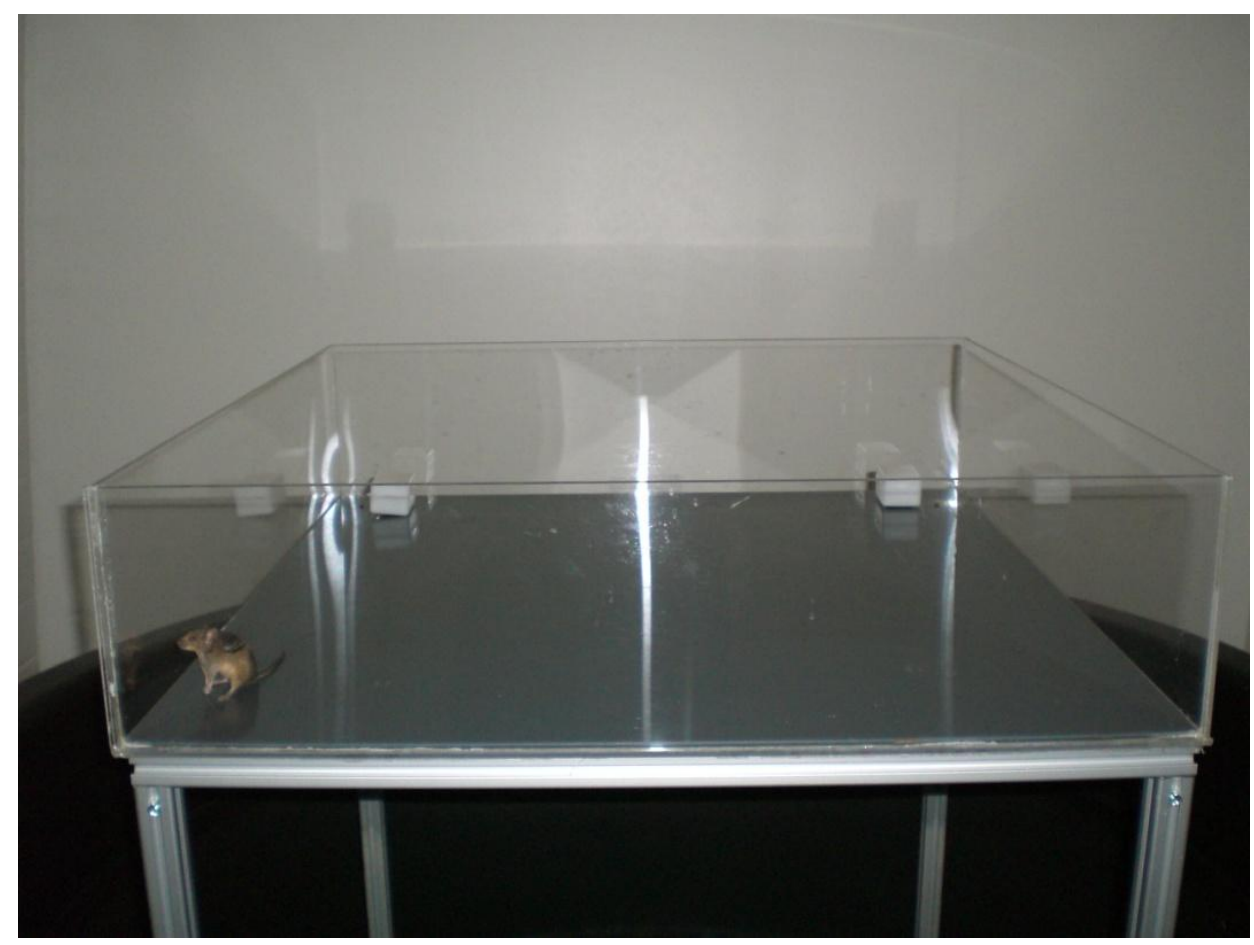

Abbildung 9: Objekterkennungstest

\subsubsection{Open Field}

Mit Hilfe des Open-Field-Tests kann das Verhalten von Nagetieren auf einer freien Fläche untersucht werden. Dieser Test gibt somit Aufschluss über die Aktivität, das Erkundungsverhalten sowie das Vermeidungsverhalten der Tiere. Die Neugier der Nagetiere, eine unbekannte Umgebung zu erkunden, steht hier in Konflikt mit dem natürlichen Vermeidungsverhalten gegenüber offenen, freien und ungeschützten Flächen.

Die Versuchsanordnung bestand aus einer quadratischen, freien Fläche $(80 \mathrm{~cm} \mathrm{x}$ $80 \mathrm{~cm}$ ), die von $20 \mathrm{~cm}$ hohen, durchsichtigen Plexiglaswänden umgeben war, so dass die Tiere nicht flüchten konnten. Das Open Field befand sich in einem separaten Raum mit konstanter Lichtintensität und frei von störenden Hintergrundgeräuschen. Über der Fläche war ein computergesteuertes Videosystem angebracht, das die Tiere jeweils für fünf Minuten aufzeichnete. Mit Hilfe des Computers wurde das Open Field in 16 gleich große Quadrate eingeteilt. Jede Maus wurde zu Beginn des Versuches genau in die Mitte gesetzt, von wo aus sie fünf Minuten Zeit hatte, die gesamte freie Fläche zu erkunden. Nach jeder Maus wurde die Versuchsapparatur mit 70\% Ethanol gereinigt, um deren Geruch zu neutralisieren. Gemessen wurden jeweils die Anzahl der Quadrantenüberschreitungen sowie die Zeit, die die Tiere im zentralen und im peripheren Teil des Open Fields verbracht haben. Als peripherer Teil wurden nur die vier äußeren Eckqua- 
drate gewertet, während die vier inneren Quadrate den zentralen Teil des Open Fields bildeten.

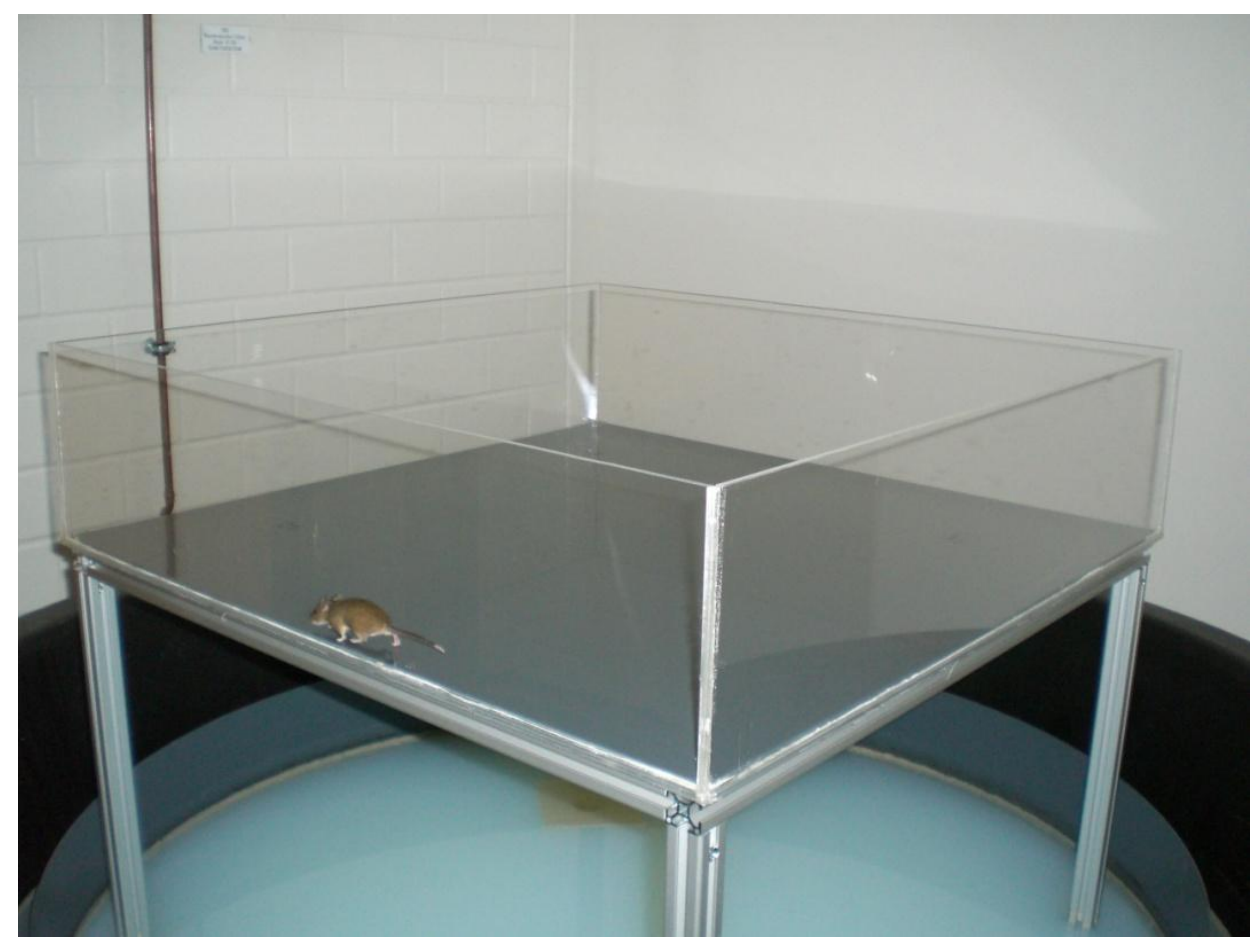

Abbildung 10: Open Field

\subsubsection{Minuten Open Field}

Der Versuchsaufbau dieses Tests ist nahezu identisch zum Open-Field-Test, jedoch mit dem Unterschied, dass die Tiere nacheinander für jeweils 90 Minuten in das Open Field gesetzt wurden. Mit Hilfe des Videosystems und des Computers wurde die Anzahl der Quadrantenüberschreitungen gemessen und aufgezeichnet. Dieser Test gibt Auskunft über hyperaktive Verhaltensweisen. Eine sich normal verhaltende Maus würde sich nach der Explorationsphase in eine Ecke des Feldes setzen und aufhören herumzulaufen. Eine hyperaktive Maus tut dies nicht. Sie legt eine lange Strecke zurück und macht kaum Ruhephasen.

\subsubsection{Morris Water Maze}

Das Morris Water Maze ist ein etablierter Test zur Untersuchung des räumlichen Lernens von Nagetieren.

Dabei wurden die Tiere an acht aufeinander folgenden Tagen in einen mit Wasser $\left(21^{\circ} \mathrm{C}\right)$ gefüllten Pool (Durchmesser $120 \mathrm{~cm}$ ) gesetzt, in dem eine für die Tiere nicht erkennbare Plattform $(13 \mathrm{~cm}$ x $13 \mathrm{~cm}$ ) einen $\mathrm{cm}$ unter der Wasseroberfläche angebracht 
war. Um die optische Erkennung der Plattform zu verhindern, wurde das Wasser mit ungiftiger Tiefengrundfarbe angefärbt und eingetrübt. Die Tiere wurden an jedem Trainingstag von jeder der vier Seiten des Pools aus einmal für je eine Minute ins Wasser gesetzt. In dieser Zeit sollten die Tiere die Plattform finden. Falls sie in der vorgegebenen Zeit nicht gefunden wurde, wurden die Mäuse für 15 Sekunden auf die Plattform gesetzt. Anhand von vier definierten Anhaltspunkten, die am Wasserbecken angebracht waren (roter Kreis, gelber Stern, grünes Quadrat, blaues Dreieck), lernten die Tiere mit der Zeit, sich zu orientieren und die Plattform zu lokalisieren. Eine an ein Computersystem angeschlossene Kamera detektierte dabei den Weg und die Latenzzeit, d.h. die Zeit, die die Tiere benötigten, um die Plattform zu finden. Für den Gedächtnistest am neunten Tag wurde die Plattform aus dem Pool entfernt. Die Tiere wurden für je eine Minute in den Pool gesetzt, und mit Hilfe der Kamera und des Computersystems wurde der jeweilige Aufenthalt der Tiere aufgezeichnet. Wie lange sich das Tier dabei in dem Quadranten aufhielt, in dem sich zuvor die Plattform befand, und wie oft das Tier die betreffende Stelle überquerte, gibt Aufschluss über das räumliche Lernen der Tiere.

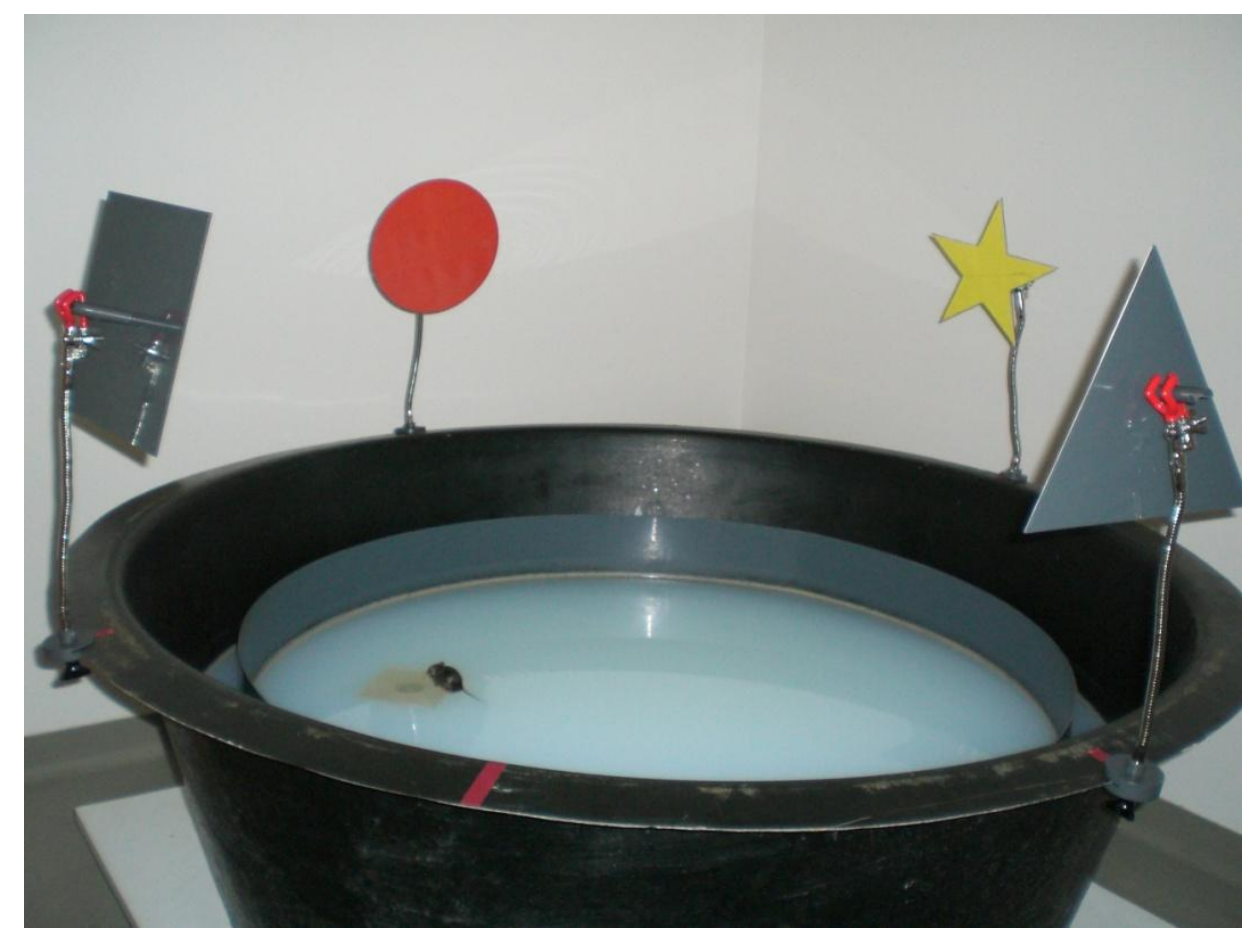

Abbildung 11: Morris Water Maze 


\subsubsection{Nestbauverhalten}

Um das Nestbauverhalten der beiden Mauslinien zu beurteilen, wurden die Tiere einzeln in einen neuen Käfig mit frischem Streu und einem frischen Zellstofftuch gesetzt. Jedes Tuch hatte eine feste Größe von $12 \mathrm{~cm}$ x $36 \mathrm{~cm}$ und sollte den Tieren als Nestbaumaterial dienen. In den Käfigen durften sich außer dem Zellstofftuch keine weiteren, für den Nestbau potentiell geeigneten Gegenstände wie z.B. Papierrollen oder ähnliches befinden. Nach 24 Stunden wurde das Nest der Tiere nach dem folgenden Fünf-PunkteSchema (Deacon 2006) bewertet:

a) Nestmaterial nicht erkennbar berührt (> 90\% intakt), (1 Punkt).

b) Nestmaterial teilweise zerrissen (50-90\% intakt), (2 Punkte).

c) Nestmaterial größtenteils zerrissen, aber kein eindeutiger Nestplatz: Weniger als $50 \%$ des Nestmaterials ist intakt, aber weniger als $90 \%$ befindet sich innerhalb eines Käfigviertels. Das bedeutet, dass das Nestmaterial nicht zu einem Nest geformt ist, sondern im Käfig verteilt liegt. Zu beachten ist, dass zwar das Material manchmal in einem abgegrenzten Nestgebiet liegt, die Definition aber besagt, dass 50-90\% des Materials zerrissen sein muss (3 Punkte).

d) Ein erkennbares, aber flaches Nest: $90 \%$ des Nestmaterials ist zerrissen, das Material ist innerhalb eines Käfigviertels zu einem Nest geformt, aber das Nest ist flach.

Die Wandhöhe des Nests beträgt weniger als 50\% der Körperhöhe der Maus (4 Punkte).

e) Ein (fast) perfektes Nest: Mehr als 90\% des Materials ist zerrissen, das Nest hat eine Mulde. Die Wandhöhe des Nests beträgt mehr als 50\% der Körperhöhe der Maus (5 Punkte).

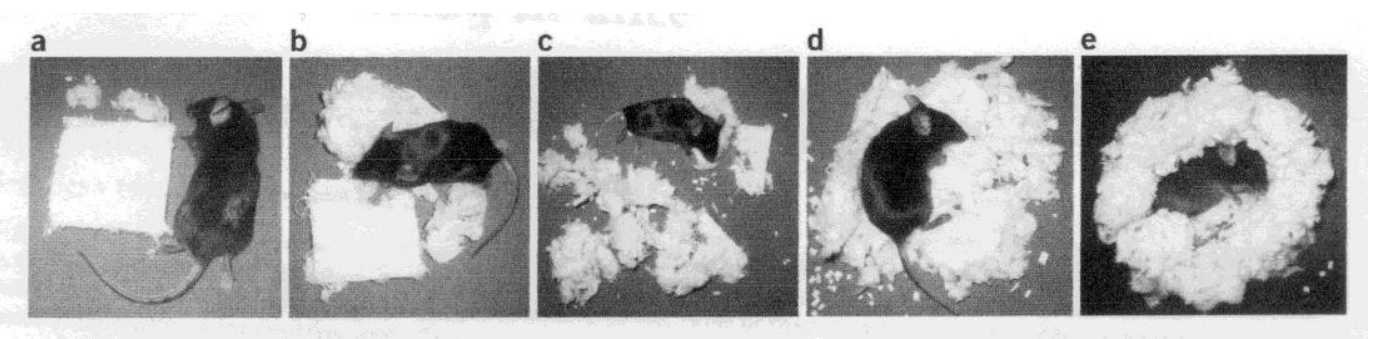

Abbildung 12: Fünf-Punkte-Skala des Nestbauverhaltens (Deacon 2006, S. 1119) 


\subsection{Statistische Analyse}

Die statistische Analyse der Daten erfolgte mit dem Student's t-Test des Statistikprogramms GraphPad Prism 4 für alle normalverteilten Werte und dem Wilcoxon-MannWhitney-Test des Statistikprogramms Statistica 9. Als signifikant wurden Daten gewertet, für die man einen $\mathrm{p}$-Wert $<0,05$ erhielt. Alle Ergebnisse sind als Mittelwert \pm Standardfehler angegeben. Die Signifikanzniveaus wurden bei den einzelnen Experimenten entsprechend dargestellt $(\mathrm{p}<0,001: * * * ; \mathrm{p}<0,01: * * ; \mathrm{p}<0,05: *)$. 


\title{
3 Ergebnisse
}

\subsection{Phänotyp}

Die Prnp ${ }^{0 / 0-}$ Mäuse und die Wildtyp-Mäuse jeder Altersgruppe zeigten keine signifikanten Unterschiede in Bezug auf den Körperbau, die Körperlänge oder das Körpergewicht.

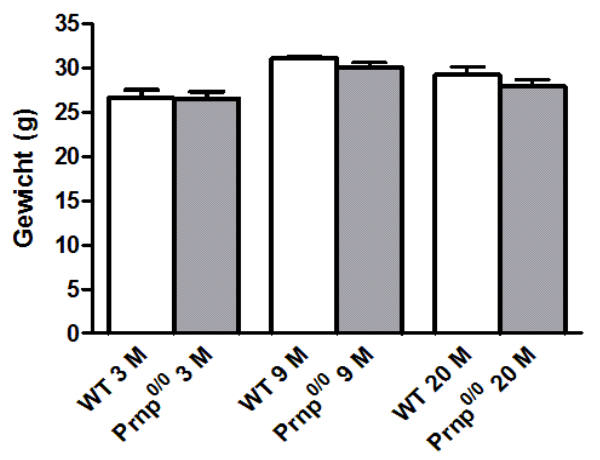

\begin{abstract}
Abbildung 13: Vergleich des Körpergewichts der Prnp ${ }^{0 / 0}$-Mäuse und der WT-Mäuse. $\mathrm{Zu}$ sehen sind die Körpergewichte der Prnp ${ }^{0 / 0}$-Mäuse und der Wildtyp-Mäuse (WT) der drei Altersgruppen 3 Monate, 9 Monate und 20 Monate. Die Wildtyp-Mäuse dienten als Kontrollgruppe und wurden in jeder Altersgruppe mit den Prnp ${ }^{0 / 0}$-Mäusen verglichen. Zusätzlich wurden die Prnp ${ }^{0 / 0}$-Mäuse und die WT-Mäuse der verschiedenen Altersgruppen untereinander verglichen. Die Daten sind als Mittelwerte \pm SEM angegeben. Vergleiche der Gruppen wurden mit dem t-Test für unverbundene Stichproben berechnet. In keiner der drei Altersgruppen konnte ein signifikanter Unterschied im Körpergewicht nachgewiesen werden.
\end{abstract}

Auffällig am äußeren Erscheinungsbild war jedoch das Haarverteilungsmuster der Mäuse. Die Prnp ${ }^{0 / 0}$-Mäuse im Alter von neun und 20 Monaten wiesen einen Haarverlust an Kopf und Rücken auf, der bei den Wildtyp-Mäusen nicht zu sehen war. Lediglich bis zum Alter von drei Monaten konnten keine Unterschiede im äußeren Erscheinungsbild festgestellt werden (Abb. 14). 
A

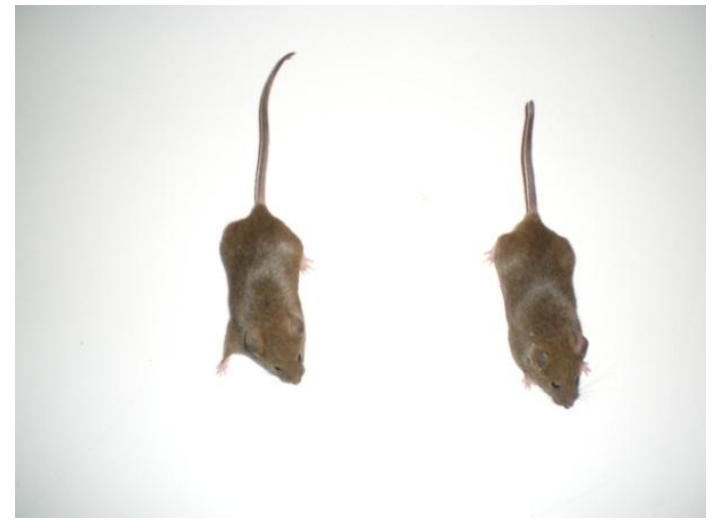

B

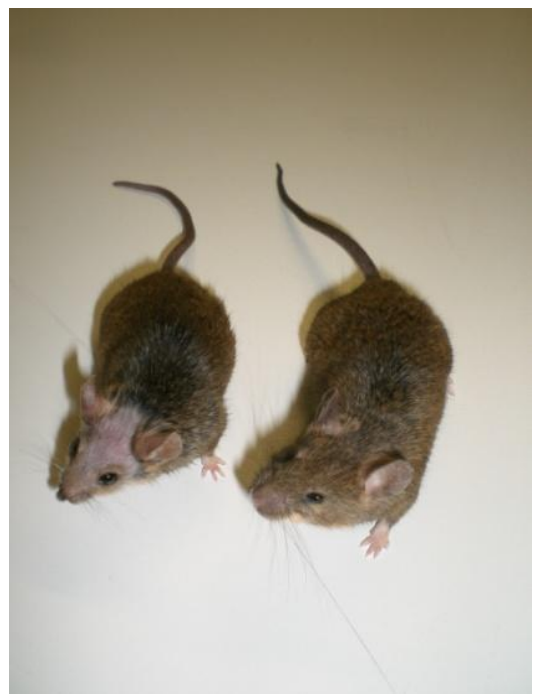

Abbildung 14: Vergleich von Prnp ${ }^{0 / 0}$-Maus und Wildtyp-Maus (WT) im Alter von drei und 20 Monaten.

(A) Drei Monate alte Tiere: links WT-, rechts Prnp ${ }^{0 / 0}$-Maus. In dieser Altersgruppe ist kein Unterschied im äußeren Erscheinungsbild festzustellen.

(B) 20 Monate alte Tiere: links Prnp ${ }^{0 / 0}$-Maus, rechts WT. Auffällig ist der Haarverlust der Prnp ${ }^{0 / 0}$-Maus an Kopf und Nacken.

\subsection{Darstellung von verschiedenen $\operatorname{PrP}^{\mathrm{c}}$-Isoformen in den Gehirnen von WT-Mäusen}

Um zu zeigen, dass die Knockout-Mäuse kein Prion-Protein exprimieren, wurden die Gehirne der Tiere entnommen. Aus den separierten Teilen Hippocampus, Cortex, Cerebellum und Bulbus olfactorius wurden Hirnhomogenate hergestellt, die anschließend im Western Blot auf das Vorhandensein von $\mathrm{PrP}^{\mathrm{c}}$ geprüft wurden. Sowohl die vier genannten Hirnregionen der Prnp ${ }^{0 / 0}$-Mäuse als auch der Wildtyp-Mäuse wurden untersucht, wozu der monoklonale Anti-Prion-Protein Antikörper SAF32 verwendet wurde (Verdünnung 1:400). Die Hirnproben der Wildtyp-Mäuse zeigten Banden mit einem korrespondierenden Molekulargewicht von $27 \mathrm{kDa}$ bis $35 \mathrm{kDa}$, während in den Hirnproben der Prnp ${ }^{0 / 0}$-Mäuse in diesem Bereich keine Banden zu sehen waren (Abb. 15A). Daraus folgt, dass die $\operatorname{Prnp}^{0 / 0}$-Mäuse kein $\operatorname{PrP}^{\mathrm{c}}$ exprimieren. In einem weiteren Western Blot sollte der Nachweis von $\operatorname{PrP}^{\mathrm{c}}$ durch Deglykosylierung der Glykoformen des $\operatorname{PrP}^{\mathrm{c}}$ erbracht werden. Hierzu wurde das Homogenat des Cortex einer Wildtyp-Maus aufgetragen und untersucht. Im Hirnhomogenat liegt $\mathrm{PrP}^{\mathrm{c}}$ als di-, mono- oder unglykosylierte Form vor. Nach der Deglykosylierung ließ sich eine deutliche Zunahme der Bandenintensität der unglykosylierten Form $(27 \mathrm{kDa})$ im Vergleich zur unbehandelten Probe beobachten (Abb. 16A). 
Mit Hilfe des 17B4-Antikörpers (Verdünnung 1:100), der lediglich die beiden $\operatorname{PrP}^{\mathrm{c}}$ Isoformen erkennt, die nicht an Asparagin (Asp) 197 glykosyliert sind, konnte gezeigt werden, dass die Mäusegehirne im Gegensatz zu humanem Liquor (Schmitz et al. 2010) Asp 181 monoglykosyliertes $\operatorname{PrP}^{c}$ exprimieren (Abb. 16B). Dieser Western Blot zeigte zusätzlich ein verstärktes Bandenmuster für $\operatorname{PrP}^{\mathrm{c}}$ im Bereich des Hippocampus im Vergleich zu den drei anderen Hirnbereichen. Dies lässt eine Rolle des $\operatorname{PrP}^{c}$ in kognitiven Funktionen und im Lernverhalten vermuten.

A

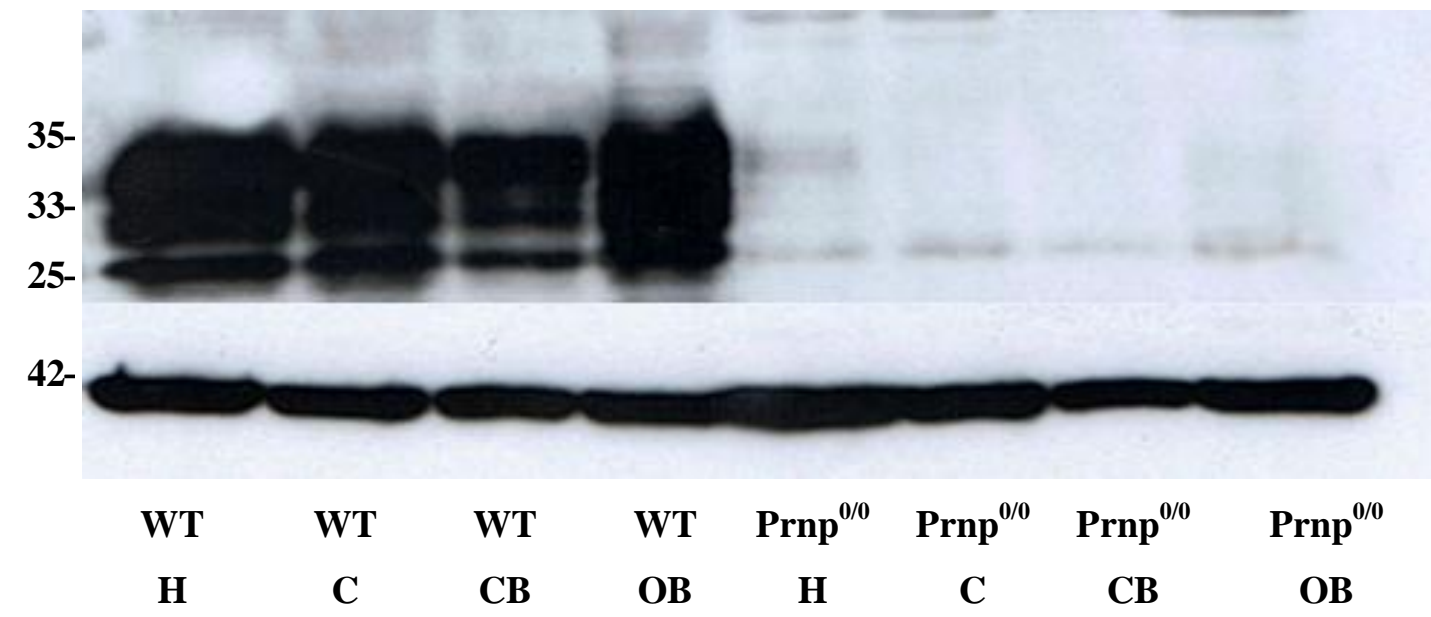

Abbildung 15: Fehlende Expression von $\operatorname{PrP}^{\mathrm{c}}$ bei den $\operatorname{Prnp}^{\mathbf{0} /}$-Mäusen.

(A) Die Hirnhomogenate des Hippocampus (H), Cortex (C), Cerebellums (CB) und Bulbus olfactorius (OB) wurden mittels 12\% SDS-PAGE getrennt und mit dem Anti-Prion-Protein Antikörper SAF32 detektiert. Bei den Wildtyp-Mäusen (WT) konnte $\operatorname{PrP}^{\mathrm{c}}$ in allen vier Hirnbereichen nachgewiesen werden, während bei den Prnp ${ }^{0 / 0}$-Mäusen keine Banden zu erkennen waren. (B) Um zu zeigen, dass vergleichbare Proteinmengen aufgetragen wurden, wurde die Membran gestrippt und mit dem anti- $\beta$-Actin-Antikörper behandelt. 
A

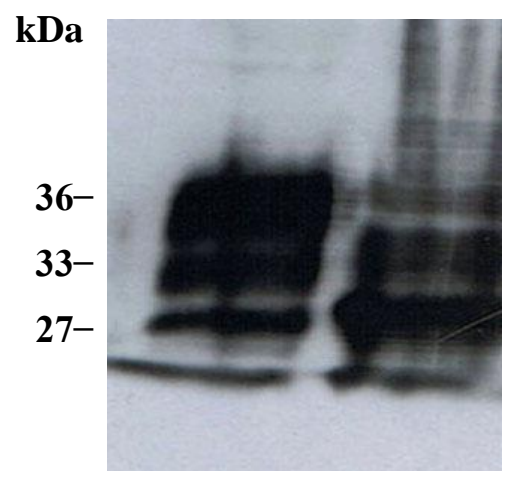

B

kDa

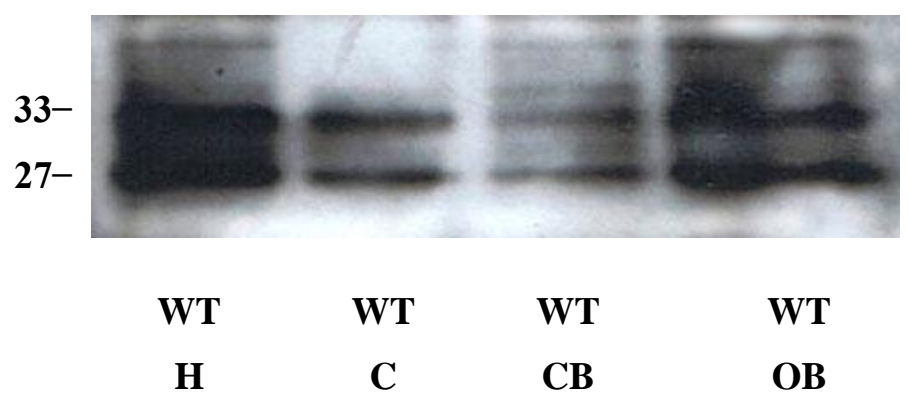

Abbildung 16: Deglykosylierung des $\operatorname{PrP}^{\mathrm{c}}$ mit PNGaseF.

(A) Hirnhomogenat vom Cortex einer Wildtyp-Maus (WT) wurde mit PNGaseF deglykosyliert. Die linke Bande zeigt das glykosylierte PrP in di-, mono- und unglykosylierter Form, die rechte zeigt nach der Behandlung mit PNGaseF eine Zunahme der unglykosylierten Form bei $27 \mathrm{kDa}$.

(B) Die Hirnregionen Hippocampus (H), Cortex (C), Cerebellum (CB) und Bulbus olfactorius (OB) einer Wildtyp-Maus wurden durch 12\% SDS-PAGE getrennt und mit Hilfe des 17B4 Antikörpers analysiert. Dargestellt sind die monoglykosylierte Form des PrP bei 33 kDa sowie die unglykosylierte Form bei $27 \mathrm{kDa}$. Auffällig ist auch die verstärkte Bandenzeichnung des $\operatorname{PrP}^{\mathrm{c}}$ im Bereich des Hippocampus.

\subsection{Verändertes Nestbauverhalten bei Prnp ${ }^{0 / 0}$-Mäusen}

Eine weitere Auffälligkeit war das Verhalten der Tiere beim Nestbau. Als Nestmaterial erhielt jede Maus ein Zellstofftuch. Die Bewertung der Nester erfolgte jeweils nach 24 Stunden mit Hilfe einer Fünf-Punkte-Skala (Deacon 2006). Die Wildtyp-Mäuse jeder Altersklasse verarbeiteten über $90 \%$ des Nestmaterials und formten dieses in der Käfigecke zu einem runden Nest, so dass außerhalb dieser kein verstreut liegendes Nestmaterial zu finden war. Die Nester unterschieden sich lediglich in Höhe und Durchmesser, so dass jeweils ein Punktwert von vier oder fünf vergeben werden konnte. Im Vergleich zu den Wildtypen ließ sich bei den Prnp ${ }^{0 / 0}$-Mäusen kein bzw. ein nur sehr gering ausgeprägtes Nestbauverhalten beobachten. Nach 24 Stunden hatten die meisten Prnp ${ }^{0 / 0}$ Mäuse jeder Altersklasse das Nestmaterial nicht verarbeitet, sondern es in seinem ursprünglichen Zustand belassen. Nur wenige Prnp ${ }^{0 / 0}$-Mäuse hatten das Tuch zerrissen, jedoch meist nur zu einem kleinen Teil. $50 \%$ bis $90 \%$ des Nestmaterials blieben intakt, was jeweils nur mit einem Punktwert von eins oder zwei bewertet werden konnte. Darüber hinaus fiel auf, dass die Wildtypen ihre Nester nicht beschmutzten, wohingegen die Prnp ${ }^{0 / 0}$-Mäuse das Zellstofftuch nach wenigen Tagen einnässten und einkoteten (Abb. 17). 
A

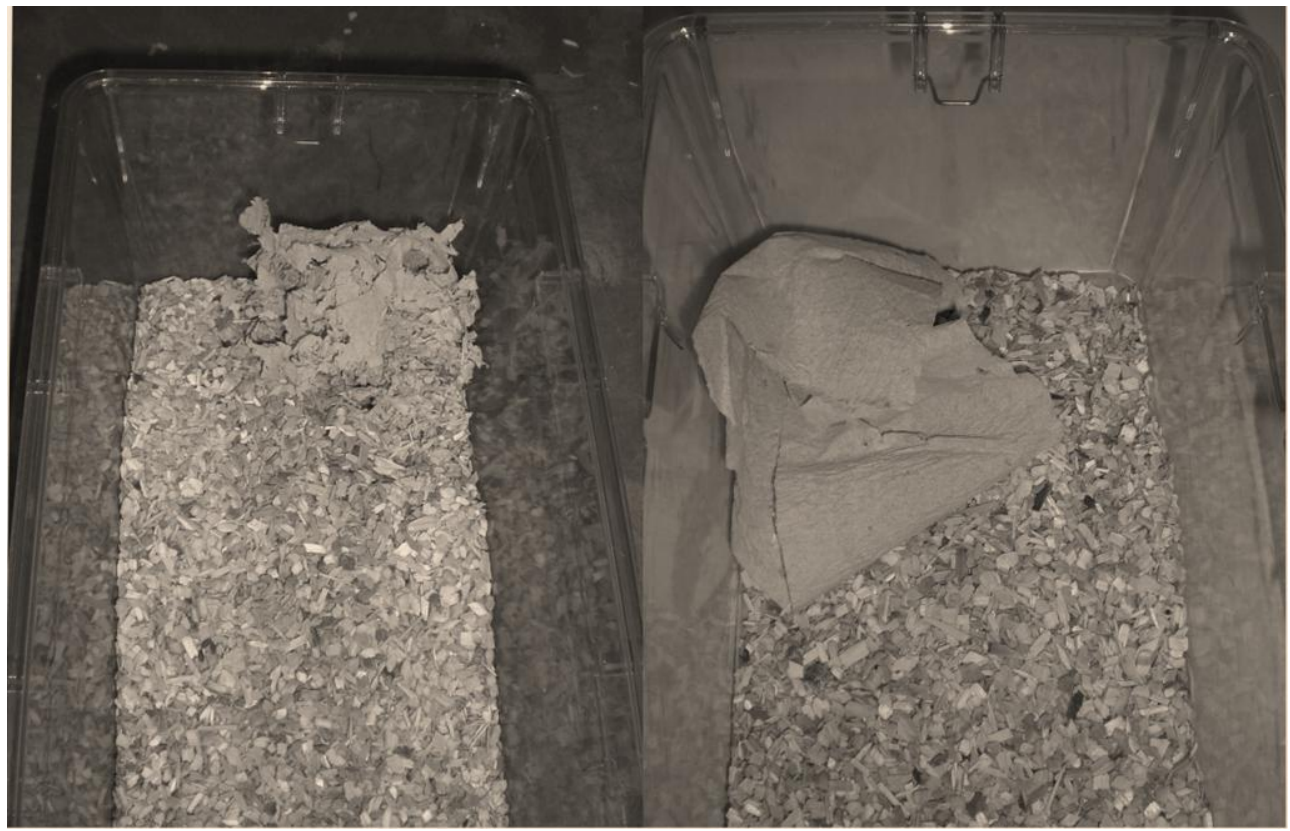

B

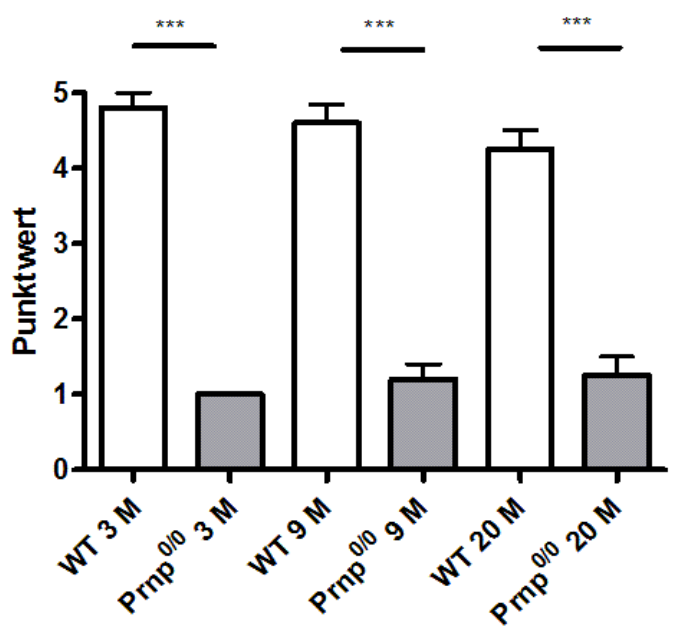

Abbildung 17: Nestbauverhalten von WT- und Prnp ${ }^{0 / 0}$-Mäusen.

(A) Links ist das Nest einer Wildtyp-Maus (WT) zu sehen. Das Zellstofftuch ist zu über 90\% zerkleinert und in einer Käfigecke zu einem dichten Nest geformt. Im restlichen Käfig befindet sich kein weiteres Nestmaterial. Rechts ist das Nest einer Prnp ${ }^{0 / 0}$-Maus zu sehen. Das Zellstofftuch ist nach 24 Stunden nahezu unberührt.

(B) Die Nester der Tiere wurden nach einer Fünf-Punkte-Skala bewertet. Die Prnp ${ }^{0 / 0}$-Mäuse zeigten in jeder Altersklasse ein signifikant geringer ausgeprägtes Nestbauverhalten als die WT. Die Daten wurden mit dem Wilcoxon-Mann-Whitney-Test berechnet.

\subsection{Abnahme des Angstverhaltens und erhöhte Latenzzeit bei Prnp ${ }^{0 / 0}$ - Mäusen im fünf Minuten Open-Field-Test}

Der Open-Field-Test gibt Aufschluss über die Aktivität sowie über das Angst- und Erkundungsverhalten der Tiere. Als Messwerte dienten die Überschreitungen der Quadranten, die Latenzzeit bis zum ersten Linienübertritt und die Zeit, die die Tiere im pe- 
ripheren oder zentralen Teil des Open Fields verbrachten. Da die Tiere Schutz am Rand des Feldes suchen und in der Regel offene, freie Flächen meiden, spiegelt der Aufenthalt im peripheren Teil des Feldes ein höheres Angstverhalten wieder, während der randferne, zentrale Aufenthalt mit einem geringeren Angstverhalten verbunden ist. Die Latenzzeit bis zum ersten Überschreiten einer Linie gibt Aufschluss über das Explorationsverhalten und über das Verhalten der Tiere im Umgang mit einer neuen Umgebung.

Im Erkundungsverhalten der Tiere konnten innerhalb der drei Altersgruppen keine Unterschiede zwischen den Wildtyp-Mäusen und den Prnp ${ }^{0 / 0}$-Mäusen festgestellt werden. Beide Mauslinien zeigten innerhalb der gleichen Altersgruppe eine annähernd identische Anzahl von Linienüberschreitungen. Auch innerhalb der Gruppe der Prnp ${ }^{0 / 0}$-Mäuse konnte im Altersvergleich keine signifikante Abnahme der Aktivität zwischen den drei und 20 Monate alten Prnp ${ }^{0 / 0}$ Mäusen festgestellt werden. Eine Zunahme der Aktivität zeigten die Prnp ${ }^{0 / 0}$-Mäuse im Alter von neun Monaten, diese war jedoch nicht signifikant. Im Vergleich dazu konnte bei den Wildtyp-Mäusen eine signifikante Abnahme der Aktivität innerhalb der Altersspanne von drei Monaten und 20 Monaten beobachtet werden ( $<<0,05 ; \mathrm{t}$-Test). Die höchste Aktivität zeigten die Wildtyp-Mäuse im Alter von drei Monaten (Abb. 18).

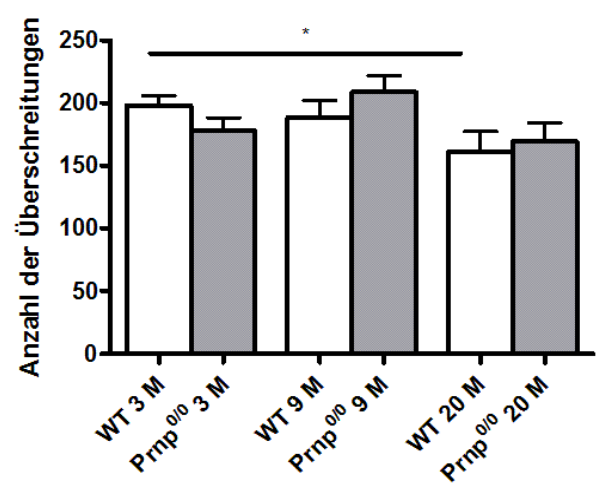

\begin{abstract}
Abbildung 18: Anzahl der Linienüberschreitungen im Open-Field-Test.
Die Wildtyp-Mäuse (WT) dienten als Kontrollgruppe und wurden in jeder Altersgruppe mit den Prnp ${ }^{0 / 0}$-Mäusen verglichen. Zusätzlich erfolgte ein Vergleich von Prnp ${ }^{0 / 0}$ - und WT-Mäusen verschiedener Altersgruppen untereinander. Die Daten wurden als Mittelwerte \pm SEM angegeben. Vergleiche der Gruppen wurden mit dem t-Test für unverbundene Stichproben berechnet. $* \mathrm{p}<0,05 ; * * \mathrm{p}<0,01 ; * * * \mathrm{p}<0,001$.
\end{abstract}

Die Latenzzeit der Prnp ${ }^{0 / 0}$-Mäuse bis zum ersten Überschreiten einer Linie war in jeder Altersgruppe signifikant höher als in der jeweiligen Kontrollgruppe ( $p<0,001 ; \mathrm{t}$-Test). Weder bei den Prnp ${ }^{0 / 0}$ - noch bei den Wildtyp-Mäusen kam es im Lebensalter zwischen drei und 20 Monaten zu einer merklichen Veränderung in der Latenzzeit (Abb. 19). 


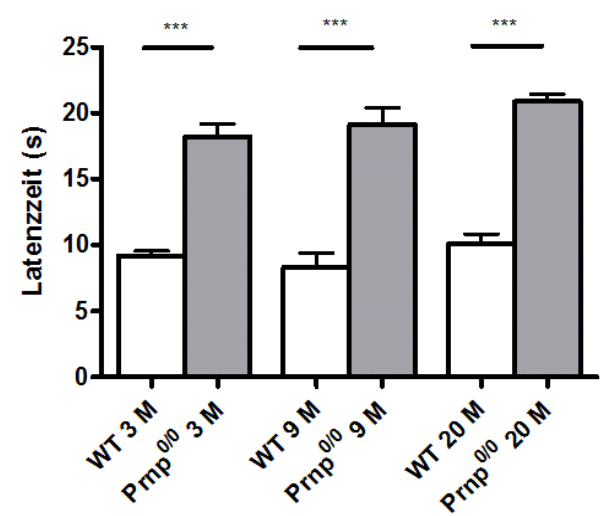

\begin{abstract}
Abbildung 19: Latenzzeit im Open-Field-Test.
Die Wildtyp-Mäuse (WT) dienten als Kontrollgruppe und wurden in jeder Altersgruppe mit den Prnp ${ }^{0 / 0}$-Mäusen verglichen. Zusätzlich erfolgte ein Vergleich von Prnp ${ }^{0 / 0}$ - und WT-Mäusen verschiedener Altersgruppen untereinander. Die Daten wurden als Mittelwerte \pm SEM angegeben. Vergleiche der Gruppen wurden mit dem t-Test für unverbundene Stichproben berechnet. $* \mathrm{p}<0,05 ; * * \mathrm{p}<0,01 ; * * * \mathrm{p}<0,001$.
\end{abstract}

Die Analyse des Angstverhaltens im Open-Field-Test offenbarte deutliche Unterschiede zwischen den Prnp ${ }^{0 / 0}$-Mäusen und ihrer Kontrollgruppe. Aber auch innerhalb der beiden Mauslinien zeigten sich altersabhängige Differenzen. Die Prnp ${ }^{0 / 0}$-Mäuse wiesen in jeder Altersgruppe eine höhere Verweildauer im zentralen Bereich des Open Fields auf, was auf ein niedrigeres Angstverhalten der Prnp ${ }^{0 / 0}$-Mäuse hindeutet. Dieser Unterschied war jedoch erst bei den 20 Monate alten Tieren signifikant ( $\mathrm{p}<0.05$; $\mathrm{t}$-Test). Während des Alterungsprozesses kam es auch bei den Wildtyp-Mäusen zwischen drei und neun Monaten zu einer signifikanten Zunahme der Aufenthaltsdauer im zentralen Teil des Feldes ( $\mathrm{p}<0,01$; $\mathrm{t}-$ Test $)$, verbunden mit einer Abnahme des Angstverhaltens in dieser Lebensphase. Im Alter zwischen neun und 20 Monaten nahm die Aufenthaltsdauer im Zentrum wieder deutlich $\mathrm{ab}(\mathrm{p}<0,01 ; \mathrm{t}-$ Test $)$ und entsprach etwa dem Niveau der drei Monate alten Tiere.

Das Angstverhalten der Prnp ${ }^{0 / 0}$-Mäuse nahm mit zunehmendem Alter deutlich ab, was sich in einer signifikant höheren zentralen Aufenthaltsdauer der 20 Monate alten $\operatorname{Prnp}^{0 / 0}$-Mäuse im Vergleich zu den drei Monate alten zeigte $(\mathrm{p}<0,01 ; \mathrm{t}$-Test). Die höchste Abnahme im Angstverhalten der Prnp ${ }^{0 / 0}$-Mäuse war im Alter zwischen drei und neun Monaten zu beobachten, während danach die Aufenthaltsdauer im Zentrum ungefähr auf dem gleichen Niveau blieb (Abb. 20). 


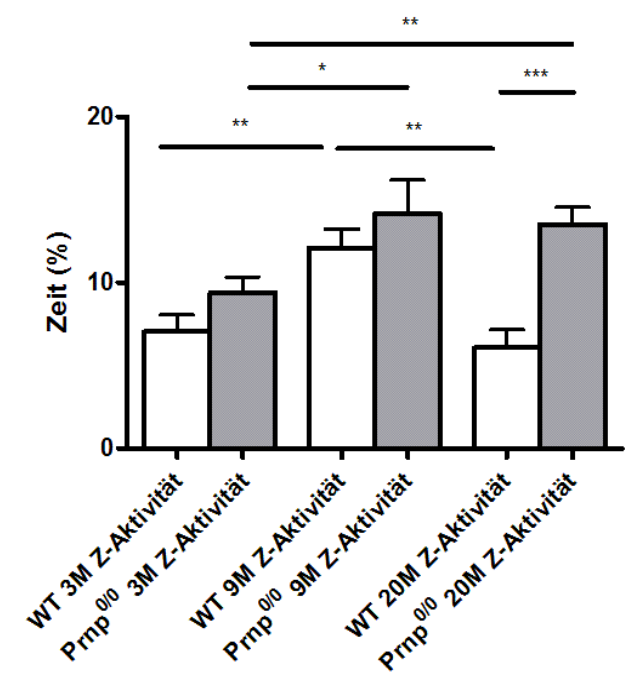

Abbildung 20: Aufenthalt im Zentrum im Open-Field-Test.

Die Wildtyp-Mäuse (WT) dienten als Kontrollgruppe und wurden in jeder Altersgruppe mit den Prnp ${ }^{0 / 0}$-Mäusen verglichen. Zusätzlich erfolgte ein Vergleich von Prnp ${ }^{0 / 0}$ - und WT-Mäusen verschiedener Altersgruppen untereinander. Die Daten wurden als Mittelwerte \pm SEM angegeben. Vergleiche der Gruppen wurden mit dem t-Test für unverbundene Stichproben berechnet. $* \mathrm{p}<0,05 ; * * \mathrm{p}<0,01 ; * * * \mathrm{p}<0,001$.

$\operatorname{Prnp}^{0 / 0}$-Mäuse zeigten in jeder Altersgruppe eine annähernd gleiche Aufenthaltsdauer im peripheren Teil des Feldes, während diese bei den Wildtyp-Mäusen im Alter zwischen neun und 20 Monaten signifikant zunahm ( $\mathrm{p}<0,05$; $\mathrm{t}$-Test) und auf eine Zunahme von Angst in diesem Lebensalter hindeutet (Abb. 21).

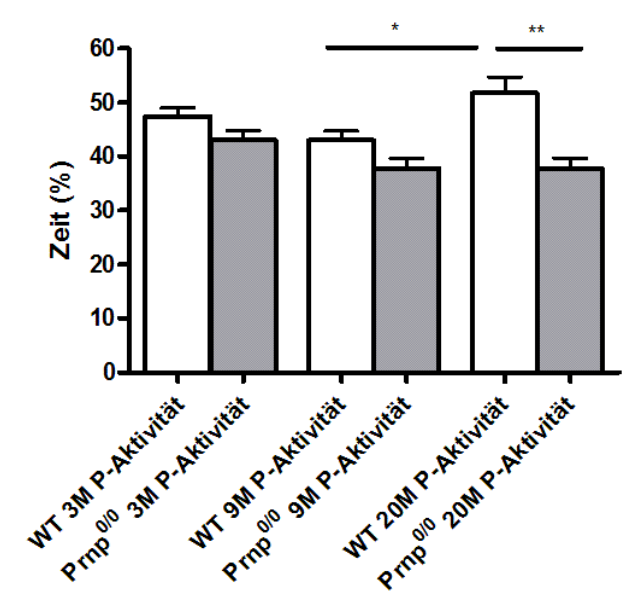

\footnotetext{
Abbildung 21: Aufenthalt in der Peripherie im Open-Field-Test.

Die Wildtyp-Mäuse (WT) dienten als Kontrollgruppe und wurden in jeder Altersgruppe mit den Prnp ${ }^{0 / 0}$-Mäusen verglichen. Zusätzlich erfolgte ein Vergleich von Prnp ${ }^{0 / 0}$ - und WT-Mäusen verschiedener Altersgruppen untereinander. Die Daten wurden als Mittelwerte \pm SEM angegeben. Vergleiche der Gruppen wurden mit dem t-Test für unverbundene Stichproben berechnet. $* \mathrm{p}<0,05 ; * * \mathrm{p}<0,01 ; * * * \mathrm{p}<0,001$.
} 
Um die Aktivität der Tiere zu vergleichen, wurde der Weg gemessen, den die Mäuse im fünf Minuten Open Field zurücklegten. In keiner Altersgruppe traten signifikante Unterschiede zwischen den Wildtyp- und den Prnp ${ }^{0 / 0}$-Mäusen auf. Dies zeigt, dass die Tiere einer Altersgruppe eine annähernd gleiche Wegstrecke zurücklegten, sich dabei aber entweder bevorzugt am Rand oder im Zentrum des Open Fields aufhielten. Eine altersbedingte Abnahme der Aktivität der Tiere ist bei beiden Mauslinien zu beobachten (Abb. 22).

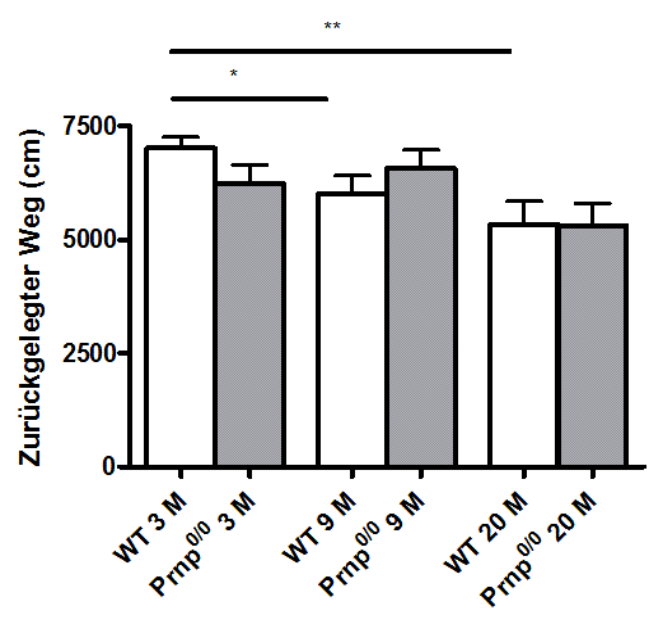

Abbildung 22: Zurückgelegter Weg im Open-Field-Test.

Die Wildtyp-Mäuse (WT) dienten als Kontrollgruppe und wurden in jeder Altersgruppe mit den Prnp ${ }^{0 / 0}$-Mäusen verglichen. Zusätzlich erfolgte ein Vergleich von Prnp ${ }^{0 / 0}$ - und WT-Mäusen verschiedener Altersgruppen untereinander. Die Daten wurden als Mittelwerte \pm SEM angegeben. Vergleiche der Gruppen wurden mit dem t-Test für unverbundene Stichproben berechnet. $* \mathrm{p}<0,05 ; * * \mathrm{p}<0,01 ; * * * \mathrm{p}<0,001$.

\subsection{Abnahme des Aktivitäts- und Erkundungsverhaltens bei drei Mo- nate alten Prnp ${ }^{0 / 0}$-Mäusen im 90 Minuten Open-Field-Test}

Der 90 Minuten Open-Field-Test zeigt die Aktivität und das Angstverhalten der Tiere über einen längeren Beobachtungszeitraum. Als Messparameter dienten wie im fünfminütigen Test die Anzahl der Linienüberschreitungen, der zentrale und der periphere Aufenthalt der Tiere im Open Field sowie der Weg, den die Tiere zurücklegten.

Im Aktivitätsverhalten zeigte sich ein deutlicher Unterschied zwischen den drei Monate alten Prnp ${ }^{0 / 0}$-Mäusen und ihrer Kontrollgruppe. Die Prnp ${ }^{0 / 0}$-Mäuse legten, gemessen an der Anzahl der Linienüberschreitungen, einen signifikant kürzeren Weg im Open Field zurück als die Wildtypen ( $\mathrm{p}<0,001$; $\mathrm{t}$-Test). Im Durchschnitt überschritten die Wildtypen 1442 Linien, während die Prnp ${ }^{0 / 0}$-Mäuse auf nur 477 Linienüberschreitungen kamen. Vom dritten bis zum neunten Lebensmonat nahm die Aktivität der Prnp ${ }^{0 / 0}$-Mäuse 
signifikant $\mathrm{zu}(\mathrm{p}<0,01 ; \mathrm{t}$-Test $)$ und war im Alter von 20 Monaten am höchsten. Die Wildtypen zeigten hingegen über alle Altersgruppen hinweg keine deutlichen Schwankungen in der Aktivität (Abb. 23).

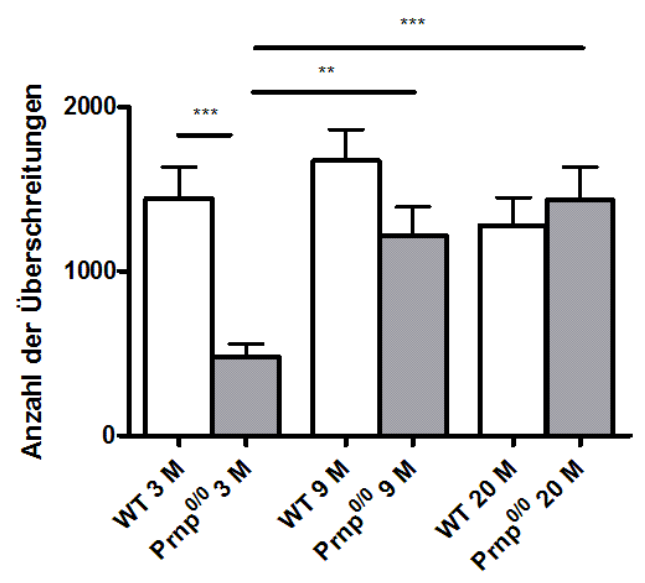

Abbildung 23: Anzahl der Linienüberschreitungen im 90 Minuten Open-Field-Test.

Die Wildtyp-Mäuse (WT) dienten als Kontrollgruppe und wurden in jeder Altersgruppe mit den Prnp ${ }^{0 / 0}$-Mäusen verglichen. Zusätzlich erfolgte ein Vergleich von Prnp ${ }^{0 / 0}$ - und WT-Mäusen verschiedener Altersgruppen untereinander. Die Daten wurden als Mittelwerte \pm SEM angegeben. Vergleiche der Gruppen wurden mit dem t-Test für unverbundene Stichproben berechnet. $* \mathrm{p}<0,05 ; * * \mathrm{p}<0,01 ; * * * \mathrm{p}<0,001$.

In Bezug auf das Angstverhalten im 90 Minuten Open Field verbrachten die drei Monate alten Prnp ${ }^{0 / 0}$-Mäuse signifikant weniger Zeit im Zentrum als ihre Kontrollgruppe ( $\mathrm{p}<0,01 ; \mathrm{t}-$ Test), sondern hielten sich bevorzugt im Randbereich des Feldes auf. Es gab unter ihnen auch Tiere, die während der 90 Minuten nicht einmal das Zentrum betraten. Im Alter zwischen drei und neun Monaten nahm die Aufenthaltsdauer der Prnp ${ }^{0 / 0}$ Mäuse im Zentrum signifikant zu (p<0,001; t-Test) und war im Alter von 20 Monaten am größten. Die Wildtyp-Mäuse zeigten im Vergleich dazu eine konstante Aufenthaltsdauer im zentralen und peripheren Teil des Open Fields über die gesamte Altersspanne hinweg (Abb. 24 A, B). 
A

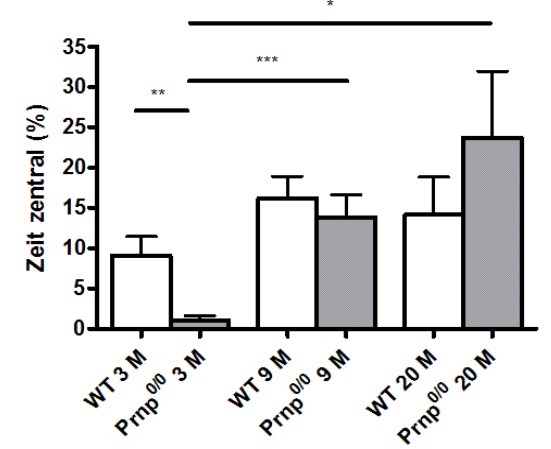

B

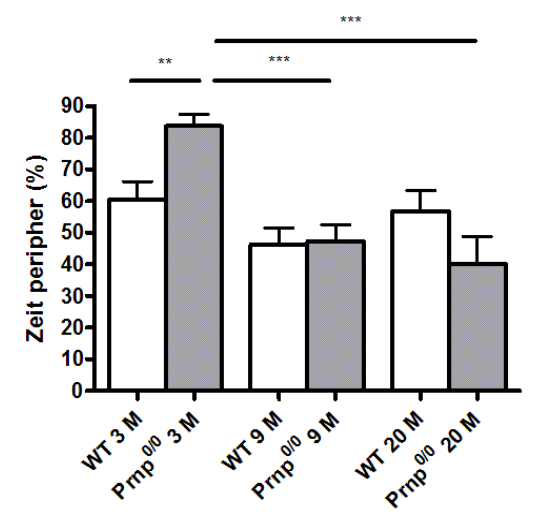

\begin{abstract}
Abbildung 24: Aufenthalt im Zentrum (A) und in der Peripherie (B) im 90 Minuten Open-Field-Test.

Die Wildtyp-Mäuse (WT) dienten als Kontrollgruppe und wurden in jeder Altersgruppe mit den Prnp ${ }^{0 / 0}$-Mäusen verglichen. Zusätzlich erfolgte ein Vergleich von Prnp ${ }^{0 / 0}$ - und WTMäusen verschiedener Altersgruppen untereinander. Die Daten wurden als Mittelwerte \pm SEM angegeben. Vergleiche der Gruppen wurden mit dem t-Test für unverbundene Stichproben berechnet. ${ }^{*} \mathrm{p}<0,05 ; * * \mathrm{p}<0,01 ; * * * \mathrm{p}<0,001$.
\end{abstract}

\title{
3.6 Zunahme der Aufenthaltsdauer in den offenen Armen des Eleva- ted Plus Maze bei Prnp ${ }^{0 / 0}$-Mäusen
}

Zur weiteren Untersuchung des Angstverhaltens der beiden Mauslinien wurde der EPM-Test durchgeführt. Als Messparameter dienten hier die Anzahl der Eintritte in die offenen bzw. geschlossenen Arme sowie die in das Zentrum des EPM, der sog. Plattform. Der Aufenthalt auf den offenen Armen entspricht hierbei einem niedrigeren Angstverhalten, während der Aufenthalt auf den geschlossenen Armen auf eine höhere Angst der Mäuse hindeutet. Die Plattform wurde bei der Evaluation zu den offenen Armen gezählt und somit als offene Fläche angesehen (Lobão-Soares et al. 2007). Die Aktivität der Tiere wurde anhand der zurückgelegten Wegstrecke auf dem EPM gemessen.

Der EPM-Test zeigte deutliche Unterschiede im Angstverhalten, sowohl im Vergleich als auch innerhalb der beiden Mauslinien in Bezug auf die unterschiedlichen Altersklassen. Die Prnp ${ }^{0 / 0}$-Mäuse hielten sich in jeder Altersgruppe weniger auf den geschlossenen Armen auf als die WT-Mäuse. Dieser Unterschied war jedoch nur im Alter von neun Monaten signifikant ( $\mathrm{p}<0.01$; $\mathrm{t}-$ Test) (Abb. 25). 


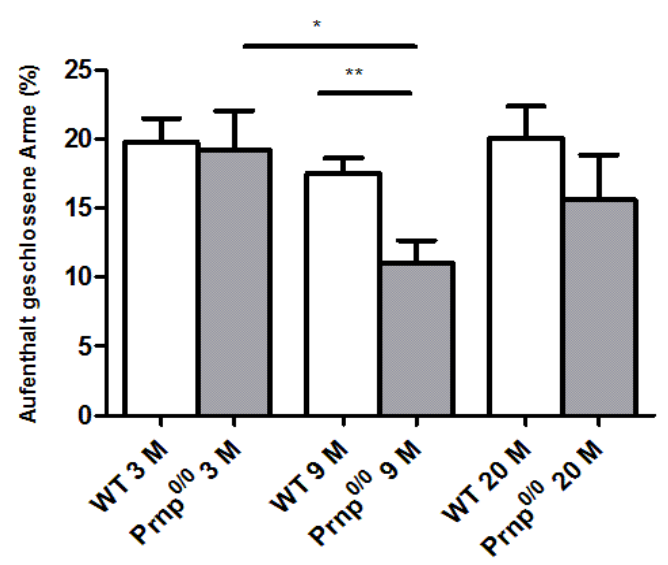

Abbildung 25: Aufenthalt auf den geschlossenen Armen des EPM.

Die Wildtyp-Mäuse (WT) dienten als Kontrollgruppe und wurden in jeder Altersgruppe mit den Prnp ${ }^{0 / 0}$-Mäusen verglichen. Zusätzlich erfolgte ein Vergleich von Prnp ${ }^{0 / 0}$ - und WT-Mäusen verschiedener Altersgruppen untereinander. Die Daten wurden als Mittelwerte \pm SEM angegeben. Vergleiche der Gruppen wurden mit dem t-Test für unverbundene Stichproben berechnet. $* \mathrm{p}<0,05 ; * * \mathrm{p}<0,01 ; * * * \mathrm{p}<0,001$.

Eine signifikante Zunahme der Aufenthaltsdauer auf den offenen Armen ließ sich bei den Prnp ${ }^{0 / 0}$-Mäusen im Alter zwischen drei und neun Monaten feststellen $(\mathrm{p}<0,01 ; \mathrm{t}$ Test), während die 20 Monate alten Prnp ${ }^{0 / 0}$-Mäuse keine Unterschiede im Vergleich zu den neun Monate alten Tieren aufwiesen. Ebenso wie die Prnp ${ }^{0 / 0}$-Mäuse zeigten auch die Wildtyp-Mäuse eine signifikant längere Aufenthaltsdauer auf den offenen Armen im Alter zwischen drei und neun Monaten ( $\mathrm{p}<0,01$; t-Test) (Abb. 26A). Im Zentrum des EPM hielten sich beide Maustypen in etwa gleich lange auf. Es konnte lediglich beobachtet werden, dass es bei beiden Mauslinien zu einer altersabhängigen kontinuierlichen Abnahme der Aufenthaltsdauer im Zentrum kam, die sowohl bei den Prnp ${ }^{0 / 0}$ Mäusen ( $\mathrm{p}<0,01$; $\mathrm{t}-$ Test), als auch bei den Wildtypen ( $\mathrm{p}<0,05$; $\mathrm{t}-$ Test) im Alter zwischen drei und neun Monaten statistisch signifikant war (Abb. 26B). 
A

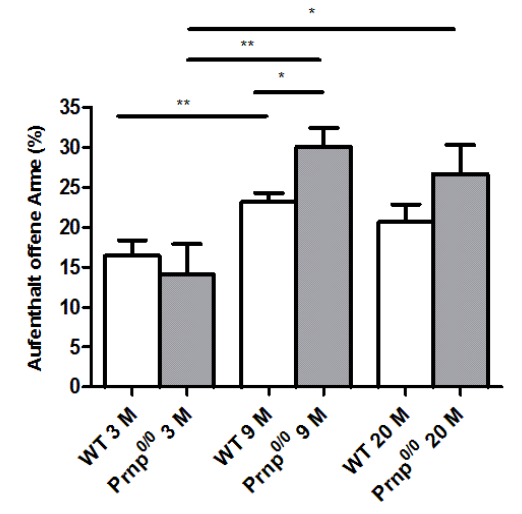

B

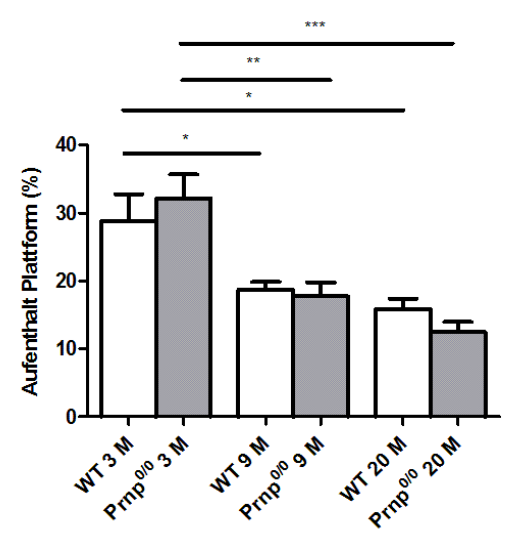

Abbildung 26: Aufenthalt auf den offenen Armen (A) und im Zentrum (B) des EPM.

Die Wildtyp-Mäuse (WT) dienten als Kontrollgruppe und wurden in jeder Altersgruppe mit den Prnp ${ }^{0 / 0}$-Mäusen verglichen. Zusätzlich erfolgte ein Vergleich von Prnp ${ }^{0 / 0}$ - und WT-Mäusen verschiedener Altersgruppen untereinander. Die Daten wurden als Mittelwerte \pm SEM angegeben. Vergleiche der Gruppen wurden mit dem t-Test für unverbundene Stichproben berechnet. $* \mathrm{p}<0,05 ; * * \mathrm{p}<0,01 ; * * * \mathrm{p}<0,001$.

Beim Vergleich der Eintritte in die geschlossenen Arme zeigten sich keine signifikanten Unterschiede (Abb. 27A). Die Anzahl der Eintritte in die offenen Arme inklusive Plattform offenbarte jedoch signifikante Unterschiede zwischen beiden Mauslinien. Die Prnp $^{0 / 0}$-Mäuse aller Altersklassen betraten weitaus öfter die offenen Arme und die Plattform als ihre Kontrollgruppe. Diese Differenz zwischen den Prnp ${ }^{0 / 0}$-Mäusen und den Wildtypen war im Alter von drei $(\mathrm{p}<0,05$; $t$-Test $)$ und 20 Monaten $(\mathrm{p}<0,001)$ signifikant. Die drei Monate alten Prnp ${ }^{0 / 0}$-Mäuse betraten auch signifikant häufiger die Plattform als ihre Kontrollgruppe $(\mathrm{p}<0,01)$. Die Anzahl der Eintritte in die offenen Arme nahm bei den Prnp ${ }^{0 / 0}$-Mäusen mit fortschreitendem Alter kontinuierlich zu. Signifikant war diese Zunahme zwischen dem dritten und neunten Lebensmonat ( $p<0,05 ; t-T e s t)$. Dieses Phänomen war auch bei den Wildtypen zu beobachten. Die neun Monate alten Wildtypen betraten die offenen Arme signifikant häufiger als die dreimonatigen $(\mathrm{p}<0,01 ; \mathrm{t}-$ Test$)$, wobei das Betreten der offenen Arme nach dem neunten Lebensmonat wieder leicht abnahm (Abb. 27B, C). 
A

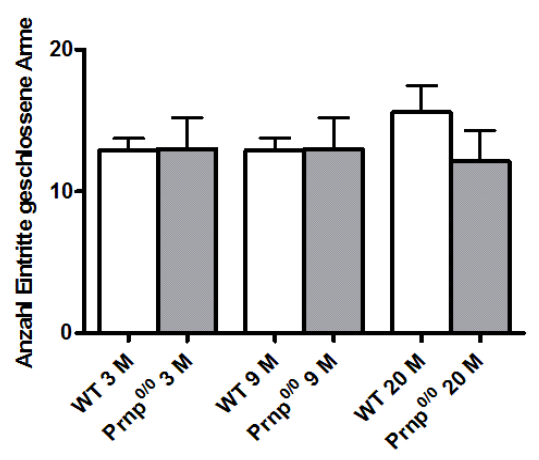

C

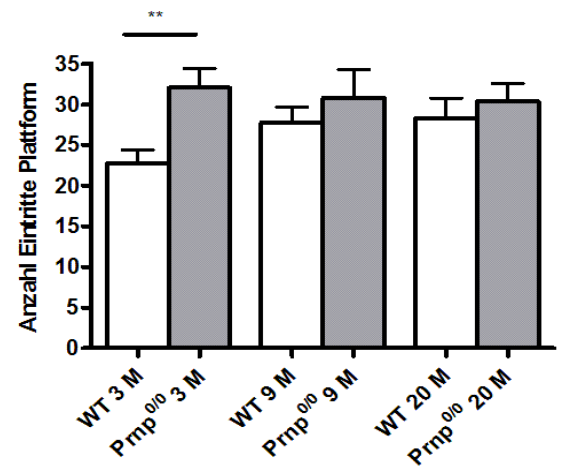

B

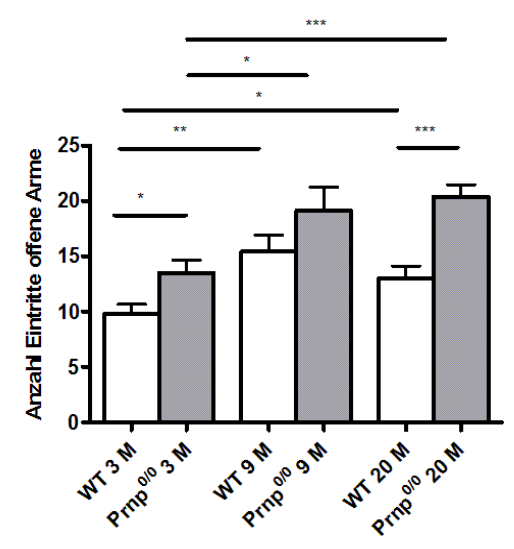

Abbildung 27: Anzahl der Eintritte in die geschlossenen Arme (A), in die offenen Arme (B) und in die Plattform (C).

Die Wildtyp-Mäuse (WT) dienten als Kontrollgruppe und wurden in jeder Altersgruppe mit den Prnp ${ }^{0 / 0}$-Mäusen verglichen. Zusätzlich erfolgte ein Vergleich von Prnp ${ }^{0 / 0}$ - und WT-Mäusen verschiedener Altersgruppen untereinander. Die Daten wurden als Mittelwerte \pm SEM angegeben. Vergleiche der Gruppen wurden mit dem t-Test für unverbundene Stichproben berechnet. $* \mathrm{p}<0,05 ; * * \mathrm{p}<0,01 ; * * * \mathrm{p}<0,001$.

Bei Betrachtung des zurückgelegten Weges ergaben sich in keiner der drei Altersgruppen signifikante Unterschiede zwischen den Prnp ${ }^{0 / 0}$-Mäusen und ihrer Kontrollgruppe, was auf eine gleiche Aktivität beider Mauslinien im EPM schließen lässt. Dabei bevorzugten die Prnp ${ }^{0 / 0}$-Mäuse ab einem Alter von neun Monaten eher die offenen Arme und die Wildtypen ab diesem Alter eher die geschlossenen Arme. Beide Mauslinien zeigten eine signifikante altersabhängige Abnahme der Aktivität zwischen neun und 20 Monaten $(\mathrm{p}<0,001 ; \mathrm{t}$-Test) (Abb. 28). 


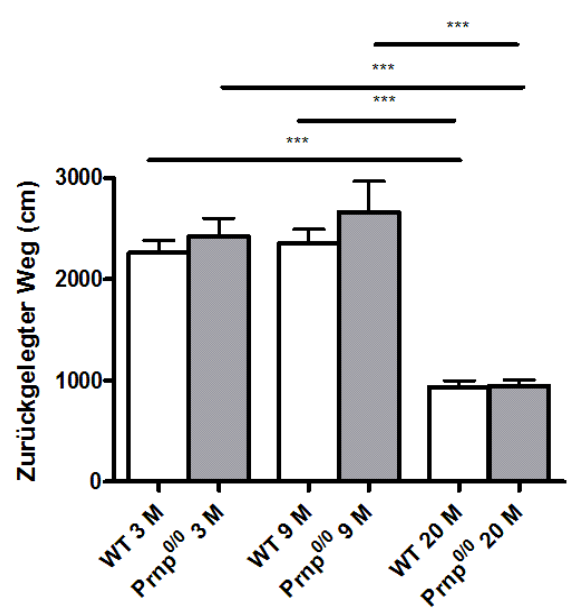

Abbildung 28: Zurückgelegter Weg im EPM.

Die Wildtyp-Mäuse (WT) dienten als Kontrollgruppe und wurden in jeder Altersgruppe mit den Prnp ${ }^{0 / 0}$-Mäusen verglichen. Zusätzlich erfolgte ein Vergleich von Prnp ${ }^{0 / 0}$ - und WT-Mäusen verschiedener Altersgruppen untereinander. Die Daten wurden als Mittelwerte \pm SEM angegeben. Vergleiche der Gruppen wurden mit dem t-Test für unverbundene Stichproben berechnet. $* \mathrm{p}<0,05 ; * * \mathrm{p}<0,01 ; * * * \mathrm{p}<0,001$.

\subsection{Geringeres Erstarrungsverhalten bei Prnp ${ }^{0 / 0}$-Mäusen im Furcht- konditionierungstest}

Dieser Test untersucht die Gedächtnisleistung der Tiere anhand ihres erlernten Angstverhaltens auf einen aversiven Stimulus. Das Erstarren („Freezing“) der Tiere galt als Parameter für die erlernte Furcht und wurde alle zehn Sekunden gemessen.

Um sicher zu gehen, dass alle Versuchstiere die gleiche Schockintensität erhielten und den Elektroschock auch ähnlich empfanden, wurde die mittlere Geschwindigkeit der Tiere in der Versuchsbox aufgezeichnet und ausgewertet. Diese diente in der Phase vor dem Schock (Pause) und während der zweisekündigen Schockphase als Vergleichswert. Bei allen Tieren konnte eine deutliche Zunahme der mittleren Geschwindigkeit während der Schockphase festgestellt und daraus geschlossen werden, dass alle den Elektroschock erhalten hatten. Sowohl während der Pause als auch während der Schockphase zeigten beide Mauslinien in allen Altersgruppen keine Unterschiede in der mittleren Geschwindigkeit (Abb. 29). Demzufolge müssen beide Gruppen unabhängig von ihrem Alter den Schock ähnlich empfunden haben. Die Tiere hatten somit alle die gleiche Grundvoraussetzung, so dass eine Vergleichbarkeit des assoziativen Lernens und der Gedächtniskonsolidierung gewährleistet war. 


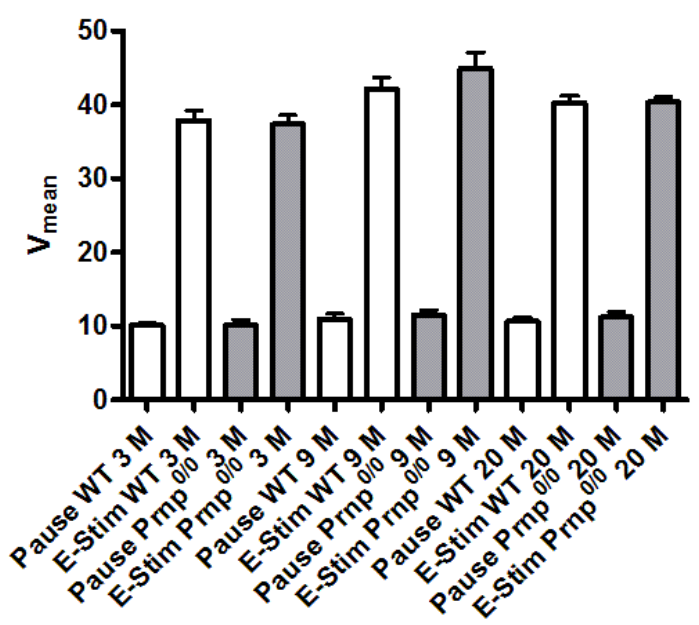

\begin{abstract}
Abbildung 29: Mittlere Geschwindigkeit der Tiere während der Schockphase und während des schockfreien Intervalls.

Um sicher zu gehen, dass alle Tiere den Elektroschock erhalten haben, wurde die mittlere Geschwindigkeit $\left(\mathrm{V}_{\text {mean }}\right)$ der Prnp ${ }^{0 / 0}$-Mäuse und der Wildtyp-Mäuse (WT) während der schockfreien Pause und während der elektrischen Stimulation (E-Stim) gemessen. Dabei nahm in der Schockphase die mittlere Geschwindigkeit der Tiere zu. Die Wildtyp-Mäuse dienten als Kontrollgruppe und wurden in jeder Altersgruppe mit den Prnp ${ }^{0 / 0}$-Mäusen verglichen. Zusätzlich erfolgte ein Vergleich der Prnp ${ }^{0 / 0}$ - und der WT-Mäuse in den verschiedenen Altersgruppen untereinander. Die Daten sind als Mittelwerte \pm SEM angegeben. Vergleiche der Gruppen wurden mit dem t-Test für unverbundene Stichproben berechnet.
\end{abstract}

\title{
3.7.1 Kontextabhängige Furchtkonditionierung
}

Die kontextabhängige Furchtkonditionierung offenbarte deutliche Unterschiede im Verhalten der beiden Mauslinien. Im Alter von drei Monaten war noch keine signifikante Differenz in der Häufigkeit des Erstarrens zwischen den Prnp ${ }^{0 / 0}$-Mäusen und ihrer Kontrollgruppe festzustellen. Die Prnp ${ }^{0 / 0}$-Mäuse erstarrten in dieser Altersgruppe sogar etwas häufiger als die Wildtypen. In der Gruppe der neunmonatigen Tiere erstarrten dagegen die $\operatorname{Prnp}^{0 / 0}$-Mäuse deutlich seltener als die Wildtypen $(\mathrm{p}<0,001$; $\mathrm{t}$-Test). Zwischen den drei und neun Monate alten Prnp $^{0 / 0}$-Mäusen kam es zu einer signifikanten Abnahme des Freezings ( $<<0,001$; t-Test), während bei den Wildtypen kein Unterschied zwischen diesen Altersgruppen bestand. Unter den 20 Monate alten Tieren erstarrten die $\operatorname{Prnp}^{0 / 0}$-Mäuse signifikant seltener als die Wildtyp-Mäuse $(\mathrm{p}<0,001 ; \mathrm{t}$-Test). Weitere wichtige Beobachtungen waren, dass im Alter zwischen neun und 20 Monaten bei beiden Mauslinien das Erstarrungsverhalten signifikant abnahm und dass das Erstarren bei den Prnp ${ }^{0 / 0}$-Mäusen nach dem dritten Lebensmonat kontinuierlich zurückging, während diese Abnahme bei den Wildtypen weniger ausgeprägt war und erst nach dem neunten Lebensmonat auftrat (Abb. 30). 


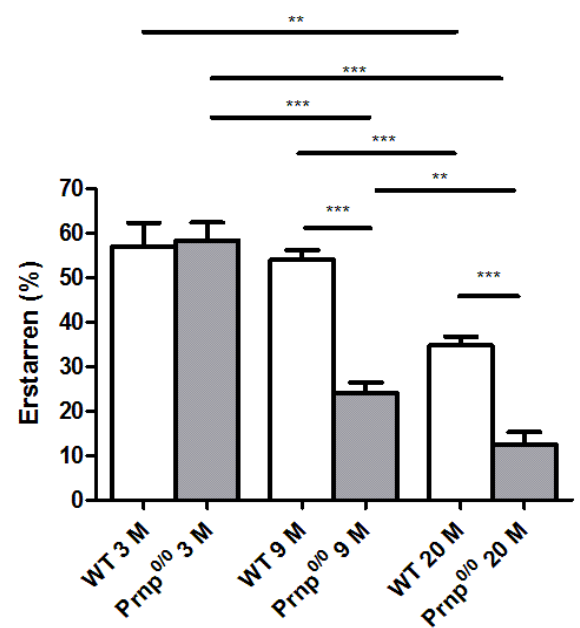

Abbildung 30: Freezingverhalten der Prnp ${ }^{0 / 0}$-Mäuse und der WT-Mäuse in der kontextabhängigen Furchtkonditionierung.

Beide Mauslinien wurden in den Altersklassen 3, 9 und 20 Monate in der kontextabhängigen Furchtkonditionierung getestet. Hierbei wurde das Erstarrungsverhalten der Tiere untersucht. $\operatorname{Prnp}^{0 / 0}$ - und WT-Mäuse verschiedener Altersgruppen wurden miteinander verglichen. Die Daten sind als Mittelwerte \pm SEM angegeben. Vergleiche der Gruppen wurden mit dem t-Test für unverbundene Stichproben berechnet. $* * p<0,01 ; * * * p<0,001$.

\subsubsection{Tonabhängige Furchtkonditionierung}

Die tonabhängige Furchtkonditionierung ergab ähnliche Ergebnisse wie die kontextabhängige Furchtkonditionierung. Die Prnp ${ }^{0 / 0}$-Mäuse erstarrten in jeder Altersgruppe signifikant seltener als die Kontrollmäuse. Der erste Unterschied im Freezingverhalten ließ sich hier bereits im Alter von drei Monaten beobachten. Bei beiden Mauslinien nahm die Freezingdauer nach dem dritten Lebensmonat kontinuierlich ab und erreichte den niedrigsten Wert im Alter von 20 Monaten. Sowohl bei den Prnp ${ }^{0 / 0}$ - als auch bei den Wildtyp-Mäusen nahm das Furchtverhalten zwischen dem dritten und dem neunten Lebensmonat signifikant ab ( $\mathrm{p}<0,001$; t-Test) (Abb. 31).

In der kontextabhängigen Furchtkonditionierung des ersten Tages erstarren die Prnp ${ }^{0 / 0}$ Mäuse deutlich häufiger als in der tonabhängigen Furchtkonditionierung des zweiten Versuchstages. Um diese Diskrepanz näher zu untersuchen, wurde eine weitere Gruppe von drei Monate alten Prnp ${ }^{0 / 0}$-Mäusen und Wildtypen untersucht. Diese Tiere wurden in umgekehrter Reihenfolge der beiden Versuchstage getestet, um zu überprüfen, ob das verminderte Erstarrungsverhalten bei der tonabhängigen Furchtkonditionierung zeitoder tonabhängig war. Beide Versuchsreihen stimmten miteinander überein. Auch hier 
erstarrten die Prnp ${ }^{0 / 0}$-Mäuse in der tonabhängigen Furchtkonditionierung deutlich weniger als in der kontextabhängigen Furchtkonditionierung des zweiten Versuchstages.

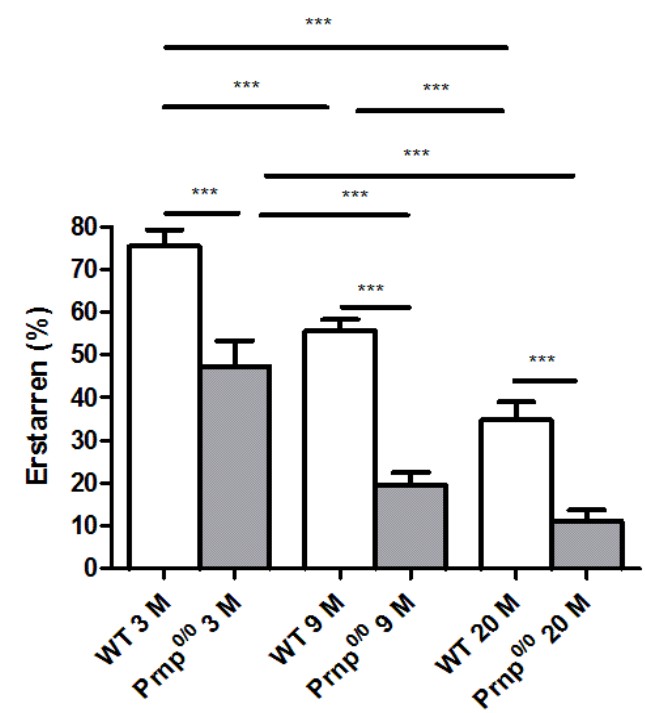

Abbildung 31: Erstarrungsverhalten der $\operatorname{Prnp}^{0 / 0}$-Mäuse und der WT-Mäuse in der tonabhängigen Furchtkonditionierung.

Beide Mauslinien wurden in den Altersklassen 3, 9 und 20 Monate in der tonabhängigen Furchtkonditionierung getestet. Hierbei wurde das Erstarrungsverhalten der Tiere untersucht. Die Wildtyp-Mäuse (WT) dienten als Kontrollgruppe und wurden in jeder Altersgruppe mit den Prnp ${ }^{0 / 0}$-Mäusen verglichen. Zusätzlich erfolgte ein Vergleich der Prnp ${ }^{0 / 0}$ - und der WTMäuse verschiedener Altersgruppen untereinander. Die Daten sind als Mittelwerte \pm SEM angegeben. Vergleiche der Gruppen wurden mit dem t-Test für unverbundene Stichproben berechnet. $* * * p<0,001$.

\subsection{Kein Unterschied der motorischen Fähigkeiten zwischen Prnp ${ }^{0 / 0}$ - Mäusen und Wildtyp-Mäusen}

Das Rotarod ermöglicht eine Charakterisierung der motorischen Fähigkeiten sowie der Beweglichkeit der Tiere. Als Vergleichswert diente bei diesem Test die Zeit, die sich die Tiere auf dem rotierenden Balken halten konnten. Aus altersbedingten Gründen musste der Test für die Gruppe der 20 Monate alten Tiere modifiziert und deren Fähigkeiten entsprechend angepasst werden. So wurde für das Training eine Rotationsgeschwindigkeit von 4 bis $10 \mathrm{Upm}$ gewählt, die bei jedem Trainingslauf etwas gesteigert wurde, bis sich die Tiere nach fünf Trainingseinheiten sicher auf dem rotierenden Balken halten konnten. Für den Test wurde bei den 20 Monate alten Tieren eine Rotationsgeschwindigkeit von 5 bis $15 \mathrm{Upm}$ eingestellt.

In der Altersklasse der drei und neun Monate alten Mäuse konnte der Rotarod-Test unter standardisierten Bedingungen durchgeführt werden. Für das Training wurde hier 
eine Rotationsgeschwindigkeit von 10 Upm gewählt.Während der Testphasen wurde die Geschwindigkeit von 5 auf 40 Upm gesteigert.

In keiner der drei Altersgruppen ließ sich ein signifikanter Unterschied zwischen den Prnp $^{0 / 0}$-Mäusen und ihrer Kontrollgruppe feststellen. Beide Mauslinien hielten sich in den jeweiligen Altersgruppen vergleichbar lange auf dem rotierenden Balken. Eine deutliche Abnahme der motorischen Fertigkeiten konnte in Abhängigkeit vom Alter der Tiere beobachtet werden. Die Fähigkeit, auf dem rotierenden Balken zu balancieren, nahm sowohl bei den $\operatorname{Prnp}^{0 / 0}-(\mathrm{p}<0,01 ; \mathrm{t}$-Test $)$ als auch bei den Wildtyp-Mäusen ( $\mathrm{p}<0,001$; $\mathrm{t}$-Test) im Alter zwischen drei und neun Monaten signifikant ab (Abb. 32A). Ein direkter Vergleich der 20 Monate alten mit den drei und neun Monate alten Tieren war aufgrund der oben beschriebenen Modifizierung des Tests nicht möglich. Es konnte jedoch eine deutlich schlechtere motorische Leistungsfähigkeit der 20 Monate alten Mäuse festgestellt werden, daher führte diese Gruppe den Test unter erleichterten Bedingungen durch (Abb. 32B).

A

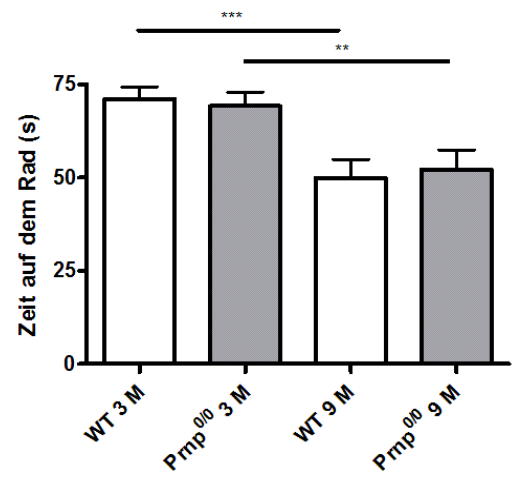

B

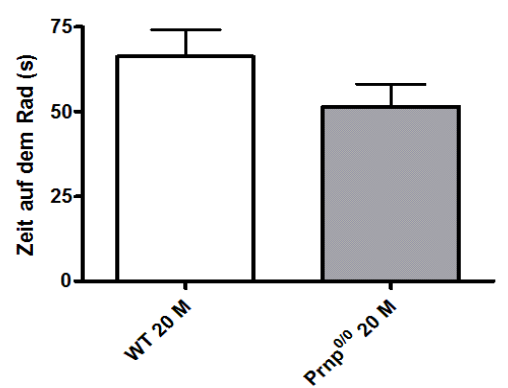

Abbildung 32: Analyse der motorischen Fähigkeiten von Prnp ${ }^{0 / 0}$-Mäusen und WTMäusen im Rotarod-Test.

Beide Mauslinien wurden in den Altersklassen 3, 9 und 20 Monate im Rotarod getestet. Dabei wurde die Zeit, die sich die Tiere auf dem rotierenden Balken halten konnten, gemessen.

(A) Vergleich der 3 Monate alten mit den 9 Monate alten Tieren.

(B) Die Gruppe der 20 Monate alten Tiere ist separat dargestellt, da bei ihnen der Test altersbedingt unter vereinfachten Bedingungen durchgeführt werden musste. Die Daten sind als Mittelwerte \pm SEM angegeben. Vergleiche der Gruppen wurden mit dem t-Test für unverbundene Stichproben berechnet. $* * \mathrm{p}<0,01 ; * * * \mathrm{p}<0,001$.

\subsection{Abnahme der kognitiven Funktionen bei Prnp ${ }^{0 / 0}$-Mäusen}

Der Objekterkennungstest dient zur Untersuchung der kognitiven Fähigkeiten der Mäuse. Um die Gedächtnisleistung der Tiere beurteilen zu können, wurde die prozentuale Zeit, die die Tiere an dem neuen Objekt verbrachten, sowie die prozentuale Anzahl der Kontakte an dem neuen Objekt gemessen. Der zurückgelegte Weg während der fünfmi- 
nütigen Testphase gibt Aufschluss über die Aktivität und das Erkundungsverhalten der Tiere.

Bei der Anzahl der Berührungen des neuen Objektes sowie der Zeit, die die Tiere mit der Erkundung dessen verbrachten, zeigten sich deutliche Unterschiede der kognitiven Leistungsfähigkeit zwischen den $\operatorname{Prnp}^{0 / 0}$ - und Wildtyp-Mäusen. Während sich beide Mauslinien im Alter von drei Monaten noch nicht signifikant in ihrer Gedächtnisleistung unterschieden, nahm diese bei den Prnp ${ }^{0 / 0}$-Mäusen im Alter zwischen drei und neun Monaten signifikant $a b(\mathrm{p}<0,01 ; \mathrm{t}$-Test). Auch die Wildtypen zeigten eine geringe Abnahme ihrer kognitiven Leistungsfähigkeit in dieser Altersspanne ( $p>0.05$; t-Test). Interessanterweise unterschieden sich hierin die $\operatorname{Prnp}^{0 / 0}$ - von den WT-Mäusen ab einem Alter von neun Monaten. Die Prnp ${ }^{0 / 0}$ Mäuse verbrachten signifikant weniger Zeit an dem neuen Objekt als die Wildtypen ( $<<0,01$; t-Test), was darauf hindeutet, dass sie sich weniger gut an das alte erinnern konnten. Im Alter zwischen neun und 20 Monaten kam es bei den Prnp ${ }^{0 / 0}$-Mäusen zu einer weiteren Verschlechterung der kognitiven Leistungsfähigkeit, während sich die Wildtypen im Alter von 20 Monaten nicht wesentlich von der neun Monate alten Kontrollgruppe unterschieden.

Die Prnp ${ }^{0 / 0}$-Mäuse hingegen verbrachten im Alter von 20 Monaten signifikant weniger Zeit am neuen Objekt als die Wildtypen ( $p<0,001$; $t$-Test), was als eine deutliche Abnahme ihrer kognitiven Fähigkeit interpretiert werden kann (Abb. 33B). Um zu zeigen, dass sich die beiden Mauslinien einer Altersgruppe nicht in ihrer motorischen Fähigkeit und Aktivität unterschieden, wurde der Weg, den die Tiere in der fünfminütigen Erkundungsphase zurücklegten, gemessen. In keiner der drei Altersgruppen war ein signifikanter Unterschied festzustellen (Abb. 33C). Es konnte lediglich eine altersbedingte Abnahme der motorischen Aktivität im Alter zwischen neun und 20 Monaten gezeigt werden. Diese Abnahme ließ sich sowohl bei den Wildtypen als auch bei den Prnp ${ }^{0 / 0}$ Mäusen beobachten. 
A

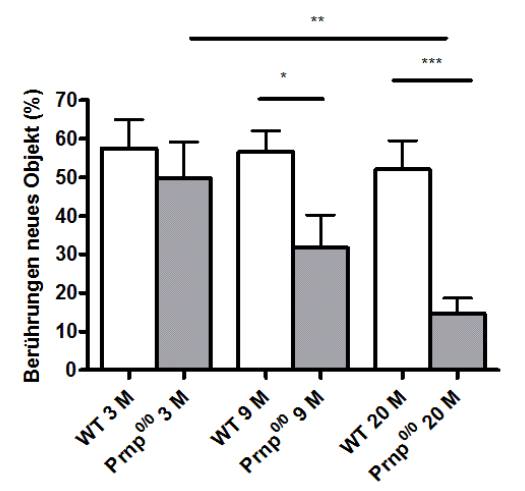

C

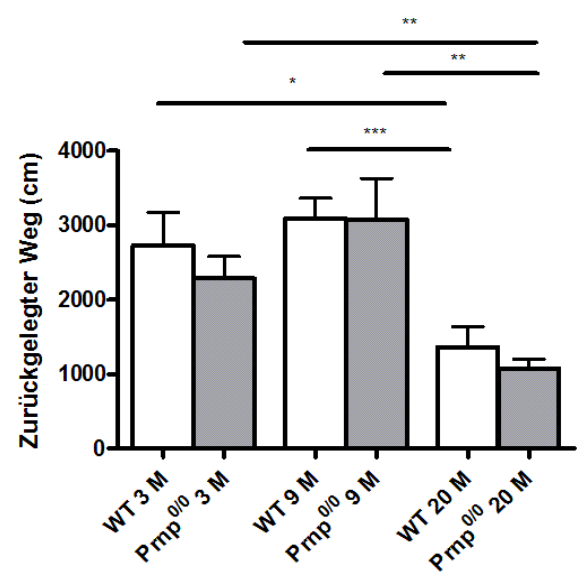

B

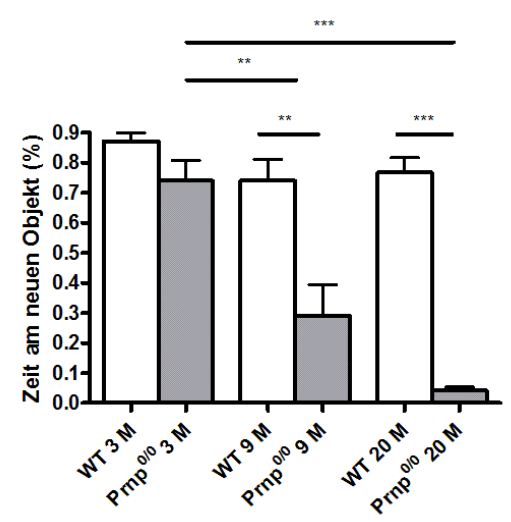

Abbildung 33: Verhalten der Prnp ${ }^{0 / 0}$-Mäuse und der WT-Mäuse im Objekterkennungstest.

Beide Mauslinien wurden in den Altersklassen 3, 9 und 20 Monate im Objekterkennungstest getestet. Folgende Parameter wurden untersucht:

(A) Zahl der Berührungen des neuen Objekts im Verhältnis zum bekannten, (B) am neuen Objekt verbrachte Zeit im Verhältnis zu der am bekannten Objekt, (C) zurückgelegter Weg. Die Wildtyp-Mäuse (WT) dienten als Kontrollgruppe und wurden in jeder Altersgruppe mit den Prnp $^{0 / 0}$-Mäusen verglichen. Zusätzlich wurden Prnp ${ }^{0 / 0}$ - und WT-Mäuse der verschiedenen Altersgruppen untereinander verglichen. Die Daten sind als Mittelwerte \pm SEM angegeben. Vergleiche der Gruppen wurden mit dem t-Test für unverbundene Stichproben berechnet. ${ }^{*} \mathrm{p}<0,05$; $* * \mathrm{p}<0,01 ; * * * \mathrm{p}<0,001$.

\subsection{Kein Unterschied im räumlichen Lernen zwischen $\operatorname{Prnp}^{0 / 0}$-Mäu- sen und Wildtyp-Mäusen im Morris Water Maze}

Das Morris Water Maze ist ein etablierter Test zur Beurteilung des räumlichen Lernvermögens von Nagetieren. Da dieser eine hohe körperliche Anstrengung für die Tiere darstellt, konnte er nur mit den drei und neun Monate alten Mäusen durchgeführt werden. Schon beim Rotarod-Test zeigte sich, dass die 20 Monate alten Tiere bereits zu schwach waren, um den vierminütigen Schwimmtest durchzuhalten. Diese körperliche Schwäche war sowohl bei den Prnp ${ }^{0 / 0}$ - als auch bei den Wildtyp-Mäusen zu beobachten, 
so dass die komplette 20 Monate alte Testgruppe vom Morris-Water-Maze-Test ausgeschlossen werden musste.

Als Messparameter für das räumliche Lernvermögen dienten die Zeit, die die Tiere in dem Quadranten verbrachten, in dem zuvor die Plattform stand, sowie die Anzahl der imaginären Plattformüberschreitungen. Die zurückgelegte Distanz beim Schwimmen zeigte die Aktivität der Tiere an. Um deren Lernzuwachs beurteilen zu können, wurde während der achttägigen Trainingsphase täglich die durchschnittliche Zeit gemessen, die die Tiere brauchten, um die Plattform zu finden. Dabei konnten keine signifikanten Unterschiede zwischen den Prnp ${ }^{0 / 0}$-Mäusen und den Wildtypen beider Altersgruppen gefunden werden. Auch beim Vergleich zwischen den beiden Altersklassen ergaben sich keine deutlichen Unterschiede (Abb. 34).

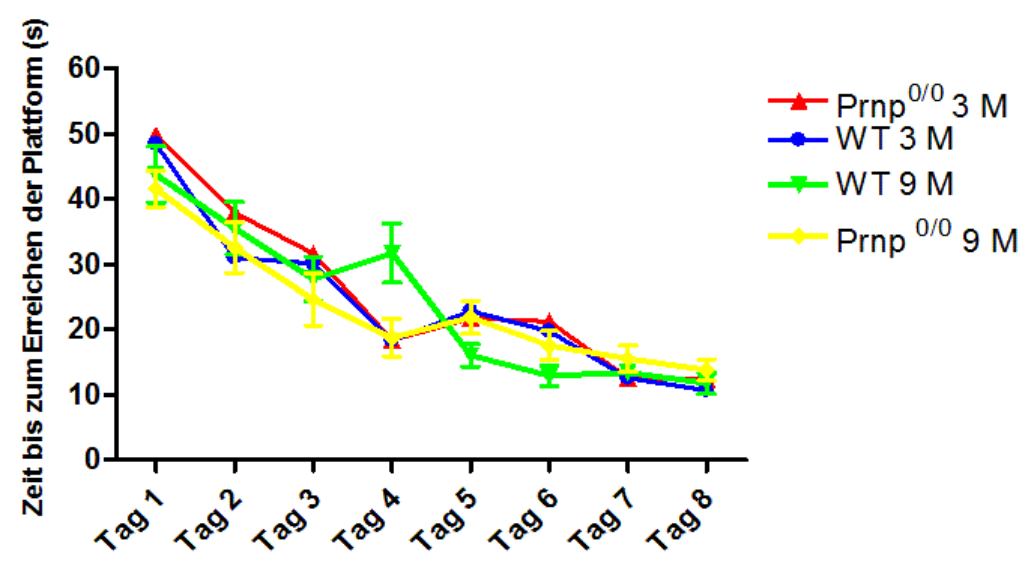

Abbildung 34: Lernkurve der Prnp ${ }^{0 / 0}$ - und WT-Mäuse im Morris-Water-Maze-Test.

Dargestellt ist der Lernzuwachs der drei und neun Monate alten Tiere während der achttägigen Trainingsphase. Gemessen wurde die Zeit, die die Tiere benötigten, um die Plattform zu erreichen. Die Wildtyp-Mäuse (WT) dienten als Kontrollgruppe und wurden in jeder Altersgruppe mit den Prnp ${ }^{0 / 0}$-Mäusen verglichen. Zusätzlich erfolgte ein Vergleich der Prnp ${ }^{0 / 0}$ - und der WTMäuse verschiedener Altersgruppen untereinander. Die Daten sind als Mittelwerte \pm SEM angegeben. Vergleiche der Gruppen wurden mit dem t-Test für unverbundene Stichproben berechnet. Es konnte kein Unterschied im Lernzuwachs zwischen Prnp ${ }^{0 / 0}$ - und den WildtypMäusen festgestellt werden.

Am neunten Tag wurde die Plattform aus dem Wasser entfernt, um das räumliche Lernvermögen der Tiere zu testen. Im Vergleich zu den Wildtypen verbrachten die Prnp ${ }^{0 / 0}$ Mäuse sowohl im Alter von drei als auch im Alter von neun Monaten weniger Zeit in dem Quadranten, in dem zuvor die Plattform stand. Die Unterschiede waren jedoch in beiden Altersgruppen nicht signifikant. Des Weiteren konnte bei beiden Mauslinien im Lebensalter zwischen drei und neun Monaten eine Abnahme der Aufenthaltsdauer im Bereich der Plattform beobachtet werden, aber auch diese erwies sich als nicht signifi- 
kant (Abb. 35B). Eine noch genauere Beurteilung des räumlichen Lernvermögens der Mäuse ermöglicht die Anzahl der Plattformüberschreitungen. Hierbei mussten sich die Tiere genau in dem Bereich aufhalten, in dem zuvor die Plattform gestanden hatte. Auch hier war die Anzahl bei den Wildtypen beider Altersgruppen jeweils größer als die der Prnp ${ }^{0 / 0}$-Mäuse, die Differenzen waren jedoch wiederum nicht signifikant. Ana$\log$ zur Aufenthaltsdauer nahm auch die Anzahl der Plattformüberquerungen im Alter zwischen drei und neun Monaten sowohl bei den Prnp ${ }^{0 / 0}$ - als auch bei den WildtypMäusen leicht ab (Abb. 35A). Beide Mauslinien legten im Alter von drei und neun Monaten eine vergleichbare Distanz im Morris Water Maze zurück, so dass von vergleichbaren Schwimmfähigkeiten ausgegangen werden konnte. Die Aktivität der Tiere beim Schwimmen blieb im Alter zwischen drei und neun Monaten konstant und zeigte keine altersbedingte Abnahme (Abb. 35C).

A

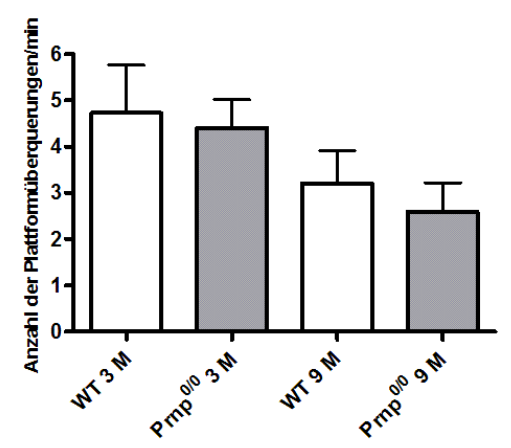

C

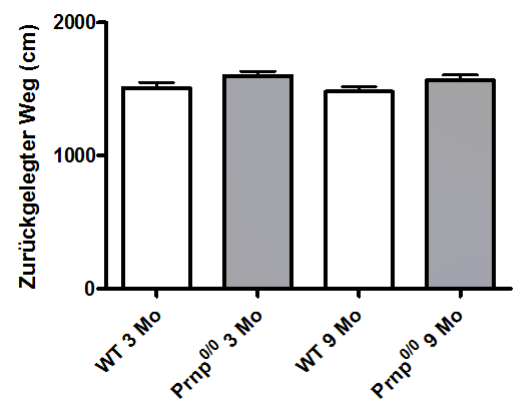

B

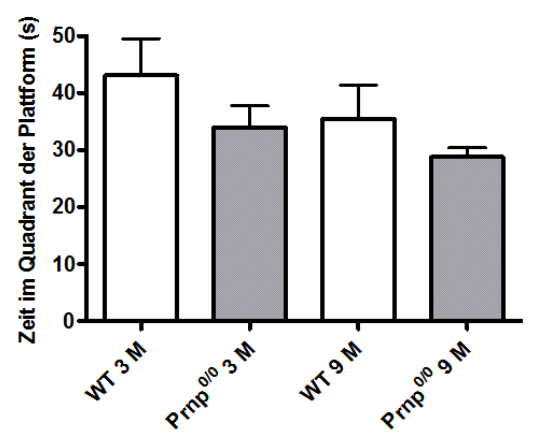

Abbildung 35: Verhalten der Prnp ${ }^{0 / 0}$ - und der WT-Mäuse im Morris Water Maze. Beide Mauslinien wurden in den Altersklassen 3 und 9 Monate im Morris Water Maze getestet. Folgende Parameter wurden untersucht: (A) Anzahl der Plattformüberschreitungen, (B) Zeit im Quadranten der Plattform, (C) zurückgelegter Weg. Die Wildtyp-Mäuse (WT) dienten als Kontrollgruppe und wurden in jeder Altersgruppe mit den Prnp ${ }^{0 / 0}$-Mäusen verglichen. Die Daten sind als Mittelwerte \pm SEM angegeben. Vergleiche der Gruppen wurden mit dem t-Test für unverbundene Stichproben berechnet.*p<0,05; **p<0,01;***p<0,001. 


\section{Diskussion}

Die vorliegende Arbeit befasst sich mit der Fragestellung, welche Rolle das $\operatorname{PrP}^{c}$ in der Verhaltensphysiologie einnimmt. Dabei wurde der Schwerpunkt der Untersuchungen auf das Angst- und Lernverhalten, die Gedächtniskonsolidierung, das natürliche Erkundungsverhalten und auf die motorischen Fähigkeiten gelegt. Darüber hinaus wurde die Rolle des $\operatorname{PrP}^{\mathrm{c}}$ in angeborenen Verhaltensweisen näher untersucht. Ein weiteres Ziel dieser Arbeit war die Untersuchung der Funktion von $\operatorname{PrP}^{\mathrm{c}}$ während des natürlichen Alterungsprozesses.

Obwohl in den vergangenen Jahren bereits einige Studien unter Einsatz verschiedener experimenteller Modelle erfolgten, ist die Funktion des $\operatorname{PrP}^{c}$ bis heute noch nicht vollständig verstanden. Insbesondere die Rolle des $\operatorname{PrP}^{\mathrm{c}}$ in der Verhaltensphysiologie wird in der Literatur kontrovers diskutiert. Das mag zum Teil an den unterschiedlichen Mauslinien liegen, die seit der Generierung der ersten Prion-Protein-Knockout-Mäuse hergestellt wurden. Dazu zählen die Linien Nagasaki (Sakaguchi et al. 1996) und Edinburgh (Manson et al. 1994) sowie die Tiere der Mauslinien Zürich I (Büeler et al. 1992) und Zürich II (Rossi et al. 2001). Da die Mäuse der Linien Nagasaki und Zürich II zusätzlich eine Überexpression des Proteins Doppel (Dpl) aufweisen (Moore et al. 1999), wurden in der vorliegenden Arbeit nur Tiere der Linie Zürich I verwendet. Bei Dpl handelt es sich um ein $\mathrm{PrP}^{\mathrm{c}}$-ähnliches Protein, das im Kleinhirn der Tiere eine Degeneration von Körnerzellen und Purkinje-Zellen hervorruft und die Entwicklung von Ataxien verursacht (Moore et al. 2001). Diese Phänomene wurden bei Zürich-I-Mäusen nicht beschrieben.

\subsection{Veränderungen im nativen Nestbauverhalten bei Prnp ${ }^{0 / 0}$-Mäusen}

Das Bauen von Nestern ist im gesamten Tierreich weit verbreitet und bei kleinen Nagetieren wie Mäusen ein wichtiges angeborenes Verhalten. Das Nest bietet den Tieren wichtigen Schutz für das eigene Überleben und die Fortpflanzung. So hilft es den Mäusen bei der Regulation und dem Erhalt der Körpertemperatur. Dies ist für die Tiere insofern von Bedeutung, da ihre relativ große Körperoberfläche sie anfällig für den Verlust von Körperwärme macht. Darüber hinaus dient das Nest der Reproduktion und sichert das Überleben der Nachkommen. Ferner ist es ein wichtiger Schutz vor Feinden und dient zur Tarnung (Deacon 2006). Der Test zum Nestbauverhalten der Mäuse zeigte erstmals, dass dies bei den Prnp ${ }^{0 / 0}$-Mäusen im Vergleich zu den Wildtyp-Mäusen deutlich geringer ausgeprägt bzw. gar nicht vorhanden war. Dieser Test wurde in der Litera- 
tur bisher noch nicht an $\operatorname{Prnp}^{0 / 0}$-Mäusen beschrieben. Das veränderte Nestbauverhalten der Prnp ${ }^{0 / 0}$-Mäuse konnte in allen drei Altersklassen beobachtet werden, so dass angenommen werden kann, dass das Alter der Tiere keinen Einfluss auf den Nestbau hat. Das fehlende Nestbauverhalten wurde zuvor schon an mit Scrapie infizierten Mäusen beobachtet und stellte sich als ein sehr sensitiver Indikator für die Scrapie-Infektion heraus (Cunningham et al. 2003). Es konnte gezeigt werden, dass die ersten klinischen Zeichen bei mit Scrapie infizierten Mäusen erst nach 22 Wochen auftraten, während das Nestbauverhalten der Tiere bereits nach zehn bis elf Wochen post infectionem signifikant beeinträchtigt war (Kim et al. 1997). Das veränderte Nestbauverhalten bei den $\operatorname{Prnp}^{0 / 0}$ - und den mit Scrapie infizierten Mäusen weist darauf hin, dass $\operatorname{PrP}^{\mathrm{c}}$ eine wichtige Rolle in angeborenen Verhaltensweisen spielt. Für dessen Funktion bei der Ausbildung lebenswichtiger, angeborener Verhaltensweisen spricht auch die Tatsache, dass das Prion-Protein ein evolutionär hochkonserviertes Protein ist, das sich im Laufe der Entwicklung nur wenig verändert hat und unter den Säugetieren weit verbreitet ist. Das Nestbauverhalten wird jedoch noch von einer Reihe weiterer Faktoren, insbesondere dem Hormonsystem, beeinflusst (Bond et al. 2002). Dies spielt in erster Linie bei weiblichen Mäusen eine Rolle, die durch ihren hormonellen und reproduktiven Status im Nestbau beeinflusst werden (Lisk et al. 1969). Für den vorliegenden Test wurden jedoch ausschließlich männliche Versuchstiere verwendet, so dass der hormonelle Einfluss hier eine eher untergeordnete Rolle spielt und andere Mechanismen zum Tragen kommen.

\subsection{Einfluss des $\operatorname{PrP}^{\mathfrak{c}}$ auf das Erkundungs- und Bewegungsverhalten}

Das Erkunden von neuen Umgebungen ist wie der Nestbau eine angeborene Verhaltensweise von Nagetieren. Zur Beobachtung des Erkundungsverhaltens wurden die Tiere jeweils für fünf Minuten und in einem zweiten Durchgang für 90 Minuten in die Testapparatur des Open Fields gesetzt. Die Neugier der Tiere, eine unbekannte Umgebung zu erkunden, steht hier in Konflikt mit dem natürlichen Vermeidungsverhalten gegenüber offenen, freien und ungeschützten Flächen, wie sie beispielsweise der OpenField-Test darbietet.

Die Prnp ${ }^{0 / 0}$-Mäuse aller drei Altersklassen zeigten sowohl im fünfminütigen als auch im 90 Minuten Test eine signifikant höhere Latenzzeit als die Tiere der Kontrollgruppen. Dieses Verhalten wurde bereits in früheren Studien belegt, in denen die Prnp ${ }^{0 / 0}$-Mäuse mehr Zeit benötigten, bis sie das Zentrum des Open Fields verließen, in das sie zuvor gesetzt wurden (Coitinho et al. 2003, Criado et al. 2005, Lobão-Soares et al. 2007). Die 
Studien zeigen, dass Prnp ${ }^{0 / 0}$-Mäuse mehr Zeit zur Bewältigung der Stresssituation benötigen, und um sich an eine neue Umgebung zu gewöhnen und diese zu erkunden. Für eine maßgebliche Rolle des $\operatorname{PrP}^{c}$ in adaptiven Verhaltensweisen spricht auch die Tatsache, dass $\operatorname{PrP}^{c}$ überexprimierende Tg-20-Mäuse im Vergleich zu den Prnp ${ }^{0 / 0}$-Mäusen eine signifikant niedrigere Latenzzeit im Open-Field-Test aufwiesen und insgesamt ein stärkeres Erkundungsverhalten zeigten (Lobão-Soares et al. 2007). Diese Beobachtungen wurden auf eine Veränderung im Transmitter-Metabolismus zurückgeführt, aufgrund einer erhöhten synaptischen $\operatorname{PrP}^{\mathrm{c}}$ Konzentration im ZNS als auch im PNS. Eine Funktion des $\operatorname{PrP}^{c}$ im System der Neurotransmitter wurde mehrfach belegt (Brown DR 2001, Mallucci et al. 2002, Mouillet-Richard et al. 2005). Eine weitere Erklärungsmöglichkeit für das veränderte Erkundungsverhalten der Prnp ${ }^{0 / 0}$-Mäuse ist das erhöhte Stresspotential in einer neuen Umgebung. Prnp ${ }^{0 / 0}$-Mäuse zeigten eine verminderte Adaptationsbereitschaft an stressvolle Situationen dadurch, dass sie nach einem fünfminütigen Schwimmtest eine signifikant höhere Latenz im Open Field aufwiesen als die entsprechende Kontrollgruppe (Nico et al. 2005).

Um das Erkundungs- und Bewegungsverhalten über einen längeren Zeitraum beobachten zu können, wurden die Tiere für 90 Minuten in das Open Field gesetzt. Bei diesem Test zeigte sich eine signifikant niedrigere Bewegungsaktivität in der Gruppe der drei Monate alten Prnp ${ }^{0 / 0}$-Mäuse und gleichzeitig eine deutlich geringere Aufenthaltsdauer im Zentrum des Open Fields. Dies könnte auf ein erhöhtes Angstverhalten der drei Monate alten Prnp ${ }^{0 / 0}$-Mäuse hindeuten. Im Gegensatz zum 90 Minuten Open Field zeigten sich im fünfminütigen Open Field keine Unterschiede hinsichtlich des Bewegungs- und Erkundungsverhaltens. Die Tiere beider Gruppen zeigten in jeder Altersklasse eine vergleichbare Aktivität. Diese Beobachtung wird von einigen Studien bestätigt (LobãoSoares et al. 2007), andere Untersuchungen kamen jedoch auch zu gegensätzlichen Ergebnissen. Roesler et al. (1999) dokumentierten eine Zunahme der Bewegungsaktivität bei der Erkundung des Open Fields bei den drei Monate alten Prnp ${ }^{0 / 0}$-Mäusen. Später durchgeführte Tests zeigten eine Abnahme in der Bewegungsaktivität bei Prnp ${ }^{0 / 0}$-Mäusen im Alter von neun und elf Monaten im fünf Minuten Open Field (Coitinho et al. 2003, Rial et al. 2009). Diese altersabhängige Aktivitätsabnahme konnte in der vorliegenden Arbeit sowohl bei den Prnp ${ }^{0 / 0}$ - als auch bei den Wildtyp-Mäusen erst in der Gruppe der 20 Monate alten Tiere bestätigt werden. Eine mögliche Erklärung für die Diskrepanz dieser Ergebnisse könnte in der unterschiedlichen Versuchsapparatur des Open Fields liegen. Das in der vorliegenden Arbeit verwendete Open Field hatte eine 
freie Fläche von $80 \mathrm{~cm}$ x $80 \mathrm{~cm}$, während die in den anderen Studien benutzten Open Fields lediglich eine Fläche von $20 \mathrm{~cm}$ x $30 \mathrm{~cm}$ bzw. $30 \mathrm{~cm}$ x $30 \mathrm{~cm}$ aufwiesen und somit deutlich kleiner waren.

\subsection{Einfluss des $\operatorname{PrP}^{\mathrm{c}}$ auf das Angstverhalten}

Angst ist biologisch gesehen ein Stresszustand von starker Intensität als Antwort auf eine wahrgenommene Bedrohung (Millan 2003). Evolutionsgeschichtlich ist sie ein wichtiger Warn- und Schutzmechanismus, der in Gefahrensituationen ein angemessenes Verhalten, beispielsweise die Flucht, einleitet und somit der Selbsterhaltung dient. In diesem Fall ist die Angst ein biologisch angelegtes und angeborenes Verhalten, das die Energiebereitstellung sichert, die bei einer Kampf- oder Fluchtreaktion benötigt wird. Da Angst durch Vermeidungs- und Fluchtverhalten oder Abwehr gekennzeichnet ist, steht sie im Gegensatz zur explorativen Neugier (Erkundungsverhalten), die mit positiv empfundener Erregung einhergeht.

In der vorliegenden Arbeit wurden verschiedene Tests zur Untersuchung des Angstverhaltens bei Nagetieren durchgeführt. An erster Stelle sei hier der Elevated-Plus-MazeTest erwähnt, der auf der Aversion von Nagetieren gegenüber offenen und ungeschützten Flächen basiert. Der Aufenthalt auf den offenen Armen der Versuchsapparatur wird hier als ein vermindertes Angstverhalten interpretiert (Carobrez und Bertoglio 2005). In diesem Test konnte sowohl bei den Prnp ${ }^{0 / 0}$-Mäusen als auch bei den Wildtypen eine altersabhängige Abnahme der Angst zwischen drei und 20 Monaten beobachtet werden, da sich die Tiere mit zunehmendem Alter verstärkt auf den offenen Armen bewegten. Die Prnp ${ }^{0 / 0}$-Mäuse zeigten jedoch in jeder Altersgruppe eine deutlich geringere Angstbereitschaft als die Tiere ihrer Kontrollgruppe. Diese Resultate stimmen mit den Ergebnissen aus dem Furchtkonditionierungstest und dem fünfminütigen Open-Field-Test überein. Die Prnp ${ }^{0 / 0}$-Mäuse hielten sich mit zunehmendem Alter häufiger im Zentrum des Open Fields auf als die Wildtyp-Mäuse. Auch bei diesem Test kann der Aufenthalt auf der freien, ungeschützten Fläche im Zentrum des Open Fields als Maß für ein vermindertes Angstverhalten angesehen werden.

Der Einfluss des Prion-Proteins auf das Angstverhalten wurde in der Vergangenheit kontrovers diskutiert. Frühere Studien kamen zu dem Ergebnis, dass Prnp ${ }^{0 / 0}$-Mäuse weniger Angst zeigen, wenn sie zuvor einer Stresssituation ausgesetzt waren (Nico et al. 2005). Unter normalen Bedingungen zeigten die Tiere keine Veränderungen in ihrem Angstverhalten im Elevated-Plus-Maze-Test (Roesler et al. 1999, Coitinho et al. 2003). 
Eine mögliche Erklärung für die Diskrepanz dieser Ergebnisse könnte in den unterschiedlichen Versuchsapparaturen des Elevated Plus Maze liegen. Die Untersuchungen von Lobão-Soares et al. (2007) stimmen mit den im Rahmen dieser Arbeit gemachten überein, dass die Prnp ${ }^{0 / 0}$-Mäuse weniger Angst zeigen als die Wildtypen. Überraschenderweise wurde in derselben Studie gezeigt, dass auch die $\operatorname{PrP}^{\mathrm{c}}$ überexprimierenden $\mathrm{Tg}$ 20 Mäuse ein geringeres Angstverhalten aufweisen (Lobão-Soares et al. 2007). Dies zeigte sich in einer erhöhten Anzahl von ,head dips“, die ebenfalls ein Ausdruck für vermindertes Angstverhalten ist. Ein weiterer Angstverhaltenstest, bei dem die Mäuse mit einer Schlange konfrontiert wurden, kam zu ähnlichen Ergebnissen. Sowohl die Prnp $^{0 / 0}$-Mäuse als auch die Tg-20-Mäuse zeigten weniger Angst als ihre Kontrollgruppe (Lobão-Soares et al. 2008). Diese Beobachtungen legen nahe, dass die Expression von $\operatorname{PrP}^{\mathrm{c}}$ in physiologischen Konzentrationen einen möglicherweise in bestimmten Hirnarealen entscheidenden Einfluss auf die Ausbildung eines angemessenen Angstverhaltens hat. Der genaue Mechanismus, mit dem $\operatorname{PrP}^{\mathrm{c}}$ das Angstverhalten beeinflusst, ist bisher noch nicht eindeutig geklärt. Es gibt jedoch in der Literatur verschiedene Erklärungsansätze. Ein möglicher wäre der Einfluss der Amygdala, einer Gehirnstruktur, die maßgeblich an der Entstehung von Angst beteiligt ist und mögliche Gefahrensituationen erkennt und bewertet. Sie ist ein Teil des Limbischen Systems, das das Angstverhalten beeinflusst (Belzung 1992, Millan 2003). Das veränderte Angstverhalten der Prnp ${ }^{0 / 0}$ Mäuse könnte in der ungewöhnlichen Lokalisation und verminderten Aktivität der Stickstoffmonoxid-Synthase (NO-Synthase) liegen (Keshet et al. 1999). Die NOSynthase ist in verschiedenen limbischen und kortikalen Strukturen wie der Amygdala oder dem Hippocampus lokalisiert (Egberongbe et al. 1994) und beeinflusst die Aktivität der beiden Neurotransmitter $\gamma$-Aminobuttersäure (GABA) und Glutamat. Ob weitere Proteine, die die NO-Synthase regulieren, eine physiologische Interaktion mit dem $\mathrm{PrP}^{\mathrm{c}}$ eingehen, sollte Gegenstand weiterer Untersuchungen sein. Darüber hinaus wird vermutet, dass durch die Inhibierung der neuronalen NO-Synthase das Angstverhalten reguliert wird (Keshet et al. 1999). Außerdem haben mehrere Studien gezeigt, dass das Angstverhalten und die Gedächtniskonsolidierung durch Glykosaminoglykane und Laminin beeinflusst werden können. Es wird angenommen, dass das $\operatorname{PrP}^{c}$ je nach Konzentration diese beiden Stoffe hoch- oder herunterregulieren kann (Pan et al. 2002, Mayer-Sonnenfeld et al. 2005, Coitinho et al. 2006).

Serotonin und seine Rezeptoruntergruppen scheinen ebenfalls einen Einfluss auf das Angst- und Vermeidungsverhalten zu haben (Graeff 2002, 2004). Zur Diskussion stehen 
besonders die Rezeptoruntergruppen $5 \mathrm{HT}_{1 \mathrm{~A}}, 5 \mathrm{HT}_{1 \mathrm{~B}}, 5 \mathrm{HT}_{2 \mathrm{~A}}, 5 \mathrm{HT}_{2 \mathrm{~B}}$ und $5 \mathrm{HT}_{2 \mathrm{C}}$. In vitroStudien zeigten, dass $\operatorname{PrP}^{\mathrm{c}}$ den $5 \mathrm{HT}_{2 \mathrm{~B}}$ Rezeptor hochregulieren und die $5 \mathrm{HT}_{1 \mathrm{~B}}$ und $5 \mathrm{HT}_{2 \mathrm{~A}}$ Rezeptoren herunterregulieren kann (Mouillet-Richard et al. 2005). Der Verlust des $\operatorname{PrP}^{c}$ könnte somit zu einer veränderten Expression der Serotonin-Rezeptoren führen und dadurch das Angstverhalten beeinflussen.

\subsection{Involvierung von $\operatorname{PrP}^{c}$ in kognitive Lernprozesse}

Kognitive Defizite gehören zu den frühen neurologischen Symptomen der CJK (Brown P et al. 1992, Prusiner 1998). Allerdings wurden sie bisher immer mit dem neuronalen Untergang durch die Erkrankung erklärt. Nichtdestotrotz wurde die Rolle des $\operatorname{PrP}^{\mathrm{c}}$ im Lernverhalten und bei der Gedächtniskonsolidierung in Tierexperimenten mehrfach untersucht, da eine Rolle des $\operatorname{PrP}^{\mathrm{c}}$ bei der Gedächtnisbildung postuliert wurde.

Eine genauere Untersuchung der Veränderungen des Lernverhaltens während eines längeren Alterungsprozesses wurde in der Literatur jedoch noch nicht hinreichend beschrieben. Coitinho et al. (2003) zeigten lediglich an neun Monate alten Prnp ${ }^{0 / 0}$-Mäusen und Ratten, dass das Kurz- und Langzeitgedächtnis im Gegensatz zu drei Monate alten Tieren beeinträchtigt ist. Diese Studie umfasste jedoch nur einen Test zur Untersuchung der Gedächtniskonsolidierung, den ,step-down inhibitory avoidance task“. Bei diesem erhalten die Tiere in der Trainingsphase einen leichten, aber unangenehmen Stromstoß, wenn sie von einer Plattform mit allen vier Füßen auf ein Bodengitter treten. In der Testphase wird die Latenz, also die Zeit bis die Tiere die Plattform verlassen, gemessen, die als Maß für die Gedächtniskonsolidierung gilt. Rial et al. (2009) beschreiben Tests an drei und elf Monate alten Prnp ${ }^{0 / 0}$ - und überexprimierenden Tg-20-Mäusen, wobei gezeigt wurde, dass die elf Monate alten Prnp ${ }^{0 / 0}$-Mäuse im Gegensatz zu den Tg-20Mäusen kognitive Defizite aufweisen. In der vorliegenden Arbeit wurden im Vergleich zu anderen Studien die kognitiven Fähigkeiten der Prnp ${ }^{0 / 0}$-Mäuse in drei unterschiedlichen Altersgruppen (drei, neun und 20 Monate) an Hand von drei verschiedenen Tests untersucht. Dazu gehörten der Objekterkennungstest, der Morris-Water-Maze- und der Furchtkonditionierungstest. Diese untersuchen jeweils verschiedene Aspekte des Lernverhaltens. So zeigt der Objekterkennungstest die kognitiven Fähigkeiten, sich an ein bekanntes Objekt zu erinnern, während der Morris-Water-Maze-Test das räumliche Lernvermögen der Tiere wiederspiegelt. Der Furchtkonditionierungstest zeigt erlerntes Angstverhalten in Bezug auf einen aversiven Stimulus. 
Die Ergebnisse des Objekterkennungstests zeigten bei den Prnp ${ }^{0 / 0}$-Mäusen im Gegensatz zu den Wildtypen eine deutliche altersabhängige Abnahme der kognitiven Fähigkeiten, wobei eine signifikante Verschlechterung der Gedächtnisleistung ab einem Alter von neun Monaten beobachtet wurde. Dieses altersabhängige Nachlassen der kognitiven Funktionen stimmt mit den Ergebnissen in der Literatur überein (Coitinho et al. 2003). Auch im Furchtkonditionierungstest konnte sowohl in der kontextabhängigen als auch in der tonabhängigen Furchtkonditionierung ein signifikant geringeres Erstarrungsverhalten bei den Prnp ${ }^{0 / 0}$-Mäusen in nahezu jeder Altersgruppe beobachtet werden. Es wurde gezeigt, dass die Prnp ${ }^{0 / 0}$-Mäuse nach dem elektrischen Stimulus ein geringeres Erstarrungsverhalten aufwiesen als die Wildtypen. Dies könnte ein Hinweis auf ein vermindertes assoziatives Lernen bei den Prnp ${ }^{0 / 0}$-Mäusen sein. Die Ergebnisse können als schlechtere kognitive Leistung in Bezug auf einen aversiven Stimulus oder aber im Fall des Elevated Plus Maze als ein vermindertes Angstverhalten interpretiert werden. Wahrscheinlich spielen jedoch beide Aspekte in dem von den Prnp ${ }^{0 / 0}$-Mäusen gezeigten Verhalten eine entscheidende Rolle. Eine wichtige Funktion bei der Gedächtniskonsolidierung des Angstverhaltens hat die Interaktion des hippocampalen $\operatorname{PrP}^{\mathrm{c}}$ mit Laminin (Coitinho et al. 2006). In früheren Studien konnte nachgewiesen werden, dass diese Interaktion die Aktivierung der PKA und ERK1/2-Signalkaskaden steuert, die eine entscheidende Bedeutung bei der Konsolidierung des Langzeitgedächtnisses haben. Darüber hinaus sorgt die $\mathrm{PrP}^{\mathrm{c}}$-Laminin-Interaktion für neuronale Plastizität und Neurogenese (Graner et al. 2000).

In der Literatur wird der Einfluss des $\operatorname{PrP}^{\mathrm{c}}$ auf das Lernverhalten und die Gedächtniskonsolidierung kontrovers diskutiert. Während frühere Studien keine Veränderungen im Lernverhalten der Prnp ${ }^{0 / 0}$-Mäuse fanden (Büeler et al. 1992, Roesler et al. 1999), deuteten spätere Untersuchungen auf einen Zusammenhang zwischen dem $\operatorname{PrP}^{c}$ und der Gedächtnisleistung von Prnp ${ }^{0 / 0}$-Mäusen hin. Einerseits wurde eine Beeinträchtigung des Langzeitgedächtnisses von Prnp ${ }^{0 / 0}$-Mäusen festgestellt (Nishida et al. 1997, Papassotiropoulos et al. 2005), wogegen andere Studien eine Leistungsveränderung des Kurzzeitgedächtnisses beobachteten (Rial et al. 2009). Coitinho et al. (2003) kamen zu der Annahme, dass die Verschlechterung der kognitiven Leistungen erst ab einem Alter von neun Monaten auftritt. Diese Beobachtungen stimmen mit den in dieser Arbeit erhaltenen Resultaten überein. Eine wichtige Struktur für die Gedächtniskonsolidierung ist der Hippocampus, der Gedächtnisinhalte aus dem Kurzzeit- in das Langzeitgedächtnis überführt. Die Untersuchungen dieser Arbeit zeigten, dass die Hippocampi der Prnp ${ }^{0 / 0}$ 
Mäuse deutlich weniger $\operatorname{PrP}^{c}$ enthalten als die der Wildtyp-Mäuse. Diese Beobachtung könnte ein weiterer Hinweis auf die schlechteren kognitiven Leistungen der Prnp ${ }^{0 / 0}$ Mäuse sein.

Bei der Diskussion der vorliegenden Ergebnisse sollte beachtet werden, dass die von Studien an genetisch modifizierten Mäusen erhaltenen Daten teilweise kontrovers gesehen werden müssen, da ihr Genverlust, ihr genetischer Hintergrund und andere kompensatorische Mechanismen die kognitiven Funktionen beeinflussen können (Banbury Conference 1997). Verhaltenstests an Prnp ${ }^{0 / 0}$-Mäusen wurden mehrfach kritisiert, seitdem diese Tiere einen gemischten genetischen Hintergrund aufweisen (129/Sv x C57BL/6J). Aus diesem Grund wurden in der vorliegenden Arbeit als Kontrollgruppe WildtypMäuse verwendet, die den gleichen gemischten Hintergrund aufweisen wie die Prnp ${ }^{0 / 0}$ Mäuse und somit eine Vergleichbarkeit beider Gruppen gewährleisten.

Das Morris Water Maze gilt als Standardtest zur Untersuchung des räumlichen Lernvermögens von Nagetieren. Räumliche Orientierung und Navigation stellen eine der wichtigsten Voraussetzungen für viele Lebewesen dar, um sich in ihrem Lebensraum zurechtzufinden (Etienne et al. 1996). Es ist für viele Tierarten von großer Bedeutung, sich Wege einzuprägen oder an Landmarken zu orientieren, um beispielsweise Futterplätze wiederzufinden. Der Morris-Water-Maze-Test zeigte im Gegensatz zu den beiden anderen Lernverhaltenstests keine unterschiedlichen Gedächtnisleistungen von Prnp ${ }^{0 / 0}$ und Wildtyp-Mäusen. Dies stimmt mit den in der Literatur genannten Ergebnissen überein, bei denen ebenfalls keine Beeinträchtigung des räumlichen Lernvermögens bei den Prnp ${ }^{0 / 0}$-Mäusen beobachtet wurde (Büeler et al. 1992, Lipp et al. 1998). Dies lässt vermuten, dass $\operatorname{PrP}^{c}$ keinen entscheidenden Einfluss auf das räumliche Lernen hat. Der Morris-Water-Maze-Test setzt eine hohe kognitive Leistung der Tiere voraus, die besonders nach einer Schädigung des Hippocampus beeinträchtigt ist (Büeler et al. 1992). Daher wird dem Hippocampus eine wichtige Funktion bei der Repräsentation der Umgebung und bei der Navigation zugeordnet (Wood et al. 1999).

Für den Mechanismus, mit dem $\operatorname{PrP}^{\mathrm{c}}$ die Gedächtniskonsolidierung und das Lernen beeinflusst, gibt es verschiedene Erklärungsansätze. Coitinho et al. (2007) zeigten in einer Studie, dass durch die Blockade der PrP $^{\mathrm{c}}$-STI1-Interaktion mit Hilfe einer intrahippocampalen Infusion mit Antikörpern gegen das $\operatorname{PrP}^{\mathrm{c}}$ oder das STI1 sowohl das Kurzzeit- als auch das Langzeitgedächtnis beeinflusst wird. Darüber hinaus induziert die PrP ${ }^{\mathrm{c}}$-STI1-Interaktion die Neurogenese, hat seine neuronale Schutzfunktion für hippocampale Neurone und verhindert Apoptose (Zanata et al. 2002). Die neu gebilde- 
ten Neurone scheinen im Hippocampus zur Bildung oder Konsolidierung des Langzeitgedächtnisses beizutragen (Lopes et al. 2005). Die Interaktion des $\operatorname{PrP}^{c}$ mit dem STI1 ist weiterhin beteiligt an der Aktivierung wichtiger Signalkaskaden wie der MAPK- und PKA-Signalkaskade (Lopes et al. 2005). Beide spielen eine essentielle Rolle in der Gedächtniskonsolidierung (Izquierdo et al. 2006). Des weiteren scheint der Codon 129Polymorphismus das Langzeitgedächtnis zu beeinflussen, da Individuen, die homozygot oder heterozygot für Methionin an Codon 129 sind, ein besseres Langzeitgedächtnis aufweisen als solche mit Valin (Papassotiropoulos et al. 2005). Zudem ist der Codon 129-Polymorphismus mit einer frühen kognitiven Leistungsabnahme verbunden (Croes et al. 2003).

Einige Untersuchungen an der Meeresschnecke Aplysia californica weisen auf eine Beteiligung des Translationsregulators CPEB bei der Ausbildung des Langzeitgedächtnisses hin. CPEB hat dabei Prionen-ähnliche Eigenschaften, indem es zwei unterschiedliche Konformationen annehmen kann: eine inaktive und eine aktive Form. Dabei sorgt 5-HT für eine Konzentrationserhöhung von inaktivem CPEB in den Synapsen. Über einen bisher unbekannten Mechanismus kann die inaktive Form in die aktive Form überführt werden, wobei die aktive Form ähnlich dem pathogenen Prion-Protein $\left(\mathrm{PrP}^{\mathrm{Sc}}\right)$ weitere CPEB-Proteine umwandeln kann. Diese sich selbst erhaltende, autoregulatorische Kaskade könnte ein weiterer möglicher Erklärungsansatz für die langfristige Speicherung von Gedächtnisinhalten darstellen (Bailey et al. 2004, Si et al. 2010).

Die Ergebnisse dieser Arbeit über das Lernverhalten und die Gedächtniskonsolidierung zeigen, dass Prnp ${ }^{0 / 0}$-Mäuse ab einem Alter von neun Monaten deutlich schlechtere kognitive Leistungen erbringen, das räumliche Lernen aber nicht beeinflusst wird, was allerdings nicht an älteren Mäusen gemessen werden konnte. Die Prnp ${ }^{0 / 0}$-Mäuse sind von dem natürlichen Alterungsprozess deutlich stärker betroffen als die Wildtyp-Mäuse. Diese Beobachtungen werden dadurch gestützt, dass die $\mathrm{Tg}-20 \mathrm{PrP}^{\mathrm{c}}$ überexprimierenden Mäuse deutlich resistenter gegenüber dem Alterungsprozess sind (Rial et al. 2009) und im Vergleich zu Prnp ${ }^{0 / 0}$ - und Wildtyp-Mäusen deutlich bessere Gedächtnisleistungen zeigen. Ein Grund dafür könnte die in mehreren Studien beschriebene neuroprotektive Funktion des $\operatorname{PrP}^{c}$ sein, womit das $\operatorname{PrP}^{\mathrm{c}}$ eine gewisse „Anti-Aging“Schutzfunktion einnimmt (Roucou et al. 2004, Shyu et al. 2005, Weise et al. 2008). 


\subsection{Keine motorischen Defizite bei Prnp ${ }^{0 / 0}$-Mäusen}

Störungen der Motorik und Koordinationsprobleme wie Ataxien sind häufig beobachtete Symptome bei den TSEs (Dossena et al. 2008). Diese Beeinträchtigungen waren eine der ersten Phänotypen, die bei Prion-Protein-Knockout-Mäusen beobachtet und auf den Verlust von $\operatorname{PrP}^{\mathrm{c}}$ sowie der damit verbundenen Degeneration von Purkinje-Zellen im Kleinhirn zurückgeführt wurden (Sakaguchi et al. 1996, Katamine et al. 1998). Bei den Tieren dieser Studien handelte es sich jedoch um Mäuse der Nagasaki Linie, weshalb für die Entwicklung der Ataxien heute vorrangig die Überexpression des Proteins Dpl und nicht der Verlust des $\operatorname{PrP}^{\mathrm{c}}$ verantwortlich gemacht wird.

Zur Untersuchung der motorischen Fähigkeiten der Tiere wurde der Rotarod-Test eingesetzt, bei dem die Tiere auf einem rotierenden Balken balancieren mussten. In keiner der drei Altersgruppen konnte ein Unterschied in Motorik oder Koordination zwischen den Prnp ${ }^{0 / 0}$-Mäusen und den Wildtypen beobachtet werden. Es lag bei beiden Mausgruppen lediglich eine altersbedingte Abnahme der motorischen und koordinatorischen Fähigkeiten vor. Diese Ergebnisse wurden schon in früheren Untersuchungen belegt, bei denen ebenfalls keine motorischen Defizite im Rotarod-Test bei Prnp ${ }^{0 / 0}$-Mäusen gefunden wurden (Lobão-Soares et al. 2007, Dossena et al. 2008). Dass die Prnp ${ }^{0 / 0}$ Mäuse keine schlechteren motorischen Leistungen erbringen, belegt auch der MorrisWater-Maze-Test, der hohe Ansprüche an Motorik und körperliche Ausdauer der Tiere stellt. Bei dessen Durchführung konnten keine signifikanten Unterschiede zwischen den Prnp $^{0 / 0}$-Mäusen und den Wildtypen beobachtet werden. Es lag keine Beeinträchtigung der Schwimmleistung der Prnp ${ }^{0 / 0}$-Mäuse vor.

Studien an überexprimierenden Tg-20-Mäusen kamen dagegen zu dem Ergebnis, dass diese Tiere signifikant bessere motorische und koordinatorische Leistungen im Rotarod zeigen als Wildtyp- und Prnp ${ }^{0 / 0}$-Mäuse (Lobão-Soares et al. 2007). Aufgrund dieser Beobachtungen und der Tatsache, dass motorische Defizite ein häufig beobachtetes Symptom von TSEs darstellen, kann ein Einfluss des $\operatorname{PrP}^{\mathrm{c}}$ auf die Motorik nicht ausgeschlossen werden. Daher sind weitere Untersuchungen zur Klärung der Funktion des $\mathrm{PrP}^{\mathrm{c}}$ hinsichtlich Motorik und Koordination notwendig. 


\section{Zusammenfassung}

Ziel der vorliegenden Arbeit war es, die Funktion des $\operatorname{PrP}^{\mathrm{c}}$ in der Verhaltensphysiologie und dessen Einfluss auf den Alterungsprozess näher zu untersuchen. In den Verhaltenstests wurden verschiedene kognitive Funktionen sowie das Angst- und Lernverhalten, das natürliche Erkundungs- und Vermeidungsverhalten sowie die motorischen Fähigkeiten der Mäuse untersucht. Zur Analyse der kognitiven Funktionen dienten das Morris Water Maze, der Furchtkonditionierungstest und der Objekterkennungstest. Die Untersuchungen dieser Arbeit zeigen, dass das Erinnerungs- und Lernvermögen der Prnp ${ }^{0 / 0}$ Mäuse sowohl im Furchtkonditionierungstest als auch im Objekterkennungstest signifikant schlechter war als das der Wildtyp-Mäuse. Bei den Prnp ${ }^{0 / 0}$-Mäusen lag während des natürlichen Alterungsprozesses eine signifikant stärkere Abnahme der kognitiven Leistungen vor. Im Gegensatz dazu konnten keine Unterschiede in Bezug auf das räumliche Lernen festgestellt werden, womit $\operatorname{PrP}^{\mathrm{c}}$ offenbar zumindest bis zu einem Alter von neun Monaten keinen Einfluss auf diese Lernform hat. Der Elevated-Plus-Maze-Test und der Open-Field-Test sind zwei unterschiedliche Verfahren zur Untersuchung des Angstverhaltens. In der vorliegenden Arbeit konnte beobachtet werden, dass Prnp ${ }^{0 / 0}$ Mäuse weniger Angst zeigten als die Wildtyp-Mäuse und dass diese mit zunehmendem Lebensalter deutlich abnimmt. Das natürliche Erkundungs- und Vermeidungsverhalten wurde mit Hilfe des Open-Field-Tests analysiert. Dabei ließen sich allerdings keine Unterschiede zwischen den Prnp ${ }^{0 / 0}$ - und den Wildtyp-Mäusen feststellen. Auch die Untersuchung der motorischen Fähigkeiten und der körperlichen Ausdauer der Tiere mit Hilfe des Rotarods ergab keine Unterschiede zwischen beiden Mauslinien. Das PrionProtein scheint weder die Motorik noch das Explorationsverhalten zu beeinflussen und die festgestellten Defizite lassen sich offenbar nicht mit abnehmenden motorischen Leistungen erklären. Im Gegensatz dazu weisen die dieser Arbeit zugrunde liegenden Untersuchungen auf einen Einfluss des $\operatorname{PrP}^{\mathrm{c}}$ auf angeborene Verhaltensweisen wie das Nestbauverhalten hin. Es konnte erstmals gezeigt werden, dass die Prnp ${ }^{0 / 0}$-Mäuse im Gegensatz zu den Wildtypen in jeder Altersklasse ein nur sehr gering ausgeprägtes Nestbauverhalten aufweisen.

Insgesamt ergab diese Studie neue Erkenntnisse über den physiologischen Einfluss von $\operatorname{PrP}^{\mathfrak{c}}$ auf das Angst- und Lernverhalten sowie auf das angeborene Nestbauverhalten der Mäuse. Insbesondere die mit zunehmendem Alter aufgetretenen Defizite im Lern- und Angstverhalten weisen auf eine „Anti-Aging“-Schutzfunktion des $\operatorname{PrP}^{c}$ hin. 


\section{Literatur}

Aguzzi A, Sigurdson C, Heikenwaelder M (2008): Molecular Mechanisms of Prion Pathogenesis. Annu Rev Mech Dis $\underline{3}, 11-40$

Alper T, Cramp WA, Haig DA, Clarke MC (1967): Does the agent of scrapie replicate without nucleic acid? Nature 214, 764-766

Bailey CH, Kandel ER, Si K (2004): The Persistence of Long-Term Memory: A Molecular Approach to Self-Sustaining Changes in Learning-Induced Synaptic Growth. Neuron $\underline{44}, 49-57$

Banbury Conference (1997): Mutant mice and neuroscience: recommendations concerning genetic background. Banbury Conference on genetic background in mice. Neuron $\underline{19}, 755-759$

Becker T (2005): BSE, Creutzfeldt-Jakob \& Co. http://daten.didaktikchemie.uni- bayreuth.de/umat/bse/prion.htm\#Die\%20Priontheorie\%20des\%20Stanley\%20P rusiner (Stand: 20.09.2010; abgerufen am 15.03.2011, 17:15 Uhr)

Belay ED (1999): Transmissible spongiform encephalopathies in humans. Annu Rev Microbiol 53, 283-314

Belzung C (1992): Hippocampal mossy fibres: implication in novelty reactions or in anxiety behaviours? Behav Brain Res $\underline{51}, 149-155$

Bond TL, Neumann PE, Mathieson WB, Brown RE (2002): Nest building in nulligravid, primigravid and primiparous $\mathrm{C} 57 \mathrm{BL} / 6 \mathrm{~J}$ and $\mathrm{DBA} / 2 \mathrm{~J}$ mice. Physiol Behav $\underline{75}, 551-555$

Braun JR, Willnow TE (1996): Die „Knockout“-Maus als Krankheitsmodell. Dtsch Ärztebl 93, 1765-1769

Brown DR (2001): Prion and prejudice: normal protein and the synapse. Trends Neurosci 24, 85-90

Brown DR, Qin K, Herms JW, Madlung A, Manson J, Strome R, Fraser PE, Kruck T, von Bohlen A, Schulz-Schäffer W (1997a): The cellular Prion-Protein binds copper in vivo. Nature $\underline{390}, 684-687$

Brown DR, Schulz-Schäffer WJ, Schmidt B, Kretzschmar HA (1997b): Prion-Protein deficient cells show altered response to oxidative stress due to decreased SOD-1 activity. Exp Neurol 146, 104-112

Brown DR, Besinger A, Herms JW, Kretzschmar HA (1998): Microglial expression of the Prion-Protein. NeuroReport $\underline{9}, 1425-1431$

Brown DR, Wong BS, Hafiz F, Clive C, Haswell SJ, Jones IM (1999): Normal PrionProtein has an activity like that of superoxide dismutase. Biochem $\mathrm{J} \underline{344}$, 15 
Brown P, Goldfarb LG, Kovanen J, Haltia M, Cathala F, Sulima M, Gibbs CJ, Gajdusek DC (1992): Phenotypic characteristics of familial Creutzfeldt-Jakob disease associates with the codon 178Asn PRNP mutation. Ann Neurol 31, 282-285

Büeler H, Fischer M, Lang Y, Bluethmann H, Lipp HP, DeArmond SJ, Prusiner SB, Aguet M, Weissmann C (1992): Normal development and behaviour of mice lacking the neuronal cell-surface PrP protein. Nature $\underline{356}, 577-582$

Büeler H, Raeber A, Sailer A, Fischer M, Aguzzi A, Weissmann C (1994): High prion and $\mathrm{PrP}^{\mathrm{Sc}}$ levels but delayed onset of disease in scrapie-inoculated mice heterozygous for a disrupted PrP gene. Mol Med 1, 19-30

Carobrez AP, Bertoglio LJ (2005): Ethological and temporal analyses of anxiety-like behavior: the Elevated Plus Maze model 20 years on. Neurosci Biobehav Rev 29, 1193-1205

Chiarini LB, Freitas AR, Zanata SM, Brentani RR, Martins VR, Linden R (2002): Cellular Prion-Protein transduces neuroprotective signals. EMBO J 21, 33173326

Coitinho AS, Roesler R, Martins VR, Brentani RR, Izquierdo I (2003): Cellular PrionProtein ablation impairs behavior as a function of age. NeuroReport $\underline{14}$, 1375-1379

Coitinho AS, Freitas AR, Lopes MH, Hajj GN, Roesler R, Walz R, Rossato JI, Cammarota M, Izquierdo I, Martins VR, Brentani RR (2006): The interaction between Prion-Protein and laminin modulates memory consolidation. Eur J Neurosci 24, 3255-3264

Coitinho AS, Lopes MH, Hajj GN, Rossato JI, Freitas AR, Castro CC, Cammarota M, Brentani RR, Izquierdo I, Martins VR (2007): Short-term memory formation and long-term memory consolidation are enhanced by cellular prion association to stress-inducible protein 1 . Neurobiol Dis $\underline{26}, 282-290$

Creutzfeldt HG (1920): Über eine eigenartige herdförmige Erkrankung des Zentralnervensystems. Z Gesamte Neurol Psychiatrie 57, 1-18

Criado JR, Sánchez-Alavez M, Conti B, Giacchino JL, Wills DN, Henriksen SJ, Race R, Manson JC, Chesebro B, Oldstone MBA (2005): Mice devoid of PrionProtein have cognitive deficits that are rescued by reconstitution of PrP in neurons. Neurobiol Dis $\underline{19}, 255-265$

Croes EA, Dermaut B, Houwing-Diustermaat JJBM, Cruts M, Breteler MM, Hofman A, van Broeckhoven C, van Duijn CM (2003): Early cognitive decline is associated with Prion-Protein codon 129 polymorphism. Ann Neurol 54, 275276

Cunningham C, Deacon R, Wells H, Boche D, Waters S, Diniz CP, Scott H, Rawlins JN, Perry VH (2003): Synaptic changes characterize early behavioural signs in the ME7 model of murine prion disease. Eur J Neurosci 17, 2147-2155

Deacon RMJ (2006): Assessing nest building in mice. Nat Protocols $\underline{3}, 1117-1119$ 
De Almeida CJ, Chiarini LB, Silva JP, Silva PM, Martins MA, Linden R (2005): The cellular Prion-Protein modulates phagocytosis and inflammatory response. $\mathrm{J}$ Leukoc Biol 77, 238-246

Dossena S, Imeri L, Mangieri M, Garofoli A, Ferrari L, Senatore A, Restelli E, Balducci C, Fiordaliso F, Salio M (2008): Mutant Prion-Protein expression causes motor and memory deficits and abnormal sleep patterns in a transgenic mouse model. Neuron $\underline{60}, 598-609$

Egberongbe YI, Gentleman SM, Falkai P, Bogerts B, Polak JM, Roberts GW (1994): The distribution of nitric oxide synthase immunoreactivity in the human brain. Neurosci $\underline{59}, 561-578$

Etienne AS, Maurer R, Seguinot V (1996): Path integration in mammals and its interaction with visual landmarks. J Exp Biol 199, 201-209

Ford MJ, Burton LJ, Li H, Graham CH, Frobert Y, Grassi J, Hall SM, Morris RJ (2002): A marked disparity between the expression of Prion-Protein and its message by neurons of the CNS. Neurosci $\underline{111}, 533-551$

Gabriel JM, Oesch B, Kretzschmar H, Scott M, Prusiner SB (1992): Molecular cloning of a candidate chicken Prion-Protein. Proc Natl Acad Sci USA $\underline{89}$, 90979101

Gadotti VM, Bonfield SP, Zamponi GW (2011): Depressive-like behavior of mice lacking cellular prion protein. (Behav Brain Res, im Druck)

Gajdusek DC, Zigas V (1957): Degenerative disease of the central nervous system in New Guinea: epidemic occurence of ,kuru“ in the native population. N Engl J Med 257, 974-978

Graeff FG (2002): On serotonin and experimental anxiety. Psychopharmacology 163, $467-476$

Graeff FG (2004): Serotonin, the periaqueductal gray and panic. Neurosci Biobehav Rev 28, 239-259

Graner E, Mercadante AF, Zanata SM, Forlenza OV, Cabral AL, Veiga SS, Juliano MA, Roesler R, Walz R, Minetti A (2000): Cellular Prion-Protein binds laminin and mediates neuritogenesis. Brain Res $\underline{76}, 85-92$

Haraguchi T, Fisher S, Olofsson S, Endo T, Groth D, Tarentino A, Borchelt DR, Teplow D, Hood L, Burlingame A (1989): Asparagine-linked glycosylation of the scrapie and cellular Prion-Proteins. Arch Biochem Biophys $\underline{274}, 1-13$

Izquierdo I, Bevilaqua LR, Rossato JI, Bonini JS, Medina JH, Cammarota M (2006): Different molecular cascades in different sites of the brain control memory consolidation. Trends Neurosci 29, 496-505

Jakob A (1921): Über eigenartige Erkrankungen des Zentralnervensystems mit bemerkenswerten anatomischen Befunden (spastische PseudoskleroseEncephalopathie mit disseminierten Degenerationsherden). Z Gesamte Neurol Psychiatrie $\underline{64}, 147-228$ 
Katamine S, Nishida N, Sugimoto T, Noda T, Sakaguchi S, Shigematsu K, Kataoka Y, Nakatani A, Hasegawa S, Moriuchi R (1998): Impaired motor coordination in mice lacking Prion-Protein. Cell Mol Neurobiol $\underline{18}$, 731-742

Keshet GI, Ovadia H, Taraboulos A, Gabizon R (1999): Scrapie-infected mice and PrP knockout mice share abnormal localization and activity of neuronal nitric oxide synthase. J Neurochem $\underline{72}, 1224-1231$

Kim JJ, Shih JC, Chen K, Chen L, Bao S, Maren S, Anagnostaras SG, Fanselow MS, De Maeyer E, Seif I (1997): Selective enhancement of emotional, but not motor, learning in monoamine oxidase A-deficient mice. Proc Natl Acad Sci USA $\underline{94}, 5929-5933$

Kretzschmar HA, Stowring LE, Westaway D, Stubblebine WH, Prusiner SB, DeArmond SJ (1986): Molecular cloning of a human Prion-Protein cDNA. DNA $\underline{5}, 315-324$

Le Pichon CE, Firestein S (2008): Expression and localization of the Prion-Protein $\operatorname{PrP}^{\mathrm{c}}$ in the olfactory system of the mouse. J of Comp Neurol 508, 487-499

Le Pichon CE, Valley MT, Polymenidou M, Chesler AT, Sagdullaev BT, Aguzzi A, Firestein S (2009): Olfactory behavior and physiology are disrupted in Prion-Protein knockout mice. Nat Neurosci 12, 60-69

Linden R, Martins VR, Prado MAM, Cammarota M, Izquierdo I, Brentani RR (2008): Physiology of the Prion-Protein. Physiol Rev $\underline{88}, 673-728$

Lipp HP, Stagliar-Bozicevic M,Fischer M, Wolfer DP (1998): A 2-year longitudinal study of swimming navigation in mice devoid of the Prion-Protein: no evidence for neurological anomalities or spatial learning impairments. Behav Brain Res $\underline{95}$, 47-54

Lisk RD, Pretlow RA, Friedman SM (1969): Hormonal stimulation necessary for elicitation of maternal nest-building in the mouse. Anim Behav 17, 730-737

Lobão-Soares B, Walz R, Carlotti CG Jr, Sakamoto AC, Calvo F, Terzian AL, da Silva JA, Wichert-Ana L, Coimbra NC, Bianchin MM (2007): Cellular PrionProtein regulates the motor behavior performance and anxiety-induced responses in genetically modified mice. Behav Brain Res $\underline{183}$, 87-94

Lobão-Soares B, Walz R, Schröder Prediger RD, Freitas RL, Calvo F, Bianchin MM, Leite JP, Landemberger MC, Coimbra NC (2008): Cellular Prion-Protein modulates defensive attention and innate fear-induced behavior evoked in transgenic mice submitted to an agonistic encounter with the tropical coral snake Oxyrhopus guibei. Behav Brain Res 194, 129-137

Lopes MH, Hajj GN, Muras AG, Mancini GL, Castro RM, Ribeiro KC, Brentani RR, Linden R, Martins VR (2005): Interaction of cellular prion and stressinducible protein 1 promotes neuritogenesis and neuroprotection by distinct signaling pathways. J Neurosci $\underline{25}, 11330-11339$

Makrinou E, Collinge J, Antoniou M (2002): Genomic characterization of the human Prion-Protein (PrP) gene locus. Mamm Genome 13, 696-703 
Mallucci GR, Ratte S, Asante EA, Linehan J, Gowland I, Jefferys JG, Collinge J (2002): Post-natal knockout of Prion-Protein alters hippocampal CA1 properties, but does not result in neurodegeneration. EMBO J $\underline{21}, 202-210$

Manson JC, Clarke AR, Hooper ML, Aitchison L, McConnell I, Hope J (1994): 129/Ola mice carrying a null mutation in $\operatorname{PrP}$ that abolishes mRNA production are developmentally normal. Mol Neurobiol $\underline{8}, 121-127$

Mayer-Sonnenfeld T, Zeigler M, Halimi M, Dayan Y, Herzog C, Lasmezas CI, Gabizon $\mathrm{R}$ (2005): The metabolism of glycosaminoglycans is impaired in prion diseases. Neurobiol Dis $\underline{20}, 738-743$

Mc Gowan JP (1922): Scrapie in sheep. Scottish J Agric $\underline{5}$, 365-375

Millan MJ (2003): The neurobiology and control of anxious states. Prog Neurobiol $\underline{70}$, 83-244

Mitsios N, Saka M, Krupinski J, Pennucci R, Sanfeliu C, Miguel TM, Gaffney J, Kumar P, Kumar S, Sullivan M (2007): Cellular prion protein is increased in the plasma and peri-infarcted brain tissue after acute stroke. J Neurosci Res $\underline{85}$, 602-611

Mitteregger G, Vosko M, Krebs B, Xiang W, Kohlmannsperger V, Nölting S, Hamann GF, Kretzschmar HA (2007): The Role of the Octarepeat Region in Neuroprotective Function of the Cellular Prion Protein. Brain Pathol 17, $174-183$

Moore RC, Lee IY, Silverman GL, Harrison PM, Strome R, Heinrich C, Karunaratne A, Pasternak SH, Chishti MA, Liang Y (1999): Ataxia in Prion-Protein (PrP)deficient mice is associated with upregulation of the novel PrP-like protein doppel. J Mol Biol 292, 797-817

Moore RC, Mastrangelo P, Bouzamondo E, Heinrich C, Legname G, Prusiner SB, Hood L, Westaway D, DeArmond SJ, Tremblay P (2001): Doppel-induced cerebellar degeneration in transgenic mice. Proc Natl Acad Sci USA $\underline{98}, 15288-$ 15293

Moser M, Colello RJ, Pott U, Oesch B (1995): Developmental expression of the PrionProtein gene in glial cells. Neuron $\underline{14}, 509-517$

Mouillet-Richard S, Ermonval M, Chebassier C, Laplanche JL, Lehmann S, Launay JM, Kellermann O (2000): Signal transduction through Prion-Protein. Science $\underline{289}, 1925-1928$

Mouillet-Richard S, Pietri M, Schneider B, Vidal C, Mutel V, Launay JM, Kellermann O (2005): Modulation of serotonergic receptor signaling and cross-talk by Prion-Protein. J Biol Chem 280, 4592-4601

Nico PB, de-Paris F, Vinade ER, Amaral OB, Rockenbach I, Soares BL, Guarnieri R, Wichert-Ana L, Calvo F, Walz R (2005): Altered behavioural response to acute stress in mice lacking cellular Prion-Protein. Behav Brain Res $\underline{162}$, $173-181$ 
Nishida N, Katamine S, Shigematsu K, Nakatani A, Sakamoto N, Hasegawa S, Nakaoke R, Atarashi R, Kataoka Y, Miyamoto T (1997): Prion-Protein is necessary for latent learning and long-term memory retention. Cell Mol Neurobiol 17, 537-545

Oesch B, Westaway D, Wälchli M, McKinley MP, Kent SBH, Aebersold R, Barry RA, Tempst P, Teplow DB, Hood LE (1985): A cellular gene encodes scrapie PrP 27-30 protein. Cell $\underline{40}, 735-746$

Pan T, Wong BS, Liu T, Li R, Petersen RB, Sy MS (2002): Cell-surface Prion-Protein interacts with glycosaminoglycans. Biochem J $\underline{368}, 81-90$

Papassotiropoulos A, Wollmer MA, Aguzzi A, Hock C, Nitsch RM, de Quervain DJ (2005): The prion gene is associated with human long-term memory. Hum Mol Genet 14, 2241-2246

Parkin ET, Watt NT, Hussain I, Eckman EA, Eckman CB, Manson JC, Baybutt HN, Turner AJ, Hooper NM (2007): Cellular Prion-Protein regulates $\beta$-secretase cleavage of the Alzheimer's amyloid precursor protein. Proc Natl Acad Sci USA $\underline{104}, 11062-11067$

Pattison IH, Jones KM (1967): The possible nature of the transmissible agent of scrapie. Vet Rec $\underline{80}, 2-9$

Pauly PC, Harris DA (1998): Copper stimulates endocytosis of the Prion-Protein. J Biol Chem $\underline{273}, 33107-33110$

Prusiner SB (1982): Novel proteinaceous infectious particles cause scrapie. Science $\underline{216}, 136-144$

Prusiner SB (1994): Molecular biology and genetics of prion diseases. Philos Trans R Soc Lond B Biol Sci $\underline{343}$, 447-463

Prusiner SB (1998): Prions. Proc Natl Acad Sci USA 95, 13363-13383

Prusiner SB, McKinley M, Groth DF, Bowman KA, Mock NI, Cochran SP, Masiarz FR (1981): Scrapie agent contains a hydrophobic protein. Proc Natl Acad Sci USA $\underline{78}, 6675-6679$

Qin K, Yang DS, Yang Y, Chishti MA, Meng LJ, Kretzschmar HA, Yip CM,Fraser PE, Westaway D (2000): Copper(II)-induced conformational changes and protease resistance in recombinant and cellular PrP. Effect of protein age and deamidation. J Biol Chem 275, 19121-19131

Rial D, Duarte FS, Xikota JC, Schmitz AE, Dafré AL, Figueiredo CP, Walz R, Prediger RD (2009): Cellular Prion-Protein modulates age-related behavioral and neurochemical alterations in mice. J Neurosci 164, 896-907

Riek R, Hornemann S, Wider G, Glockshuber R, Wüthrich K (1997): NMR characterization of the full-lenght recombinant murine Prion-Protein, $\mathrm{mPrP}(23-231)$. FEBS Lett $\underline{413}$, 282-288 
Roesler P, Walz R, Quevedo J, de-Paris F, Zanata SM, Graner E, Izquierdo I, Martins VR, Brentani RR (1999): Normal inhibitory avoidance learning and anxiety, but increased locomotor activity in mice devoid of $\operatorname{PrP}(\mathrm{C})$. Brain Res Mol Brain Res $\underline{71}$, 349-353

Rossi D, Cozzio A, Flechsig E, Klein MA, Rulicke T, Aguzzi A, Weissmann C (2001): Onset of ataxia and Purkinje cell loss in PrP null mice inversely correlated with Dpl level in brain. EMBO J 20, 694-702

Roucou X, Gains M, LeBlanc AC (2004): Neuroprotective functions of Prion-Protein. J Neurosci $\underline{75}, 153-161$

Rudd PM, Endo T, Colominas C, Groth D, Wheeler SF, Harvey DJ, Wormald MR, Serban H, Prusiner SB, Kobata A (1999): Glycosylation differences between the normal and pathogenic Prion-Protein isoforms. Proc Natl Acad Sci USA $\underline{96}, 13044-13049$

Sakaguchi S, Katamine S, Nishida N, Moriuchi R, Shigematsu K, Sugimoto T, Nakatani A, Kataoka Y, Houtani T, Shirabe S (1996): Loss of cerebellar Purkinje cells in aged mice homozygous for a disrupted PrP gene. Nature $\underline{380}, 528$ 531

Sakudo A, Hamaishi M, Hosokawa-Kanai T, Tuchiya K, Nishimura T, Saeki K, Matsumoto Y, Ueda S, Onodera T (2003): Absence of superoxide dismutase activity in a soluble cellular isoform of Prion-Protein produced by baculovirus expression system. Biochem Biophys Res Commun 307, 678683

Schmitz M, Schlomm M, Hasan B, Beekes M, Mitrova E, Korth C, Breil A, Carimalo J, Gawinecka J, Varges D, Zerr I (2010): Codon 129 polymorphism and the E200K mutation do not affect the cellular prion protein isoform in the cerebrospinal fluid from patients with Creutzfeldt-Jakob disease. Eur J Neurosci $\underline{31}, 2024-2031$

Shyu WC, Lin SZ, Chiang MF, Ding DC, Li KW, Chen SF, Yang HI, Li H (2005): Overexpression of $\mathrm{PrP}^{\mathrm{c}}$ by adenovirus-mediated gene targeting reduces ischemic injury in a stroke rat model. J Neurosci $\underline{25}, 8967-8977$

Si K, Choi YB, White-Grindley E, Majumdar A, Kandel ER (2010): Aplysia CPEB can form prion-like multimers in Sensory neurons that contribute to long-term facilitation. Cell $\underline{140}, 421-435$

Sigurdsson B (1954): Rida-a chronic encephalitis of sheep with general remarks on infections which develop slowly and some of their special characteristics. $\mathrm{Br}$ Vet J 110, 341-354

Spudich A, Frigg R, Kilic E, Kilic Ü, Oesch B, Raeber A, Bassetti CL, Hermann DM (2005): Aggravation of ischemic brain injury by Prion-Protein deficiency: Role of ERK-1/-2 and STAT-1. Neurobiol of disease 20, 442-449

Taraboulos A, Jendroska K, Serban D, Yang SL, DeArmond SJ, Prusiner SB (1992): Regional mapping of Prion-Proteins in brain. Proc Natl Acad Sci USA $\underline{89}$, 7620-7624 
Tobler I, Gaus SE, Deboer T, Achermann P, Fischer M, Rulicke T, Moser M, Oesch B, McBride PA, Manson JC (1996): Altered circadian activity rhythms and sleep in mice devoid of Prion-Protein. Nature $\underline{380}, 639-642$

Tobler I, Deboer T, Fischer M (1997): Sleep and sleep regulation in normal and PrionProtein-deficient mice. J Neurosci 17, 1869-1879

Toni M, Spisni E, Griffoni C, Santi S, Riccio M, Lenaz P, Tomasi V (2006): Cellular prion protein and caveolin-1 interaction in a neuronal cell line precedes Fyn/Erk 1/2 signal transduction. J Biomed Biotechnol 2006, 1-13

Vassallo N, Herms J (2003): Cellular Prion-Protein function in copper homeostasis and redox signalling at the synapse. J Neurochem $\underline{86}, 538-544$

Weise J, Sandau R, Schwarting S, Crome O, Wrede A, Schulz-Schaeffer W, Zerr I, Bähr M (2006): Deletion of Cellular Prion Protein Results in Reduced Akt Activation, Enhanced Postischemic Caspase-3 Activation, and Exacerbation of Ischemic Brain Injury. Stroke 37, 1296-1300

Weise J, Doeppner TR, Müller T, Wrede A, Schulz-Schaeffer W, Zerr I, Witte OW, Bähr M (2008): Overexpression of cellular Prion-Protein alters postischemic Erk1/2 phosphorylation but not Akt phosphorylation and protects against focal cerebral ischemia. Restor Neurol Neurosci 26, 57-64

Westergard L, Christensen HM, Harris DH (2007): The Cellular Prion Protein $\left(\operatorname{PrP}^{\mathrm{c}}\right)$ : Its Physiological Function and Role in Disease. Biochem Biophys Acta $\underline{1772}, 629-644$

Wood ER, Dudchenko PA, Eichenbaum H (1999): The global record of memory in hippocampal neuronal activity. Nature $\underline{397}, 613-616$

Yost CS, Lopez CD, Prusiner SB, Myers RM, Lingappa VR (1990): Nonhydrophobic extracytoplasmic determinant of stop transfer in the Prion-Protein. Nature $\underline{343}, 669-672$

Zahn R, Liu A, Luhrs T, Riek R, von Schroetter C, Lopez GF, Billeter M, Calzolai L, Wider G, Wüthrich K (2000): NMR solution structure of the human PrionProtein. Proc Natl Acad Sci USA 97, 145-150

Zanata SM, Lopes MH, Hajj G, Mercadante AF, Chiarini LB, Nomizo R, Freitas ARO, Cabral ALB, Lee KS, Juliano MA (2002): Stress-inducible protein 1 is a cell surface ligand for cellular prion that triggers neuroprotection. EMBO J 21, 3307-3316 


\section{Danksagung}

An erster Stelle möchte ich mich herzlich bei Frau Prof. Dr. Inga Zerr für die Möglichkeit zur Durchführung meiner Promotionsarbeit in der Abteilung Neurologie der Universitätsmedizin Göttingen bedanken.

Ein ganz besonders großes Dankeschön geht an meinen Betreuer Dr. Matthias Schmitz, der mir das Thema dieser Arbeit vorgestellt hat. Seine engagierte Betreuung und große Hilfsbereitschaft, die zahlreichen Anregungen sowie die angenehme Arbeitsatmosphäre haben wesentlich zum Gelingen meiner Arbeit beigetragen. Vielen Dank auch für die stetige Unterstützung und Motivation, die unersetzlich für den Fortschritt dieser Arbeit waren.

Bedanken möchte ich mich ferner bei Prof. Dr. André Fischer vom European Neuroscience Institute (ENI) Göttingen, der sich bereit erklärte, sein Labor für die Verhaltensbeobachtungen zur Verfügung zu stellen und während dieser Zeit bei Fragen stets zur Seite stand.

Herzlichen Dank auch an Dr. Govindarajan Nambirajan für seine große Hilfsbereitschaft und Unterstützung bei der Durchführung der Verhaltensexperimente sowie der Präparation der Hirnregionen.

Allen Mitarbeitern im Labor der Prionenforschungsgruppe an der Universitätsmedizin Göttingen unter der Leitung von Frau Prof. Dr. Zerr und allen weiteren Mitarbeitern der Forschungsgruppe unter der Leitung von Prof. Dr. André Fischer im Labor des European Neuroscience Institute Göttingen danke ich für die wohlwollende Unterstützung meiner Arbeit.

Für die Korrektur dieser Arbeit möchte ich mich bei meiner Tante Frau Dr. ReetzeBonorden und Herrn Dr. Ernst-August von Hammerstein bedanken. 